\title{
Study of Behavior of Equity Returns in India
}

\author{
Pankunni V. \\ 'Prasia' 'Nest', Palakkad, Kerala, India
}

\begin{abstract}
This paper examines the behavior of equity returns in India for the period from 1999-2009. The empirical tests on the data of twenty Indian stocks actively traded in the Bombay Stock Exchange leads to the findings that the stock returns were highly volatile. The presence of skewness and kurtosis of leptokurtic nature provides further evidences for the asymmetrical distribution of equity returns. Stocks bear less share of market risk and behave idiosyncratically.
\end{abstract}

Keywords: Asymmetrical distribution, Equity returns, Idiosyncratically, Leptokurtic, volatile.

\section{Introduction}

Equity return never remains stable overtime. It changes every time when a new piece of information reaches the market. Equity return is sensitive to micro and macro environmental changes. Return varies in response to changes in the assets' prices. The changes may be high or low. Minor fluctuations around the expected value will not be a cause for investors' concern. But major shifts in prices followed by violent twists in the returns may cause much distress to the investors. Such sporadic fluctuations in returns will create chaos and uncertainty. This type of volatility in return will have far reaching impact on the market and frequency of the same may adversely affect the credibility of the market. Equity returns vary in response to the stock price movement. The stock price movement in its turn is governed by a myriad of factors such as global economic condition, state of inflation, GDP factors, industry factors and the stock's idiosyncratic conditions. Idiosyncratic behavior of individual stocks in relation to market reduces the systematic bond of the scrips with the market and increases the residual values overwhelmingly A greater percentage change in return is usually called as volatility in return. Volatility in return may upset the stock prices and subsequently the equity returns. The expected volatility in prices and returns may further aggravate the future stock prices and returns. In the security analysis, the investor has to take a decision as to whether to buy a certain class of stocks or not. If the market is highly volatile, the investment becomes risky. A highly volatile stock market may endanger the investors' interest and prompt the investors to abstain from investing.

Under perception of an efficient market, the distribution of returns from equity ought to be normal. Normal distribution of returns cannot be expected under volatile situation. Volatility factors may also foretell the occurrence of business cycles. As Siegel finds, an $8 \%$ decline in return may be a sign of an impending recession and vice versa. When volatility prevails the return will become asymmetrical. As a matter of fact, the asymmetrical form of distribution of returns can be taken as a signal for the presence of volatility in returns. The volatility feedback for equity returns can be derived from standard deviation, variance, skewness and kurtosis. In recessionary periods stock returns are generally negatively skewed to the left of the mean telling a noticeable decline in returns. Similarly, peakedness of leptokurtic nature is also found. The presence of high variance, standard deviation, skews and kurtosis implies the asymmetrical distribution of returns. This asymmetry is an empirical evidence of existence of volatility in return.

\section{Previous Research}

The company fundamentals have greater influence on equity returns. Vanitha Tripathi ${ }^{1}$, in a study, found that market capitalization and price-earnings ratio have statistically significant negative relationship with equity returns while book equity to market equity ratio and debt equity ratio have statistically significant positive relationship with equity returns in India.

If the new information is favorable the returns will go up. On the contrary it will go down. In times of uncertainty the return on stock would fluctuate tremendously. The investor psychology is also an important factor which paves the way for wider fluctuations. The investor's greediness, fear, urges, hopes and speculative attitudes contribute a lot to return volatility. Changes in macroeconomic fundamentals like GDP, rate of inflation, fiscal policy of the Govt., industrial policy and stage of business cycle have tremendous impact on return volatility. Not only have the changes in the present but also expected changes had their impact on the return.

Francis X. Diebold and Kamil Yilmaz $(2008)^{2}$ found a clear link between macroeconomic fundamentals, and stock market volatility, with volatile fundamentals translating in to volatile stock markets. 
Stock Market volatility comprises of stock return volatility and Stock Price volatility. Schwert and Simon $(1997)^{3}$ had identified the Volatility as a large percentage change in prices of stocks.

According to the study by John Y.Campbell and Ludger Hent Schel $(1991)^{4}$ the average return on stocks in the long period as the number of observation increases depicts sober results without much exaggeration. Long run holding does not yield any abnormal return to the investor. What the investors expect as dividend in the future has bearing on the present and future volatility prevailing in the market. It is argued that an increase in stock market volatility raises required stock returns, and thus lowers stock prices.

Volatility passes a greater uncertainty in to the hopes of the investors. Studies reveal that volatility in the short period is stronger than that in the longer period. Daily equity return shows greater volatility than annual or five year or ten year equity return. Stock price or return volatility is found diffused in the long period. Therefore the current price of stock depends on the expected future volatility in the return. The volatility feedback is an important factor which is to be reckoned for the determination of stock price movement. Jamees M. Poterba and Lawrence H. Summers (1989) ${ }^{5}$ viewed that volatility in return can be measured and perceived through the statistics of standard deviation and variance. Large negative returns are more common than positive returns. There is consistent evidence that stock returns are positively serially correlated over short horizons, and negatively auto-correlated over long horizons. Extreme stock returns are also common even if stock returns were drawn from normal distribution, show excess kurtosis. It has long been recognized that the volatility of equity returns has changed over time. Poterba and Summers argue that these changes are short—lived, and thus should have had only a small effect on stock prices.

According to Jeremy.J.Siegel ${ }^{6}$, Changes in stock returns are considered to be a good indicator of business cycles. An $8 \%$ decline in return is a sign of impending recession. Despite increasing criticism by economists and forecasters of the ability of the stock market to predict economic recessions, it is shown that 38 of the 41 measured recessions since 1802 have been preceded by an eight per cent decline in the stock return index. Stock return volatility was generally linked with the general economic conditions. An impending depression may create panic among the investors and market participants results in spikes in stock prices and returns. But such spikes may not last for long. They were short lived and usually found for less than a year because stock volatility returned to much more normal levels within months (Schwert 2011) ${ }^{7}$. Campbell and Schel in "no news is good news" stock returns are negatively skewed, (2) extreme stock market movements are common than would be expected if stock returns were drawn from a normal distribution, so stock returns have excess kurtosis, (3) volatility is typically higher after the stock market falls than after it rises, so stock returns are negatively correlated with future volatility. Gregory R.Duffee ${ }^{9}$ observed that the distribution of long-horizon idiosyncratic returns to individual stocks is strongly asymmetric. The reason for this asymmetry is a modest, extremely persistent negative relation between a stock's return and its future idiosyncratic return volatility.

Among the fundamentals that influence stock behavior, Pindyck ${ }^{10}$ finds the pre-tax profit and variance of returns most significant rather than the risk aversion of the investors. The market return volatility is not symmetrical towards a change in the return of the individual stock and portfolio. It is responsive asymmetrically to a negative or positive change in the market and portfolio returns, due to leverage. Strong evidences were found for the existence of conditional heteroskedasticity in both market and non-market component of returns (Philip A.Braun et al) ${ }^{11}$.

\section{Objectives of the Study}

This paper is purported for studying the following:

3.1. Average return earned by the stocks in relation to the market index for the period from 1999 to 2009.

3.2. Volatility in return of the stocks for the period under study.

3.3. The symmetrical features of the return of the stocks during the period.

3.4. The systematic relationship between stocks and the market index during the period.

\section{Data and methodology}

With a view to study the equity behavior, 20 stocks belonging to 20 industries were selected randomly at convenience. All stocks were actively traded in the Bombay Stock Exchange (BSE), belonging to the class of A. Stock prices were collected from the official website of the BSE for a period of 11 years from 1999 to 2009. Daily returns, Annual returns and Holding Period Yield (HPY) were calculated from the closing prices of the stock prices. Summary statistics such as mean, standard deviation, variance, co-variance, skew, kurtosis, correlation, $\mathrm{R}^{2}$ and beta were used to study the volatility factors and bond between the stocks and the market. BSE INDEX 30 was taken as the proxy for the market. A total of 2642 market days were observed to analyze the behavior of selected 20 stocks. The study was empirical and carried out separately for each stock under four heads, viz., analysis of summary statistics, analysis of daily returns, analysis of Holding period yields and analysis of Annual returns with the help of tables and figures which is appended in the last of the paper with proper reference (V.Pankunni 2013) $)^{12}$ 


\section{Empirical Test}

In this paper, the behavior of 20 stocks belonging to 20 industries listed in the Bombay Stock Exchange is examined in detail. The equity return behavior of the stocks is studied in terms of the stocks' daily returns, average annual returns and Holding Period Yield. The volatility in returns is given paramount importance in the study. The daily returns of the individual stocks for 11 year period from 1999 to 2009 were examined to understand their behavior. Returns were calculated based on the secondary data collected from the Bombay Stock Exchange. The statistical tools like Arithmetic mean, standard deviation, measure of skewness, kurtosis and variances were used to study the daily and annual returns. Annual returns were averaged by the number of actual market working days for the relevant year. The arithmetic average returns of every year for the eleven years were studied for establishing the behavior. Similarly, Holding Period Yields of the scrips were worked from the daily returns on yearly basis for all the 11 years to study their behavior. The returns were:

5.1. Daily Returns (DR): It is the return drawn by the holder of the stock on daily basis which is calculated as below:

$$
\begin{aligned}
& D R=\left(\frac{P 1}{P 0}-1\right) 100 \quad \text { Here, } \\
& \mathrm{P}_{1}=\text { New price } \\
& \mathrm{P}_{0}=\text { Previous day's price }
\end{aligned}
$$

5.2. Annual Returns (AR): It is the average return earned by the holder in a year.

$$
=\frac{\text { Total of the daily returns for the year }}{\text { Number of actual market days for the year }}
$$

5.3. Holding Period Yield (HPY): It is the return earned by the holder in a year as a difference between closing and opening stock prices.

$$
\begin{aligned}
& \text { HPY }=\left(\frac{\text { Closing Stock Price of the Year }}{\text { Opening Stock Price of the Year }}\right)-1 \\
& =\left(\frac{P 1}{P 0}-1\right) 100
\end{aligned}
$$

\section{Empirical Analysis}

In the analysis, a detailed summary statistics were calculated for 20 selected stocks. The 20 stocks under study were the following(1) ACC, (2) Appollo Tyres, (3) Arvind Mills, (4) Ashok Leyland, (5) Asian Paints, (6) Axis Bank, (7) Ballarpur Industries, (8) Castrol, (9) Colgate Palmolive, (10) Crompton Greaves, (11) Garware Poyester, (12) Gujarat Narmada, (13) Harrison Malayalam, (14) Hindalco, (15) Indian Hotels, (16) Indian Reyons, (17) ITC, (18) ONGC, (19) Tata Steel Limited and (20) Wipro. The summary statistics employed in the study were arithmetic mean, standard deviation $(\sigma)$, variance $\left(\sigma^{2}\right)$, co-variance, skew, kurtosis, correlation, $\mathrm{R}^{2}$, and beta ( $\beta$ ) (See Table 1).

\subsection{ACC}

\subsubsection{Summary Statistics}

As per Table 1, the average return of ACC for the period from 1999 to 2009 was $0.09 \%$. But the expected return as represented by the holding period yield (HPY) for the same period was $13.5 \%$. It could be seen that the scrip's performance was much below the expected. Similarly ACC's average return was lower than the market return of $0.11 \%$. During the 11 year period the return went up to $15.6 \%$ and went down to the extent of $-91.84 \%$.

The $\sigma 3.32$ and the variance 11.04 signify volatility in the return. The range of return between the prosperity and adversity 108 was also significant and shows exceptional volatility. The distribution was negatively skewed to the extent of -7.61 which is statistically significant. The value of kurtosis is bigger than 3 . The distribution is high leptokurtic.

The correlation between ACC and BSEI was 0.025. The co-movement represented by the covariance 0.149 was not significant. The beta value 0.046 reveals relatively less systematic risk of the stock. The risk of the scrip is considerably lower than the market portfolio (Where beta is supposed to be 1 ). $R^{2}$ value is only 
0.0006 which says that only an infinitesimal part of the variance is explained by the market and the remaining $99.94 \%$ of the variance was unexplained.

\subsubsection{Daily Returns}

It can be seen from the Fig. 1 that the daily returns of ACC for 11 years from 1999 to 2009 were closely knitted with an exceptional and abnormal aberration on a particular day where the return fell drastically to the extent of $-91.84 \%$. On all other days the return drawn by the company was around the expected value $0.09 \%$. The pattern of the return is conspicuously thickly packed about either sides of the abscissa within a range of 0 and 1 per cent. The daily return has a standard deviation of 3.32 which is higher than the market $\sigma$ of 1.79. The standard deviation becomes serious when it goes beyond $3 \sigma$ to the left or right of the mean. Here the $\sigma$ is 0.32 (3.32-3) excess to the right. The daily return of ACC was highly volatile.

It can be seen from the Fig. 1 that the daily return of the scrip was volatile. Most of the values lie within a range of $-5 \%$ and $5 \%$. The $\mathrm{X}$ axis is thick and dark because on an average the daily return coincides with zero. The figure shows that the distribution was less symmetrical. The distribution of daily returns was more leaned towards left due to negative skewness. High leptokurtic kurtosis can also be viewed from the figure.

\subsubsection{Holding Period Yield}

As per table 2, the largest holding period yield was $105 \%$ in the year 2006. In the first 3 years of the decade the yield was negative. In the first year 1999 the yield was $-75 \%$. But year after year it was reducing. It can be viewed from the figure that the yield curve was rising upwards from 1999. After the peak performance in the year 2006, the yield abruptly fell down to $-6 \%$ in 2007, then again fell to a $-54 \%$ in 2008 before it rose to a magnificent $76 \%$ in 2009 . The overall performance of the scrip was prospective with an average of $13 \%$ during the decade. Since 1999 the yield tends to rise upward except in the years 2007 and 2008. For five years the scrip was earning negative holding period yield. The other six years it was making positive holding period yields. The performance can be seen from the Fig.2. The lowest holding period yields were earned in 1999. Since 1999 the holding period yield was rising at the rate of 200\%. The year 1999 had a disastrous effect on the HPY of the company. On the contrary, year 2006 was highly prospective.

The figure 2 shows the HPY curve of ACC for the period. From the figure the erratic behavior of the HPY could be understood. It could be viewed from the figure that the yield curve was rising upwards from 1999. After the peak performance in the year 2006, the yield abruptly fell down to $-6 \%$ in 2007, then again fell to a $-54 \%$ in 2008 before it rose to $76 \%$ in 2009 . The overall performance of the scrip was prospective with an average of 13\% during the decade. Since 1999 the yield tends to rise upward except in the years 2007 and 2008. The yield curve was not normal. The performance can be seen from the figure. One peak and one trough could be found in the figure for the HPY line of the scrip. The peak was in the year 2006 at $105 \%$. The trough bottoms out at 54\%. The lowest point is the starting point of the line in the year 1999.

\subsubsection{Annual Returns}

TABLE. 3, shows the rate of return earned by the scrip from 1999 to 2009. On an average the scrip had earned a return of $0.09 \%$. Except in 2000 and 2008 it had performed well. In 1999 the annual return of ACC was $0.18 \%$. In 2009 it rose to 0.27 . The rate of growth in the annual rate was 1.5 times. In two years ACC had negative annual returns. The annual return was registered in 2006 as $0.32 \%$ and the lowest $0.25 \%$ in 2008 . Year 2008 was worst for ACC. The figure 3 also elucidates the highly fluctuating nature of the return. In the case of annual return year 2008 played havoc. It was the most disastrous year in the decade for the company as far as annual returns concerned.

The Fig. 3 shows the behavior of the annual return of ACC. The curve was erratic, having lots of ups and downs and formation of a series of peaks and two troughs. From the graph it could be seen that the negative return in 2008 was the major fall in the decade for the stock ACC. Annual return line of ACC begun from higher point at Y-axis. Then it sharply fell below $-1 \%$ in year 2000. Then it rose to $0.2 \%$ in 2004.After some minor zigzag again it rose to the maximum in 2007. Immediately then the annual returns line fell sharply to the bottommost point in 2008. In 2009 annual returns recovered from the depression and went up comfortably. In this way there were full of ups downs in the movement of the annual return. In 2007 the annual return was at the peak. But in the next year 2008 it sharply fell. Again in 2009 the return went up. Annual returns never stay permanent. It was moving violently rousing uncertainty and concern to the stake holders and share holders. The annual returns of ACC were found highly volatile during the period.

\subsection{Apollo Tyres}

\subsubsection{Summary Statistics}


TABLE. 1 shows that the average return of the Apollo Tyres was $0.10 \%$ which was slightly less than the market rate of return of $0.11 \%$. The expected return represented by the HPY for the period was $24.64 \%$. The Arithmetic Mean return of the company is considerably lower than the decade's holding period yield. The return was highly and negatively skewed at a rate of -4.089 . During this period the company had made a maximum return of $25.94 \%$ and a smallest return of $-89.4 \%$. The range of the largest and smallest was 115.34 . This shows that the scrip's return was highly fluctuating. The company had a high standard deviation of 3.81. Variance also was high (14.54). The correlation between the company and the market was low as shown by the parameter $r=$ 0.009 . The value of kurtosis was 112.858. It signifies a greater amount of peakedness in the distribution. It was that of Leptokurtic. The scrip's relative volatility beta was 0.02 . It was lower than the market beta of 1.0. The beta coefficient was insignificant. $\mathrm{R}^{2}$ value of the company 0.0004 tells that $99.6 \%$ of the return was unexplained and only $0.004 \%$ was explained by the market. The scrip was not greatly influenced by the market.

\subsubsection{Daily Returns}

Fig. 4 shows the fact that the return from the company was distributed asymmetrical way. The substantial portion of the daily return had occurred on and around $\mathrm{X}$-axis or zero line. Occasional upheavals were also found off the abscissa. But they were only errors. The major chunk of return could be located in between 0 and 5t. The lowest one day return was shown on the right hand side of the figure. Excessive hump can be seen on the left hand side indicating negative skewness. The standard deviation of the scrip 3.81 revealed high volatility in the daily returns. The daily return has a standard deviation of 3.81 which is higher than the market $\sigma$ of 1.79. The standard deviation becomes serious when it goes beyond $3 \sigma$ to the left or right of the mean. There is high degree of volatility. The figure 4 shows the fact that the daily return had full of events with numerous violent vibrations about and around the mean returns. It shows that the daily return was not stable and regular. On the contrary, it was fluctuating and unstable.

\subsubsection{Holding Period Yield}

TABLE. 2 shows, that the HPY of Apollo on an average was $24.64 \%$. In 1999 the HPY was $145 \%$. In 2009 it was $140 \%$. The HPY had decreased by $3.44 \%$ during this 10 year period. The HPY was the highest in 1999 with $145 \%$. The lowest HPY was registered in 2007 as $-85 \%$. The year 2007 was worst for the stock Apollo. In 5 years the scrip incurred negative HPY and the other 6 years it had made positive HPY. Year 1999 was the most prosperous for Apollo. The HPY on an average was declining since 1999. The years 2007 and 2008 had disastrous impact on the holding period yields of the scrip. The performance 2009 was sudden recovery from the preceding years' great falls. Therefore the performance of the year 2009 cannot be expected to be stable overtime. The history of the HPY for the entire period also did not support such a surmise. The Holding period Yield of Apollo was full of uncertainties and volatilities during the period. Nothing could be predicted.

Fig. 5, Shows that Apollo's yield in the year 1999 was 145\%. In 2000 the HPY sharply fell and went down below the X-axis to the extent of $-48 \%$. But from 2001 onwards the HPY tended to go up. In this way between 1999 and 2009 the HPY widely fluctuated in zigzag manner. In 2009 again the holding period yield went up showing a prospective future. On an average in the meantime the company secured an overall HPY of 24.64 during the decade. It is to be noted that the overall tendency of Apollo's HPY is to decline since 1999. In the beginning and end of the decade only the scrip could make outstanding HPY. They could be considered only chance performance. In between these two extreme cases in all other years the scrip's HPY line was fluctuating and swinging up and down in an indecisive way creating full of uncertainties. This could be viewed from the figure. Four peaks and four troughs could be seen in the movement of the HPY line indicating sporadic volatility in the holding period yield of the Apollo.

\subsubsection{Annual Returns}

TABLE. 3, shows the annual rate of return earned by the scrip Apollo from 1999 to 2009. On an average the scrip had earned a return of $0.10 \%$. Except in 2000, 2004, 2007 and 2008 it had performed well. In 1999 the annual return of ACC was $0.50 \%$. In 2009 it decreased to $0.43 \%$. The rate of fall in the annual rate was $14 \%$. In 4 years Apollo had negative annual returns. The largest annual return was registered in 1999 as $0.50 \%$ and the lowest $-0.36 \%$ in 2008. Year 2008 was worst for Apollo. The annual return table of Apollo was very much similar to the HPY table. Years 2007 and 2008 yield negative annual returns consecutively. Its impact on the annual returns of the entire period was very high. Even though in 2009 a recovery from previous years' debacle was made, there was no sign that it would be repeated in the future. From 1999 to 2009 the annual return of the stock was showing a tendency of declining year after year. Every year there was only uncertainty about the return whether positive or negative.

The Fig. 6 shows the behavior of the annual return of Apollo. The curve was erratic, having lots of ups and downs and formation of a peak and two troughs. From the figure it could be seen that the negative return in 2008 was the major fall in the decade for the stock ACC. The annual return line started well from a high point 
on Y-axis in 1999. Then immediately it falls below zero line in deep in 2000. Then it recovers and goes up in the next years and reaches the maximum in 2003. Then abruptly it swings downwards below zero in 2004 itself. Then it recovers in 2005 and reaches another peak in 2006. There from it again makes a somersault and falls sharply below zero return point and reaches the bottommost showing the minimum annual return for Apollo. In this way the annual return was going up and down year after year recurring, creating chaos and uncertainty for the company. It indicated the magnitude of volatility in the annual return of the stock.

\subsection{Arvind Mills}

\subsubsection{Summary statistics}

TABLE. 1 shows that Arvind Mill's average annual return was $0.07 \%$. But expected return based on the past 11 years of performance as shown by the holding period yield was $14.45 \%$. On an average the company's earnings were lower than the expected. During the same period the market return was recorded as $0.11 \%$ which was much more than the company's return $0.07 \%$. The standard deviation 3.86 and variance 14.9 were significant and signals fluctuation in returns from the average. During this period company earned a maximum of $37.5 \%$ return and went as low as $-24.12 \%$ returns. The return ranged to a total of 61.26 . It reveals that the return was highly volatile. The distribution of return was not normal. The positive skewness measured as 0.77 shows the fact that the distribution was highly skewed to the right. The degree of skewness was very high. The kurtosis worked out was 7.35. It shows the presence of a peakedness of leptokurtic. The correlation coefficient of the company's return with the market was -0.33. It denotes the fact that the correlation is negative with the market index and significant. The relative volatility of the scrip with the market as denoted by the beta was -0.71. It means the company behaved less than proportionately and inversely with the market. The risk of Arvind Mills is not more than the market portfolio. The $\mathrm{R}^{2}$ value 0.109 tells the fact that only $11 \%$ of the variance 14.9 was explained by the market and $89 \%$ was unexplained.

\subsubsection{Daily Returns}

Fig. 7 shows greater fluctuation in the daily return of Aravind Mills. It can be found that almost all values fall within the range of $0 \%-5 \%$ plus or minus. Largest value and smallest value can also be noted on some exceptional days from the graph. The values were thronging about the average. The distribution is tightly knitted with some occasional exceptional behavior. The substantial portion of the daily return had occurred on and around $\mathrm{X}$-axis or zero line. Occasional upheavals were also found off the abscissa. But they were only errors. The major chunk of return could be located in between 0 and $5 \pm$. The lowest one day return was shown on the right hand side of the figure. Excessive grouping of returns can be seen on the right hand side indicating positive skewness. As the standard deviation of the scrip 3.9 in contrast to the market $\sigma$ of 1.79 revealed high volatility in the daily returns. The graph shows the fact that the daily return has full of events with numerous violent vibrations about and around the mean returns. It shows that the daily return was not stable and regular. On the contrary, it was fluctuating and unstable.

\subsubsection{Holding Period Yield}

TABLE. 2 shows, that the HPY of Arvind Mills on an average was 14.45\%. In 1999 the HPY was 37\%. In 2009 it was 118\%. The HPY had increased by 4.2 times since 1999 during this 10 year period. The HPY was the highest in 2002 with 141\%. The lowest HPY was registered in 2008 as negative $85 \%$. The year 2008 was worst for the stock Arvind. In 6 years the scrip incurred negative HPY and the other 5 years positive HPY had been earned. Year 2002 was the most prosperous for Arvind. Year 2008 had played havoc to the HPY of the company. The HPY on an average was declining since 1999. The years 2005, 2006 and 2008 had disastrous impact on the holding period yields of the scrip. The performance in 2009 was sudden recovery from the preceding years' great falls. Therefore the performance of the year 2009 cannot be expected to be stable overtime. The history of the HPY for the entire period also did not support such a surmise. As the holding period yields of Apollo was negative for most period of the decade, there was full of uncertainties and volatilities during the period. Nothing could be predicted.

The Fig.8 shows the HPY curve of Arvind for the period from 1999 to 2009.. From the figure the erratic behavior of the HPY can be understood. It can be viewed from the figure that the yield curve was rising upwards from 1999. From 1999 to 2009 Arvind's stock faced 4 peaks and 4 troughs. The HPY curve was highly fluctuating. The overall tendency of the HPY line was to decline. It could be seen that most of the years the HPY line of the company was going up and down along the x-axis. Despite this the overall performance of the company was prospective by securing $14.5 \%$. The performance of the company in 2009 was impressive while the year 2008 was worst. In the end of the decade and occasionally in some years only the scrip could make outstanding HPY. For every rise immediate fall was experienced by the scrip in the case of HPY. Whenever positive HPY was recorded it was as if a chance performance. In all years the scrip's HPY line was fluctuating and swinging up and down in an indecisive way creating full of uncertainties. This can be viewed from the 
graph. Four peaks and four troughs could be seen in the movement of the HPY line indicating sporadic volatility in the holding period yield of the Apollo.

\subsubsection{Annual Returns}

TABLE 3 shows the average annual return of Arvind Mills. During 1999-2009, in the initial three years the company had made negative returns. The average annual return was 0.07 per cent. In the year 2002 the company gained a return of $0.44 \%$. In 2004 it made the maximum for the decade $0.49 \%$. In 1999 the annual return of Arvind Mills was $-0.11 \%$. In 2009 it made a return of $0.41 \%$. Since 1999 the annual return of the scrip was increasing by 4.7 times. In 1999 the annual return was negative. For six years the stock was making negative returns. Only five years it was making positive annual returns. It all amounts to the prevalence of high uncertainty in the occurrence of the annual returns of Arvind Mills. There was chaos in the distribution of annual returns for the stock. Due to this chaos it becomes difficult to predict the future annual returns. Potential investors would be panic as to whether to invest on the stock or not. Such an amount of uncertainty in annual returns of the company was prevailing over.

It could be seen from the Fig. 9 that the average annual return of the company Arvind Mills from 1999 onwards rose from negative returns to positive and reached the maximum in 2003. Then the annual return line was falling with lot of minor ups and down. The line had been finally fallen to the lowest and worst in 2008 . Then again the line recovered and went up in 2009. The annual return line of Arvind stock was highly volatile during the period. The scrip's annual return curve was starting from low minus point on $\mathrm{Y}$-axis. Then it rose to a peak with much hesitation in 2003. There from it fell sharply and abruptly crossing zero line down to a trough in 2006. Then the annual return line again rose to a higher point in 2007. Then fell down to another major trough which was minimum annual returns for the firm in the decade in 2008. Annual return line in this way had a travail of going up and down with full of twists and turns of short-living in nature throughout its length and breadth. It all indicates high level of uncertainty prevailing in the occurrence of annual returns of the company.

\subsection{Ashok Leyland}

\subsubsection{Summary statistics}

TABLE 1 shows, that the average return earned by Ashok Leyland during the period was $0.11 \%$ which was identical to the market return. The HPY was $48.27 \%$. The HPY is much higher than the market return of $0.11 \%$. As the HPY is a proxy for expected return, the company's average return was disappointing. During the decade of 1999-2009 the company earned a largest return of 18.22. The smallest for the same period was -89.2 . The return for the period was wavering between these two values giving way to high level of uncertainty and fluctuations. The range 107.94 is big number representing high volatility of the returns. The distribution of the return was not normal. It is negatively skewed to the extent of -4.53 . Not only negatively skewed but also had leptokurtic peakedness to the extent of 115.2. The beta of the company reveals the systematic risk of the company. The beta -0.011 is negative, which only rarely happens, and lower than the beta 1.00 of the market proxy of B.S.E30. The $\mathrm{R}^{2}$ value given confirms it. The $\mathrm{R}^{2}$ value 0.005 is insignificant in the sense that only $0.005 \%$ of the total variance was explained by the market, the remaining $99.9 \%$ was unexplained by the market. It means the stock's market-related risk is insignificant.

\subsubsection{Daily Returns}

It can be seen from the Fig. 10, that most of the values range between 0-5 plus or minus. The maximum return is $18.22 \%$ and minimum $-89.2 \%$ could be observed from the graph. Minor fluctuation around the $\mathrm{x}$-axis could be traced out. The return was highly fluctuating as shown by the standard deviation and variance. The daily returns were thickly coated on either sides of the zero-line. It means the actual returns were around the mean returns. Still enormous minor and major vibrations were found about the zero line indicating high level of fluctuations in the distribution of daily return. The standard deviation of Ashok Leyland was 3.79. It is well above 3. Standard deviation above 3 is significant. The implication of it was that there were intense and violent errors about the mean daily returns signaling high degree of price and return volatility. On the left side of the distribution undue swarming or humping could be seen in the picture indicating negative skewness. It was due to the fact that the distribution was not symmetrical.

\subsubsection{Holding Period Yield}

TABLE 2 shows that the company was making a holding period yield of $48.27 \%$ for the period 1999 2009. Except 3 years the company makes good expected returns during the decade. The maximum HPY $220 \%$ was obtained in the year 2009. In the years 2003 and 1999 HPY earned was 199 and 155\% respectively. In 2009 the company's performance was exceptionally good. In 1999 the HPY of Ashok Leyland was 155\%. In 2009 it was $220 \%$. There was an overall growth of $42 \%$ in the HPY since 1999. In three years the HPY was negative. For eight years the HPY was positive. The lowest yield $-71 \%$ was made in the year 2008 . The highest HPY was 
occurred in 2009. The year 2008 was disastrous for the HPY of the stock. At the same time the year 2009 was prospective for the firm. On average the trend of the HPY was to rise upwards.

It can be seen from the Fig. 11 that in 1999 the company was sliding from 155\% to reach below cutting the x-axis. Then after 2000 it went up to $199 \%$ in 2003 . There from it fell sharply down to the all time low in 2004. After that it recovered and gathered momentum better its position by gaining the all time best of $220 \%$ in 2009. As the figure 11 shows the HPY of Ashok Leyland had full of twists and turns during the period. The yield never stayed anywhere more. It was always unstable. There was one peak in 2003. Immediately after that a deep trough was followed in 2004. Then in 2005 the HPY went up and in 2007 tended to fall down and in 2008 the HPY fell to the all time low. In this way the HPY of Ashok Leyland goes up and down all time without settling for some time anywhere. It all shows the volatility of the HPY of the stock. The line HPY starts from a high point. It ends also in a high point. Between these points it had endless ups and downs. This was due to chaos and uncertainty in the distribution of the holding period yield of the company.

\subsubsection{Annual Returns}

As per TABLE 3, from 1999 to 2009 the company was making an annual rate of $0.11 \%$. Eight years it made positive returns and 3 years negative. In 1999 the annual return was $0.50 \%$. In 2009 it was $0.54 \%$. The annual return was growing by $8 \%$ since 1999 . The highest positive return was in 2009 that is $0.54 \%$ and the lowest return it earned was in 2008 that is $-0.43 \%$. The Year 2008 was worst for Ashok Leyland. The year 2008 had done much harm to the annual returns of the company. In the decade the stock was making steadily positive returns. Only in 3 years it succumbed to negative results. High volatility was there in the flow of annual return to the stock. Highs and lows were coming in alternating years. Ups and downs were coming successively year after year. There was uncertainty in the occurrence of annual returns. It was not possible to predict the behavior of annual returns due to the high volatility.

Fig.12 shows that the return of the stock Ashok Leyland was in a zigzag manner as in a seesaw. The return went up and down of the zero line in alternating years. It reveals greater risk. Sudden uprising and decline can be observed. The highest positive return of the company was earned in the year 2009 and lowest was in 2004. Between 1999 and 2009 a sporadic volatility was found with the pattern of return. As the figure 11 had shown there were three peaks and three troughs occurred in alternating years. It became cyclical. This volatility in annual returns can be found repeating year after year. It shows the high volatility prevailing in the distribution of annual returns in the decade. It was starting from a high point in 1999. Then, the annual return was suddenly swinging down to below zero line in 2000. Then again recovered and went up to a small peak in 2001. In 2002 it further went up to a major peak in 2003. In 2004 it abruptly had fallen to deep trough. In this way the annual returns were never stable throughout the decade.

\subsection{Asian Paints}

\subsubsection{Summary statistics}

As per TABLE 1, the average return of the stock Asian Paints for 11 years was $0.09 \%$ which was less than the average return of the market $0.11 \%$ for the same period. The HPY was $23.27 \%$. The company was under performing. The company's performance was much below of what was expected of it. The large and small values reveal that the return was not widely scattered. The dispersion from the mean is normal. The standard deviation 2.09 is not significant. Therefore the company was making a stable return for the period. The return varies in between positive $11.61 \%$ and a negative $36.19 \%$ amounting to range of 47.8 . Hence the distribution was tighter. The skewness -2.9 is significant. It says that the return is not only asymmetrical but negatively skewed also. The kurtosis 57.87 signals leptokurtic form of peakedness. The correlation 0.006 between the company and the market is insignificant. The systematic risk denoted by beta 0.007 is low. $\mathrm{R}^{2}$ 0.000036 says that $0.0036 \%$ of the variance is explained by the market, while $99 \%$ of variance is unexplained by the market. The scrip was not much market-related during the period.

\subsubsection{Daily Returns}

It can be seen from the Fig.13 that the return is negatively skewed. The largest return 11.61 and the smallest $-36.19 \%$ could be located from the graph. The tightness of the distribution could also be discerned. Lot of minor fluctuations around the zero line can be viewed. The volatility of stock return about the mean value can be observed. The values were found lying within a range of $0-1 \% \pm$. The values were thickly coated along the line of X. Some values had shown tendency to fall down to the line of abscissa occasionally can also been located from the figure. Undue humping of values on the left hand side of graph can be seen due to the presence of negative skewness (-2.9) of daily returns. From the figure it could be understood that the distribution of the daily returns was not symmetrical. Minor vibrations could be located on either side of the mean returns. The lowest and highest daily returns were found in the figure 13. The daily return has a standard deviation of 2.9 which is higher than the market $\sigma$ of 1.79 but lower than $3 \sigma$. The standard deviation becomes serious when it goes beyond $3 \sigma$ to the left or right of the mean. There is not much volatility in daily return of Asian Paints. As 
the standard deviation denotes, the actual values tightly fastened to the mean return. The volatility in the daily returns was not very strong. But small errors were running around the mean of daily returns. Extreme returns indicated by kurtosis 57.87 could be viewed from the figure.

\subsubsection{Holding Period Yield}

As per TABLE 2, the average holding period yield of Asian Paints which was the expected return of the company was $23.27 \%$. The HPY was the highest in 2009 with $102 \%$. The lowest was in the year 2000 with 29\%. In 2001 the company made no yield at all. In 1999 the HPY of Asian Paints was 30\%. In 2009 it was 102\%. The HPY had increased 3.4 times since 1999. In 3 years the HPY was negative. In 8 years the HPY was positive. The tendency of the HPY was to grow. Even though the company had made positive HPY in almost all years in the decade the magnitude of this was highly uncertain. Despite the fact that Asian paints made good HPY in the entire period, the HPY was highly erratic. There was no certainty in the occurrence of the HPY. The pattern and magnitude of the HPY were highly chaotic. The pattern was uncertain because in a year the HPY was $80 \%$, in another year it was 5\%. In still another year the HPY was zero. In some years the HPY was positive and in some other year it was negative. In this way the pattern and the magnitude of the HPY of Asian paints had no certainty. This chaotic behavior entails high level of volatility to the scrip of Asian paints.

It could be seen from the Fig.14 that the HPY of Asian Paints was highly volatile throughout the decade. As in a seesaw the HPY was swinging, going ups and downs with constancy throughout the period. But the overall tendency could be located from the figure that the HPY was continuously growing upward. In the year 2009 HPY had been reached a new height in its performance. The graph vindicates what was said earlier about the HPY of Asian Paints. The HPY was driving towards persistently higher and higher points of yields. But here and there it confronted resistance and broke down. But the HPY was relentlessly was going towards better results. This thrust of the holding period yields of Asian Paints could be learnt from the figure. In the travel it faced four major troughs and peaks. The number of peaks and troughs tells the intensity of the volatility in the distribution of the HPY. More ups and downs were found in the case of Asian paints in varying pattern and magnitude. The more it is, the high the volatility of the HPY.

\subsubsection{Annual Returns}

As per TABLE 3, the average annual return of the stock Asian Paints for the period 1999-2009 was $0.09 \%$. In 1999 the annual return was $0.15 \%$. In 2009 it was $0.32 \%$. The annual return during the period had been increased at the rate of $113 \%$ since 1999. In 3 years the annual return was negative. In 8 years it was positive. The annual return was the highest in 2009 and lowest in 2000. The overall tendency of the annual return was to grow. As shown by the table, the annual returns' behavior was similar to the holding period yields of Asian paints. While the annual return in 1999 was positive, it went negative in the next year itself in 2000. Then in the next year there was no annual return at all in 2001. Then in 2002 and 2003 the scrip made nominal annual return. After that again 2004, the returns became negative. After that there was steady progress in the annual returns till 2008. In 2008 again it earned negative returns. In this way negative positive returns were earned by the stock in an alternating way. This was due to the high price volatility in the market. Therefore high level of uncertainty and chaos found with the annual return of Asian Paints.

As Fig.15 showed, in 1999 annual return of Asian paints was very high. Thereafter it declined. From 1999 to 2009 the annual return line was moving across wide fluctuations. Therefore the line of annual return was erratic and zigzag. Though the trend was to grow up, the annual return was highly volatile in nature. While the annual return in 1999 was positive, in 2000 it went negative. It could be easily found that the fluctuations in annual returns from the graph above. From the beginning of the annual return curve to its end in 2009, it went across numerous ups and downs one after another. There was no stability to any trend. There was no trend at all. In one year the annual return was positive. In the next year itself it turns to the opposite. Still the persistent trend that was underlying could be located from the graph vividly. It was that of going up. But there prevails uncertainty and chaos as to the accuracy about the occurrence of the returns whether it would be negative or positive or whether it would be a big amount or low amount. This form of uncertainty was there in the pattern and magnitude of the annual returns of Asian Paints.

\subsection{Axis Bank \\ 6.6.1. Summary Statistics}

TABLE 1 provides a summary statistics of the performance of Axis Bank for the period 1999-2009. The scrip earned an average return of $0.2 \%$ during the period. It is more than the market average of $0.11 \%$. The holding period yield worked out for the company is $60.09 \%$ which is the expected rate of return of the company. The company's performance was lower than the expected. The firm's HPY $60.09 \%$ was overwhelmingly higher than the market average of $0.11 \%$. The largest daily return of the firm was registered at $24.86 \%$ whereas the smallest was recorded as $-16.37 \%$. The quantitative difference between the large and small comes to 41.23 . It shows the volatile behavior of the stock. The same is confirmed by the statistics standard deviation with a value 
of 3.4 and a variance of 11.7. Both the standard deviation and variance are significant. The distribution of the company's earnings was not symmetrical. A skewness with value of 0.86 signals high level positive grouping and humping right to the mean value. The distribution is also having an enormous level of peakedness of leptokurtic nature to the tune of 5.07. The kurtosis is leptokurtic since the coefficient is more than 3 . The sensex and the scrip move together to the tune of 0.607 . The coefficient of covariance 0.607 is significant. Correlation coefficient which measures the interdependence between the scrip and the BSE30 the sensex is arrived at 0.099 . The systematic risk of the company was recorded at 0.19 . The beta value of the market portfolio is 1 . The scrip's beta of 0.19 is lower than the market beta of 1 . Therefore the relative volatility of the scrip vis-à-vis the market is not significant. $\mathrm{R}^{2}$ value confirms this. $\mathrm{R}^{2}$ is worked out at 0.01 . It implies that only $1 \%$ of the total variance of 11.7 was explained by the market leaving $99 \%$ unexplained.

\subsubsection{Daily Returns}

Fig.16 shows the behavior of daily return of Axis bank for the period. The returns were thickly pasted along the $\mathrm{X}$-axis on either side of it. It shows the density of occurrence of returns for the 11 year period over 2642 days of observation. An overwhelming grouping or humping can be observed on the right side of the picture. It is an indicator of the presence of high level positive skewness. The distribution of returns was not normal. Most of the values can be found within a range of $0-1 \% \pm$.The largest and smallest values of returns are also plotted in the graph. The daily return has a standard deviation of 3.42 which is higher than the market $\sigma$ of 1.79. Axis Bank's daily return was more volatile than the market. The standard deviation becomes serious when it goes beyond $3 \sigma$ to the left or right of the mean. There is volatility in the daily returns. The tail behavior of return was shown by the kurtosis 5.07. The distribution of daily return was not symmetrical. On the contrary it is highly skewed to the right to the extent of 0.86 .

\subsubsection{Holding Period Yield}

TABLE 2 shows the behavior of holding period Yield of Axis Bank for the period 1999-2009. In 1999 the HPY obtained by the firm was 47\%. In 2009 it was $91 \%$. In the meantime HPY had been increased by 1.9 times. The lowest yield secured by the scrip was $-48 \%$ in 2008 . The highest yield was $210 \%$ in 2003 . The company succumbed to negative returns in 2 years. But scrip managed to earn positive yields over 9 years. On average Axis Bank achieved $60.09 \%$ yield over the entire period under study. The table depicts the prevalence of variability of yields of high degree. Variability arises since there is difference between the actual yield obtained and the expected. In the year 1999, the actual yield was $47 \%$ whereas the expected $60.09 \%$. Here the variability was $13.09 \%$. In 2009 it was $30.91 \%$. So there was high variability which causes the high volatility in yields.

Fig.17 shows the behavior of the HPY of Axis bank during the period 1999-2009. The HPY starts from a point on the Y-axis just above but in the middle of 0 and 100\%. It moves in a straight line to settle in 2009. In the mean time it comes across 3 troughs and 4 peaks. One of the peaks was major which denoted the largest HPY secured by the scrip lying above $200 \%$ point in 2003 . One of the troughs, rather the last one in 2008 indicates the lowest HPY point with nearly $-100 \%$. Even though there are 3 falls only 2 are below zero line. On the average the holding period yield was appreciable. But the result was neither steady nor stable. The line of HPY was highly erratic. Peaks and troughs walk hand in hand. Ups and downs occur one after another cyclically and alternatively. The Fig.17 shows high degree of volatility in yields.

\subsubsection{Annual Returns}

TABLE 3 shows the behavior of annual returns of Axis Bank during the period 1999-2009. In 1999 the annual return was $0.26 \%$. In 2009 it was $0.34 \%$. The annual returns had been increased ever since 1999 by 1.3 times. So the annual return of the scrip was growing over years. The largest returns were $0.51 \%$ which occurred in 2003. On the contrary the smallest was $0.17 \%$ occurred in 2001 . The company faced negative returns over 2 years. Over 9 years the scrip gained positive returns. On average Axis Bank secured $0.21 \%$ of annual returns over the entire period under study. The average or expected annual return was $0.21 \%$. The actual returns earned by the stock in different years were either more or less than the expected. The excess or short of the returns over the expected returns was the variability in the returns. The annual returns shown by the table was showing the fact that the annuals were highly volatile.

Fig.18 shows the behavior of the annual returns of Axis bank during the period 1999-2009. The Annual returns line starts from a point on the $\mathrm{Y}$-axis just above the point $0.2 \%$. It moves in a straight line to settle in 2009. In the mean time it goes through 3 troughs and 4 peaks. One of the peaks was major which denoted the largest annual returns secured by the scrip lying above $0.4 \%$ scale in 2003 . One of the troughs, rather the second one against the year 2001 along the $\mathrm{X}$-axis indicates the lowest annual returns just below $0.2 \%$ scale on the Yaxis. Even though there are 3 falls only 2 are below zero line. On the average the holding period yield was appreciable. But the result was neither steady nor stable. The line of annual returns was highly volatile. Peaks 
and troughs occur constantly. Ups and downs come one after another frequently and alternatively. The figure shows the existence of high degree volatility in the returns.

\subsection{Ballarpur Industries \\ 6.7.1. Summary statistics}

As per TABLE 1 the average return of Ballarpur was $0.08 \%$ which was lower than the market average of $0.11 \%$. The expected return based on the HPY was $16.64 \%$. Company's average performance for the eleven year period was lower than the HPY. The dispersion from the expected value was significant as expressed by the standard deviation 3.6. The scrip had made a maximum return of $21.69 \%$ and minimum of $-79.61 \%$ during this period. This amounts to total range of 101.3 which shows a greater amount of variance. The values greatly vary in between the large and small. There is greater amount of uncertainty in the occurrence of return. The skewness -3.49 was significant in the sense that the distribution was negatively skewed. The variance also tells the same tales that there is greater fluctuation in the return stream of the company. The variance 13 is significant. The kurtosis 90.41 signals peakedness to the character of leptokurtic. The stock co varies with the market by 0.148 . The covariance is not significant. The correlation co-efficient 0.023 is not important. The beta 0.0464 does not express any serious systematic risk. $\mathrm{R}^{2}$ value 0.0005 is insignificant that only $0.05 \%$ of the variance was due to market influence. $99.95 \%$ was unexplained by the market.

\subsubsection{Daily Returns}

Fig.19 shows the pattern of the daily return for the company for the eleven years period from 1999 to 2009. The daily return was thickly packed along the X-axis with few exceptions. Barring some occasional outspreads the return in general was permeated along the zero line. The return was spread within a range of 0 $1 \%$. The high and low values can be located from the graph easily. The daily returns had a lot of minor variations around and about the line of $\mathrm{X}$ axis. Excessive grouping of values can be located on the left hand side from the center of the zero line due to negative skewness of -3.49 . The standard deviation 3.61 and variance 13 of the daily returns were found significant. The varying trend of the individual returns from the mean could be identified from the graph. The daily return was shown in the graph as thickly packed. The density of the values could be grasped from the figure. The daily excess return represented by kurtosis 90.41 was very high. The daily returns of Ballarpur industries were due to excessive price fluctuations in the market for its stock.

\subsubsection{Holding Period Yield}

TABLE 2 shows the HPY of Ballarpur Industries for the period from 1999 to 2009. The HPY of the stock on an average for the period was 16.64\%. In 1999 the HPY was 109\%. In 2009 it was $20 \%$. The HPY during the period had been declined by $82 \%$. In 2000 the HPY was zero. The HPY was largest in 1999 and smallest in 2008. The year 2008 was very bad for Ballarpur Industries. In 3 three years Ballarpur earned negative HPY. In 8 Years there was positive HPY. Generally, the tendency of the HPY was to decline. The HPY in the beginning and at the close of the decade showed greater difference. The HPY from 109\% in 1999 had fallen to a mere $20 \%$ in 2009 after 10 years meant greater failure in the performance of the stock in the market. It might be due to the price volatility in the market. The stock earned positive yields in all eight years. Only in three years it was subject to negative returns. But the impact of three years' negative performance was highly detrimental. The year 2008 had done much damage to the HPY of Ballarpur.

Fig.20 shows that HPY line starts from a peak 109\% in 1999 fell down to zero in 2000. It fell further below X-axis to -36 where it bottomed out for a recovery to another peak with $91 \%$ in 2003. Again it moved downward and rose and fell sharply the all time low of $-89 \%$ before it rises to $20 \%$ in 2009 . Though HPY was positive in almost all cases except in 3 years the overall tendency was to fall down. The HPY was erratic and mostly uncertain. The ups and down showed by the HPY denotes the existence of high degree of volatility in returns during the period. The adversity for the scrip Ballarpur Industries with lowest HPY in 2008 can be seen from the figure. The behavior of the HPY of Ballarpur Industries could be easily understood from a glance of the graph. It was highly volatile. The curve with numerous major and minor swings-downward and upward-had settled at relatively a lower point by showing the persistent trend as that of declining over years.

\subsubsection{Annual Returns}

TABLE 3 shows the annual returns of Ballarpur Industries for the period from 1999 to 2009. The annual returns of the stock on an average for the period were $0.07 \%$. In 1999 the annual returns were $0.42 \%$. In 2009 it was $0.14 \%$. The annual returns during the period had been declined by $67 \%$. The annual return was largest in 1999 and smallest in 2008. The year 2008 was very bad for Ballarpur Industries. In 2 years Ballarpur earned negative returns. In 9 Years there were positive annual returns. Generally, the tendency of the annual returns was to decline. In spite of the stock being earned positive returns for nine years, the underlying trend was identified as that of declining. This was because of the frequent interruption by the downswing in the annual returns. The downswing was due to nothing but the price volatility in the market. The continuous earning of the 
annual returns was now and then deterred by adverse changes in the stock price in the market. That was why after making nine years positive returns the stock became unable to prosper.

Fig.21 shows, that the behavior of the annual average return was very similar to that of the HPY for the period. From 1999 to 2008 the average return tends to fall and reaches the all time low of the decade in 2008. In 2009 a recovery was achieved and the annual average return increased to $0.14 \%$. The curve of annual returns was highly volatile and erratic. The general trend of the annual return of Ballarpur was to decline. The curvature of the annual returns in the graph was shown as highly erratic. It was frequently disrupted and fractured by the downtrend. Frequent interruptions marred the continuity of the annual returns line could be found broken. It was due to the wild uncertainties and fluctuations in the stock prices in the market. The price volatility in the market paved the way for the annual returns volatility since the returns were perceived from the prices of the stocks in the market. Therefore lower the price lower will be the returns also. As such the volatility was intense in the behavior of the annual returns of Ballarpur Industries. This could be discerned from the nature of the curvature of the annual returns curve in the graph. The curve had all the travails of frequent disruptions and interruptions that was why the annual returns could not be able to finish impressively in spite of nine years of positive returns.

\subsection{Castrol}

\subsubsection{Summary statistics}

As per TABLE 1 the average return of Castrol was $0.02 \%$ which was lower than the market rate of return of $0.11 \%$. Expected return based on the performance of the company in the decade was $4.82 \%$ which was much above the actual. The standard deviation 2.34 was not important. The actual would be almost near the average return. The range of variation between the largest and smallest value to the extent of 66.06 was insignificant. The variance 5.45 was below the point of significance. The standard deviation and the variance did not tell any significant volatility for the decade. The distribution of return as stated by the skewness -2.49 revealed the presence of high asymmetry. The distribution was skewed negatively. The kurtosis 71.1 is big and significant peakedness of the form of leptokurtic could be observed. The beta value 0.008 was not significant. The relative volatility between the company and the market was less. $\mathrm{R}^{2}$ value 0.000036 confirmed that $0.0036 \%$ of the variance 5.45 was explained by the market and $99.99 \%$ was unexplained.

\subsubsection{Daily Returns}

Fig.22 shows that the daily return of Castrol Ltd coincided mostly with the zero line and ranged between zero and plus or minus $1 \%$. Extreme values occurred only occasionally. The lowest return of $-48.39 \%$ could be traced from the figure. The highest return earned during the decade could also be located from the figure. It could be identified that the return was highly negatively skewed. Lot of minor volatility around and about the zero line can be seen. The daily returns of Castrol had moderate fluctuation about the mean.. The daily returns of the stock was found in the graph as thickly pasted on either side of the mean return The mean return of Castrol was given in the summary statistics table No.1 as $0.02 \%$. So it could easily be found that the earnings were densely packed within the immediate range of $0-1 \%$. Some values could also be located outside this range up to $5 \%$. But majority of values were shown in the graph lying in between $0-1 \%$ range. The standard deviation of the returns was not significant. The standard Deviation given in the summary Statistics Table No 1 was 2.34. It only confirms the tightness of the distribution. Only minor insignificant fluctuations in earning could be seen from the graph.

\subsubsection{Holding Period Yield}

TABLE 2 showed that The HPY of Castrol on an average for the period from 1999 to 2009 was $4.82 \%$. In 1999 the HPY was $-60 \%$. In 2009 it was 82\%. The HPY had increase by 136\% since 1999. In the initial three years of the decade the company made negative holding period yields. In the year 1999 the return was the lowest to the extent of $-60 \%$. Then in 2000 it improved a little but continued to earn negative HPY of $-17 \%$. The highest positive return was earned in the year 2009 to the tune of $82 \%$. On an average holding period yield for the 11 year period from 1999 to 2009 was $4.82 \%$. The holding period yield for 2009 was a high $82 \%$. Still the overall holding period yield of the stock for the 11 year period was only $4.82 \%$. It was due to frequent downside movement of the price of the stock in the market. The growth in holding period yields was at times blocked by the occurrence of negative returns. The traces of the volatility could be found with the holding period yields of the stock for the period.

Fig.23 shows the pattern of the holding period yield of Castrol. Since 1999 the yield was rising upwards. The trend of the HPY line is to go up in a stair step manner. From -60\% in 1999 the HPY ascended to $82 \%$ in 2009 gradually and successively year after year. The lowest HPY could be located in the graph in the year 1999 and the highest in the year 2009. The curvature of the holding period yield curve shows that it was confronting a lot of troubles before it reached the end point. Frequent disruptions, downswings, resistance and all that pull the curve down from going up. Still the stock managed to finish positively at the end of the decade in a stair step manner. The simile stair-step was meaningful in every respect in the sense that as in a stair-step 
for every step upward there will be immediate down step. But generally the purpose of the stair-step is to go up. In the same way the overall tendency of the holding period curve was to go up but frequently facing down steps at every up step.

\subsubsection{Annual Returns}

TABLE 3 shows that annual return of Castrol. In 1999 it was $-0.24 \%$ and in 2009 it was $0.26 \%$. The lowest annual return was recorded in the year 2004 as $-0.02 \%$. The annual return was highest in 2009 with $0.26 \%$. From 1999 onwards the negative return was improving and by 2002 it became positive to the tune of $0.05 \%$. The last three years of the decade also recorded positive returns. The highest annual return was recorded in 2009. Castrol had made negative returns and positive returns in 5 and 6 years respectively. The overall result was that the company made a $0.02 \%$ return for the 11 year period. The annual return also behaves in the same way as the HPY. It was increasing from $-0.24 \%$ to $0.26 \%$. The growth in the annual return was tremendous during the period in spite of frequent interruptions by the occurrence of negative returns. The volatility that caused the negative return created lot of chaos and uncertainty in the occurrence of annual returns. The table gives details of high levels of volatility.

From the Fig. 24 the behavior of annual return of Castrol could be understood. The annual return moves upward from the deep fall of negative $0.24 \%$ to the topmost place of $0.26 \%$ in 2009 step by step year after year. The shape of the annual return line is like stair-step. The overall trend of the annual return for the decade is that of a steady growth from -0.24 to $26 \%$. There were lots of ups and down throughout the period which were indicated by the line of annual return. The behavior showed by the table could be understood from the graph. The graph represents high level of fluctuations in the annual returns of the stock. The overall effect of the annual returns was to go up. But at times the rise of the annual returns curve was checked and disrupted by the downtrend movements. This caused the volatility in the annual returns. The consequence of it was that no one could predict the occurrence of annual returns on the stock. The volatility was there in annual returns of the company in respect of the timing and magnitude of it.

\subsection{Colgate Palmolive}

\subsubsection{Summary Statistics}

TABLE 1 shows the summary statistics of the performance of Colgate Palmolive for the period 19992009. The average return based on the daily return of the company was $0.07 \%$. The market return for the same period was $0.11 \%$. Colgate's return was lower than the market returns. Similarly, the expected return based on the Holding Period Yield of the company was $12.91 \%$. The firm's average return was also lower than the HPY. The largest daily return was $20.34 \%$. The smallest daily return was $-9.8 \%$. The quantitative difference between the large and small is 30.14 . Hence the dispersion of the return is not big. The return was closely and tightly bonded and would be lying about and around the expected value. The standard deviation 2.06 is not significant. Distribution of the return is not symmetrical. The skewness worked out as 0.88 is highly significant and confirms a high level positive skewness to the right in the distribution. The coefficient of kurtosis 6.47 is also significant. There is peakedness in the distribution. As the kurtosis is more than 3 the peakness is called as leptokurtic. The coefficient of correlation 0.011 is not significant. There is only slight relation with the market. The co-movement denoted by the covariance is 0.041 is insignificant. The beta tells that the systematic risk of the firm is lower than the market portfolio. The R2 value 0.0001 confirms that there is no much market dependence in the case of Colgate Palmolive. The market explains only $0.01 \%$ of the total variance leaving 99.99\% unexplained.

\subsubsection{Daily Returns}

Fig.25 depicts the daily return earned by Colgate Palmolive during 1999-2009. It could be noted that the returns were thickly packed along the $\mathrm{x}$-axis within a range of $0-8 \% \pm$. The largest daily return could be seen from the graph. Similarly it could also be observed that the asymmetric nature of the distribution. The distribution is overwhelmingly skewed to the right. There were 2718 days of observation. The standard deviation and variance were not significant. Minor and major vibrations were there thronging around the mean returns. Actual returns somewhat away from the mean returns. These could be viewed from the graph.

\subsubsection{Holding Period Yield}

From TABLE 2 it can be discerned that the company was making an average holding period yield for the decade as $12.91 \%$. The highest HPY was in the year 2009. It was $61 \%$. The lowest was in 2008 that is $-1 \%$. In three years the company was making negative yields. The remaining eight years it was making positive returns. In the year 1999 the HPY was 9\%. In 2009 the HPY was 61\%. The growth in HPY during the period since 1999 was $577 \%$. The overall tendency of the scrip is to make positive yields. There were high volatility from the expected to actual. The actual holding periods were highly different and fluctuating. Even negative returns were drawn in 
certain years.

Fig.26 shows the pictorial representation of the Holding period yield earned by the firm. The pattern of the HPY could be understood from the figure. HPY is having the shape of stair-step. The distribution had full of peaks and troughs, ups and downs. Peaks and troughs recur one after another, year after year. The overall tendency of the HPY had been to rise. The volatility of the holding period yield could be seen from the figure. The line of HPY was like a stair-step going up in zigzag way. Every up was followed by a downswing. In this way the holding period yield exhibits high volatility.

\subsubsection{Annual Returns}

TABLE 3 shows the annual return earned by Colgate Palmolive for the period 1999-2009. In the year 1999 the company earned an annual return of $0.10 \%$. At the close of the decade in 2009 it managed to earn an annual average return of $0.21 \%$. During the 10 year period since 1999 the company's annual rate of return had increased from 0.10 to $0.21 \%$. A growth of $110 \%$ was achieved in the annual returns by Colgate Palmolive during the period. The highest annual return based on the daily return was registered as $0.21 \%$ in 2009 . The lowest was recorded at $-0.09 \%$ in 2000 . During this period the company earned negative annual returns in 2 years, that is in 2000 and 2002.The remaining 9 years Colgate was making only positive returns. On an average the company earned an annual return of $0.07 \%$ during the period.

Fig.27 shows the behaviour of annual returns of Colgate Palmolive pictorially. The growth of the earnings from $0.1 \%$ to $0.21 \%$ achieved by the company during the period was depicted in the graph. With a lot of twists and turns Colgate relentlessly steered to grow can be discerned from the figure. The actual annual returns were far off from the mean annual returns. There were volatility in the form negative returns and ups and downs in the occurrence of annual returns of the stock. These volatility in the annual returns spread chaos and uncertainty in the expectations of the returns.

\subsection{Crompton Greaves}

\subsubsection{Summary statistics}

TABLE 1 provides a summary statistics of the performance of Crompton Greaves for the period 19992009. The scrip earned an average return of $0.17 \%$ during the period. It is more than the market average of $0.11 \%$. The holding period yield worked out for the company is $61.91 \%$ which is the expected rate of return of the company. The company's performance is lower than the expected. The firm's HPY 61.91 was much better than the market average of $0.11 \%$. The largest daily return of the firm was registered as $20.48 \%$ whereas the smallest was recorded as $-78.97 \%$. The quantitative difference between the large and small comes to 99.45 . It shows wide dispersion of return from the expected value. Therefore the variability in returns was very great in the case of Crompton Greaves during the period. The same was indicated by the statistic standard deviation with a value of 3.97 and a variance of 15.78. Both the standard deviation and variance are significant. The distribution of company's earnings was not symmetrical. A skewness with value of -2.54 signals high level negative grouping and hunchness left to the mean. The distribution is also having an enormous level of peakedness of leptokurtic nature to the tune of 59.27. The kurtosis is leptokurtic since the coefficient is more than 3. The sensex and the scrip move together to the tune of 0.361 . The coefficient of covariance 0.361 is significant. Correlation coefficient which measures the interdependence between the scrip and the BSE30 the sensex is arrived at 0.051 . The coefficient is significant at 0.01 level of significance. Systematic risk of the company was recorded at 0.113 . The beta value of the market portfolio is 1 . The scrip's beta of 0.113 is lower than the market beta of 1 . Therefore the relative volatility of the scrip vis-à-vis the market is not significant. $R^{2}$ value confirms this. $\mathrm{R}^{2}$ is worked out at 0.0026 . It implies that only $00.26 \%$ of the total variance of 15.78 was explained by the market leaving $99.74 \%$ unexplained.

\subsubsection{Daily Returns}

The daily returns of Crompton Greaves are plotted in the Fig.28. It can be seen that the returns were thickly packed along the line of X-axis on either sides of it within a range of $0-10 \% \pm$. The largest daily return can be located from the figure. Grouping of items on the left side of the graph signals negative skewness and asymmetrical character of the distribution. The standard deviation 3.97 and variance 15.78 were significant. They denote the presence of high volatility in the daily return.

\subsubsection{Holding Period Yield}

TABLE 2 shows that in 1999 the Holding Period Yield of Crompton was -9\%. In 2009 HPY was 197\%. The HPY of the firm was growing from 1999 to 2009 by 23 times. The highest HPY was recorded at $197 \%$ in 2009. The lowest was registered as $-72 \%$ in 2006. Negative and positive HPY were earned by the firm in 5 and 6 years respectively. The overall tendency was to grow. The actual holding period yields of the scrip highly vary from the average. The actual yield consists of negative and higher and lower yields. These ups and 
downs make the yield more uncertain and chaotic. The price volatility in the market causes such wide fluctuations in the holding period yield variability.

Fig.29 shows the behavior of the holding period yield of Crompton Greaves. The graph shows a series of upheavals and fluctuations during the period. From -9\% to 197\% the HPY had been moving through a lot of ups and downs and peaks and troughs. The highest and lowest HPY can be read out from the figure. The curve makes wide cyclical fluctuation during the period showing large amount of volatility. The nature of the curvature of holding period yield reveals the immense presence of volatility in the Holding period yield. The curve had three major peaks and four troughs. These peaks and troughs constitute the variability of the actual from the expected. The variability that was found in the actual holding period yields caused full of uncertainties and chaos in the expectation of the stock during the period.

\subsubsection{Annual Returns}

TABLE 3 shows the behavior of the average annual returns based on the daily returns of Crompton Greaves during the period 1999-2009. In 1999 the company made $0.12 \%$ return. In 2009 it went up to $0.51 \%$. Return for the last 11 years had been increased by 4.25 times. The lowest annual return was in the year 2008 . The highest return in the year 2009 was recorded as $0.51 \%$. The company earned negative returns in 4 years and positive returns in 7 years. The overall performance was $0.17 \%$. The underlying tendency of the annual return is to increase. The average annual return was $0.17 \%$. In the year 2009 the annual return was $0.51 \%$. Here the variability of actual over the average or expected was $0.34 \%$. The variability of the actual was very high in the annual returns. There were negative annual returns also. So the magnitude of the variability and volatility of the annual returns of the company was immense.

Fig.30 shows the behavior of annual return of the company Crompton Greaves. From 1999 to 2009 the movement of the return line is plotted in the graph. The movement of the return was not smooth. It was highly uncertain with full of ups and downs. The highest return in 2009 and the lowest return in 2008 are readable from the graph. The overall tendency of the return can also be understood from the figure as growing up. Most of the values lie above and below the average annual return of $0.17 \%$. This can be known from the graph. The depth of the variability can be known from the graph. The distribution of the annual return had full of upheavals and variations.

\subsection{Garware Polyester}

\subsubsection{Summary statistics}

TABLE 1 shows a summary statistics of the performance of Garware Polyester for the period 19992009. The scrip earned an average return of $0.17 \%$ during the period. It was more than the market average of $0.11 \%$. The holding period yield worked out for the company is $62.73 \%$ which was the expected rate of return of the company. The company's performance was lower than the expected. The firm's HPY $62.73 \%$ was much better than the market average of $0.11 \%$. The largest daily return of the firm was registered as $30.77 \%$ whereas the smallest was recorded as $-22.5 \%$. The quantitative difference between the large and small comes to 53.27. It shows a greater amount of variability. Therefore the variability in returns was very high in the case of Garware Polyester during the period. The same was indicated by the statistic standard deviation with a value of 4.8 and a variance of 23.4. Both the standard deviation and variance are significant. The distribution of the company's earnings was not symmetrical. A skewness with value of 0.87 signals high level of positive grouping and hunchness right to the mean. The distribution was also having an enormous level of peakedness of leptokurtic nature to the tune of 4.08 . The sensex and the scrip move together to the tune of 0.318 . The coefficient of covariance 0.318 is significant. Correlation coefficient which measures the interdependence between the scrip and the BSE30 the sensex is arrived at 0.036. The coefficient is not significant. The systematic risk of the company was recorded at 0.0976 . The beta value of the market portfolio is 1 . The scrip's beta of 0.0976 is lower than the market beta of 1 . Therefore the relative volatility of the scrip vis-à-vis the market is not significant. R2 value confirms this. $\mathrm{R}^{2}$ is worked out at 0.0013 . It implies that only $00.13 \%$ part of the total variance of 23.4 was explained by the market leaving $99.87 \%$ unexplained.

\subsubsection{Daily Returns}

Fig. 31 shows the daily returns generated by the scrip for the period under study. The return was thickly pasted on either sides of the $\mathrm{X}$-axis within range of $0-8 \% \pm$. There were full of minor and major variations thronging surrounding the abscissa. The large and small values of returns could be readable from the graph. The $\sigma$ of the daily return 4.86 tells the presence high volatility. The return was not symmetrically distributed. It was positively skewed to the extent of 0.87 . 


\subsubsection{Holding Period Yield}

TABLE 2 shows the Holding Period Yield (HPY) earned by Garware Polyester during the period 19992009. In the year 1999 the HPY secured was $-7 \%$. In the year 2009 it was $146 \%$. From 1999 to 2009 the HPY had gone up by 26 times. The smallest value of HPY $-80 \%$ was earned in 2008 and the largest $554 \%$ in 2002. The company faced negative returns for 6 years and positive returns were earned for 5 years. The average HPY for the entire period was $62.73 \%$. The yield in 2009 was $146 \%$ which was greater than expected yield of $62.73 \%$ by 2.3 times. The actual HPY was considerably different from the expected. This variability tells the existence high volatility in the holding period yield of the stock. While the expected yield was $62.73 \%$ in 1999 the actual was only $-7 \%$. This difference between the actual and the average was striking and recorded high levels of volatility in the HPY of the stock of Garware Polyester.

Fig.32 gives a pictorial representation of the facts stated in the analysis of the HPY table. The graph shows that the HPY from $-7 \%$ in 1999 rises to the topmost of the peak in 2002 . Then it slides down to stay at the zero line with minor variations. Then in 2009 it again went up to an appreciable height. The movement of the HPY line of Garware Polyester was very tumultuous and tough to the close of 2009 after 2002.The volatility in the yield causes the line HPY to vary in this way shown by the graph. High level of fluctuations from the expected was the reason for the presence of the peaks and troughs and the ups and downs of the yield curve.

\subsubsection{Annual Returns}

TABLE 3 furnishes the information regarding the annual returns based on the daily returns of Garware Polyester. In 1999 the company had made an annual return of $0.20 \%$. In 2009 it had made a return of $0.47 \%$. From 1999 to 2009 the company's returns went up by 2.335 times. The largest annual return was $0.87 \%$ which was earned in 2002. The lowest -0.57 was earned in 2008. The annual returns were negative in 2 years. The remaining 9 years the company had made positive returns. The average annual return for the entire period was $0.17 \%$. In 1999 the annual return was 0.2 it was very near to the expected. In 2000 the annual return was 0.05 . Difference between the actual and the expected was (0.17-0.05)0.12. The difference between the actual and average was big. The actual was greater than the expected annual return. This variability in return was greater in all years. In certain years there were even negative returns. Therefore the graph depicts the high volatility of the annual returns of Garware Polyester.

Fig. 33 shows what was said earlier. The annual return of Garware Polyester was going continuously ups and down throughout the period. One major peak and trough can be seen from graph. They show the largest and smallest value of the company's annual return for the period. The movement of annual return was in a straight line with full of fluctuations. One major peak and trough could be located in the graph. It shows the existence of high fluctuations in return distribution of the scrip. Other minor peaks and troughs could also be located in the graph. The variability between the expected annual return and the actual was bigger in the case of garware Polyester. Therefore high volatility was found in the movement of annual returns curve. The flow of the line was not smooth. On the contrary, it was full of violent twists and turns.

\subsection{Gujarath Narmada}

\subsubsection{Summary statistics}

TABLE 1 provides a summary statistics of the performance of Gujarat Narmada for the period 19992009. The scrip earned an average return of $0.12 \%$ during the period. It was more than the market average of $0.11 \%$. The holding period yield worked out for the company was $37.82 \%$ which is the expected rate of return of the company. The company's performance was lower than the HPY. The firm's HPY 37.82 was much better than the market average of $0.11 \%$. The largest daily return of the firm was registered as $18.11 \%$ whereas the smallest was recorded as $-15.66 \%$. The quantitative difference between the large and small comes to 33.77 . It shows bigger difference between the average returns and actual returns in the distribution. Therefore the variability in returns is high in the case of Gujarat Narmada during the period. The same was implied by the statistics standard deviation with a value of 3.24 and a variance of 10.5. Both the standard deviation and variance were significant. The distribution of the company's earnings was not symmetrical. A skewness with value of 0.41 signals some amount of positive hunchness to the right of the mean. The distribution is also having an enormous level of peakedness of mesokurtic nature to the tune of 2.97. The sensex and the scrip move together to the tune of 0.093 . The coefficient of covariance 0.093 is not significant. Correlation coefficient which measures the interdependence between the scrip and the BSE30 the sensex was arrived at 0.016. The coefficient is not significant . The systematic risk of the company was recorded at 0.029 . The beta value of the market portfolio is 1 . The scrip's beta of 0.029 is lower than the market beta of 1 . Therefore the relative volatility of the scrip vis-à-vis the market is not significant. $\mathrm{R}^{2}$ value confirms this. $\mathrm{R}^{2}$ is worked out at 0.00026 . It implies that only $0.026 \%$ of the total variance of 10.5 was explained by the market leaving $99.974 \%$ unexplained. 


\subsubsection{Daily Returns}

In Fig.34 the daily returns generated by the scrip Gujarat Narmada is plotted for the period under study. The return was thickly pasted on either sides of the X-axis within range of $0-8 \% \pm$. There were full of minor and major variations thronging surrounding the abscissa. The large and small values of returns could be readable from the graph. As shown in the graph the daily returns of the stock were highly variable. The standard deviation and variance of the distribution given in the TABLE 1 were significant. The figure shows the fluctuations around and about the average mean of the daily returns. Undue grouping of values were found to the right side of the centre due to the skewness of the distribution.

\subsubsection{Holding Period Yield}

TABLE 2 shows the Holding Period Yield (HPY) earned by Gujarat Narmada during the period 19992009. In the year 1999 the HPY secured was 165\%. In the year 2009 it was $85 \%$. From 1999 to 2009 the HPY had gone down by 1.9 times. The smallest value of HPY -7\% was in 2004 and the largest 165\% in 1999. The company faced negative returns for 5 years and positive returns were earned for 6 years. The average HPY for the entire period was $37.82 \%$.

The HPY registered for various years were all either above or below the average HPY of $37.82 \%$. There existed high degree of variability. In certain years negative yields also had shown high volatility in the yields. The ups and downs and the peaks and troughs were all due to this variability of actual yield over the expected. The HPY of the stock was highly volatile for the period.

Fig. 35 gives a pictorial representation of the facts stated in the analysis of the HPY table. The graph shows that the HPY from $165 \%$ in 1999 falls down crossing the X-axis in 2000. Then it went up to the peak point in 2003. Then it falls abruptly. In this way it goes ups and down cyclically in a straight line up to 2008 to reach and touch the bottom most level marking the all time low point before rising up to the topmost in 2009 . The movement of the HPY line was very tumultuous and tough to the close of 2009 after 1999. The line of HPY shows high variability from the expected yield. The actual was never near to the expected. They were either bigger or considerably lower. That was why the curvature formed zigzag nature. High peaks and troughs depicted this extreme variability in the yield.

\subsubsection{Annual Returns}

TABLE 3 shows the behavior of annual returns earned by Gujarat Narmada during 1999-2009. In 1999 the annual return was $0.51 \%$. In 2009 it was 0.29 . There was 1.75 times fall in the annual return from1999 to 2009. The largest annual return earned $0.37 \%$ was in 2003 and the lowest was -0.47 in 2008 . The average annual return for the entire period was $0.11 \%$. The largest annual return earned $0.37 \%$ had variability of $0.26 \%$ over the expected annual return of $0.11 \%$. The smallest $-0.47 \%$ was $0.58 \%$ lower than the expected $0.11 \%$. This difference between the actual and expected was very big. When $0.11 \%$ was expected, even negative returns were drawn. There was high degree of volatility.

Fig. 36 shows the behavior of annual return of Gujarat Narmada. Starting from a good position of $0.50 \%$ in 1999 the line ends at $0.29 \%$ a lower level in 2009 . In between these two points the company's annual return confronts 4 major troughs and 3 lofty peaks before settling in 2009.

\subsection{Harrison Malayalam}

\subsubsection{Summary statistics}

TABLE 1 provides a summary statistics of the performance of Harrison Malayalam for the period 1999-2009. The scrip earned an average return of $0.16 \%$ during the period. It is more than the market average of $0.11 \%$. The holding period yield worked out for the company was $51.91 \%$ which was the expected rate of return of the company. The company's performance was lower than the expected. The firm's HPY 51.91 was much better than the market average of $0.11 \%$. The largest daily return of the firm was registered as $32.97 \%$ whereas the smallest was recorded as $-23.73 \%$. The quantitative difference between the large and small comes to 56.7 . It shows that the returns were highly variable. Therefore the variability in returns was high in the case of Harrison Malayalam during the period. The same is implied by the statistic standard deviation with a value of 4.07 and a variance of 22.18. Both the standard deviation and variance are significant. The distribution of the company's earnings was not symmetrical. A skewness with value of 0.69 signals high level of positive grouping and hunchness to the right of the mean value. The distribution was also having an enormous level of peakedness of leptokurtic nature to the tune of 3.95. The kurtosis is leptokurtic since the coefficient is more than 3 . The sensex and the scrip moved together to the tune of 0.093. The coefficient of covariance 0.093 is not significant. Correlation coefficient which measures the interdependence between the scrip and the BSE30 the sensex was arrived at 0.011. It reveals a low level of positive correlation between the stock and market. The systematic risk of the company was recorded at 0.029 . The beta value of the market portfolio is 1 . The scrip's beta of 0.029 is 
lower than the market beta of 1 . Therefore the relative volatility of the scrip vis-à-vis the market was not significant. $\mathrm{R}^{2}$ value confirms this. $\mathrm{R}^{2}$ is worked out at 0.00012 . It implies that only $0.012 \%$ of the total variance of 22.18 was explained by the market leaving $99.988 \%$ unexplained.

\subsection{2 .Daily Returns}

As in Fig. 37 the daily return of Harrison Malayalam was having sudden fluctuation about the mean value. It was more especially in the recent years. The daily return ranges between 0 and plus or minus $5 \%$. This could be seen from the figure. The large and small values can also be identified from the graph. There were a total of 2642 days of observations. Wide fluctuation from the mean could be seen in the daily returns of Harrison Malayalam. The $\sigma$ and variance of the daily returns of the stock were high (see TABLE 1). The range of returns between the largest and smallest value entails lot of uncertainty. The distribution of daily returns was skewed to the right to the tune of 0.69 . It was an asymmetrical distribution.

\subsubsection{Holding Period Yield}

TABLE 2 describes the Holding period yield of Harrison Malayalam. In 1999 the HPY obtained by the firm was $-27 \%$. In 2009 it was 231\%. The increase in HPY was 9.5 times since 1999. The lowest HPY was -71 in 2008. The highest was $360 \%$ in 2004. In 6 years the company earned negative returns. The remaining 5 years the company made positive HPY. The overall HPY for the entire period was $51.91 \%$. In the first three years the holding period yield of the stock was all negative. But the expected HPY was $51.91 \%$. The dispersion was amazing. Similarly, the highest yield obtained in 2004 was $306 \%$ while the expected was only $51.91 \%$. In this way wide variability could be identified between the actual and the expected. It all amounted to the high volatility in the actual yield of Harrisons Malayalam.

Fig. 38 also depicted the same. The HPY in the years 2002-2004 formed a peak. The highest HPY in 2004 can be identified as the peak point. The two peaks above the X-axis represented the positive return. All the other part of the line was below the X-axis. As per the graph, the HPY for the period shows high volatility. The difference between the actual yield obtained and the expected found largely different. Therefore the HPY was found to be uncertain and chaotic. The major peak shown in the figure in 2004 was quite unexpected and accidental. It was a clear evidence of the presence of high degree of volatility. There were small peaks and major and minor troughs shown by the graph. They all represented the presence of high volatility in the yield obtained by the stock during the period.

\subsubsection{Annual Returns}

TABLE 3 shows the behavior of the average annual return of the company. In 1999 the annual return was $0.06 \%$. In 2009 it was $0.58 \%$. The highest annual return was recorded at $0.68 \%$ in 2003 . The lowest was recorded at $-0.34 \%$ in 2008 . In 6 years the company faced negative annual returns while in 5 years it made positive annual returns. The average for the 11 year period was $0.13 \%$.

In the first three years the annual returns obtained were all negative. The expected annual returns worked out were $0.13 \%$. There was considerable gap between the expected and the actual. Similarly, wide difference could be noted in the case of smallest annual return and the expected value. The largest annual returns obtained were $0.68 \%$ against the expected value of $0.13 \%$. The smallest return achieved was -0.34 against the expected $0.13 \%$. What was found from the table was that the existence of wide variability between the expected and the actual.

As per Fig.39 the annual return of the company Harrisons Malayalam in the year 2003 and 2004 were very high represented in the figure by peak. In 2008 the annual return almost touched the abscissa. It was the lowest return point for the period. The movement of the annual return line was very fluctuating and tumultuous. It was because of the variability between the actual returns obtained and expected; the curve of annual returns was making such a twists and turns in its way. One major peak and trough were mainly found in the graph. It shows the existence high degree of volatility in the annual returns of the company.

\subsection{Hindalco}

\subsubsection{Summary statistics}

TABLE 1 provides a summary statistics of the performance of Hindalco for the period 1999-2009. The scrip earned an average return of $0.05 \%$ during the period. It is less than the market average of $0.11 \%$. The holding period yield worked out for the company was $21.27 \%$ which was the expected rate of return of the company. The company's performance was lower than the expected. The firm's HPY 21.27 was much better than the market average of $0.11 \%$. The largest daily return of the firm was registered as $18.4 \%$ whereas the smallest was recorded as $-89.78 \%$. The quantitative difference between the large and small comes to 108.18 . It shows wide dispersion of return from the average. Therefore the variability in returns was very great in the case of Hindalco during the period. The same is told by the statistics standard deviation with a value of 3.32 and a 
variance of 11.05. Both the standard deviation and variance were significant. The distribution of the company's earnings was not symmetrical. A skewness with a value of -7.03 signals high level negative grouping and hunchness to the left side of the mean value. The distribution was also having an enormous level of peakedness of leptokurtic nature to the tune of 194.2. The sensex and the scrip move together to the tune of -0.113 . The coefficient of covariance -0.113 was not significant. Correlation coefficient which measures the interdependence between the scrip and the BSE30 the sensex was arrived at -0.019 . The systematic risk of the company was recorded at -0.0353 . The beta value of the market portfolio was 1 . The scrip's beta of -0.0353 was lower than the market beta of 1 . Therefore the relative volatility of the scrip vis-à-vis the market was not significant. $R^{2}$ value confirms this. $\mathrm{R}^{2}$ was worked out at 0.000361 . It implied that only $0.036 \%$ of the total variance of 11.05 was explained by the market leaving $99.964 \%$ unexplained.

\subsubsection{Daily Returns}

Fig. 40 shows the behavior of the daily stock return of the Hindalco. The daily returns were thinly spread on the zero line within a range of $0-5 \% \pm$. There was lot of minor variations on either side of the abscissa. The largest return was registered on the 1669 days' observation since 1999. The return was negatively skewed. The fluctuation in the return from the stock cannot be considered violent.

As per TABLE 1 the standard deviation and variance in the daily returns were given. From the graph above, it could be understood that they were all important. The deviations found above and around the mean was above $3 \sigma$ was significant. The minor variations from the mean returns were found with the daily returns.

\subsubsection{Holding Period Yield}

TABLE 2 shows the holding period yield of Hindalco for the period 1999-2009. In the year 1999 the HPY was 56\%. In 2009 it was 197\%. HPY increased during this period by 3.5 times. The largest value of HPY was earned in 2009 itself. The amount of it was 197\%. The lowest HPY was $-90 \%$ in 2005. In 5 years Hindalco earned negative yields. The underlying trend of the HPY was to increase. The average HPY for the entire period under study was $21.27 \%$.

The actual holding period yield achieved by the scrip was considerably different from the expected whether it was positive or negative. The highest HPY achieved was $197 \%$ against the expected $21.27 \%$. Note the difference between the expected and actual. The difference was $175.73 \%$. Volatility was there to the extent of $175.73 \%$ from the expected value. Similarly, the smallest HPY was $-90 \%$ against the expected $21.27 \%$. That meant a difference of the actual from the expected to the tune of $111.27 \%$. In this way there was wide volatility in the HPY of the stock.

Fig. 41 depicts the behavior of the HPY pictorially. The HPL line starts from the Y-axis and fall. Then rise to make a peak in 2003. Then it falls steeply cutting the abscissa. There are many peaks and troughs in the picture. They all show the rough and tough movement of the HPY line before it settles at a top point in 2009. The wide variability expressed by the table was shown in the graph. The line of HPY was found varying from the expected in the forms of peaks and troughs and twists and turns. This behavior of the curve depicted the existence of high degree of volatility in the holding period yield of the stock.

\subsubsection{Annual Returns}

TABLE 3 shows the annual return of Hindalco for the period under study. In 1999 the annual return recorded was $0.25 \%$. In 2009 it was $0.53 \%$. The annual return increased during this period by 2.12 times. The highest return was recorded as $0.53 \%$ which achieved in 2009 itself. The lowest $-0.46 \%$ was occurred in 2008 . Negative annual returns were obtained in 5years. The overall average annual return for the entire period under study was $0.05 \%$. The actual annual returns obtained by the stock over years were shown in the table were far different from the expected $0.05 \%$. See the difference between $0.53 \%$ the highest return against the expected $0.05 \%$. High variability was found. In the same way the annual returns of every year were entirely different from the expected. In all these cases wide volatility were found.

The behavior of annual average return for the period under study of Hindalco is shown in Fig.42. The annual return during the period was highly fluctuating. There is a major peak formation and two deep troughs during the period. The troughs were highly damaging to the overall performance of the annual returns. It adversely affected the average annual returns for the entire period. The recent trough was the lowest average point. The variability in the annual returns was already depicted in the table. It could be seen in the graph also. The curve had violent fluctuations from the expected value. The curve went berserk in many years. Sometimes even below zero regardless of the expected. It all showed the existence of high degree of volatility in the annual returns. 


\subsection{Indian Hotels}

\subsubsection{Summary statistics}

TABLE 1 provides a summary statistics of the performance of Indian Hotels for the period 1999-2009. The scrip earned an average return of $0.04 \%$ during the period. It is more than the market average of $0.11 \%$. The holding period yield worked out for the company was $14 \%$ which was the expected rate of return of the company. The company's performance was lower than the expected. The firm's HPY 14\% was much better than the market average of $0.11 \%$. The largest daily return of the firm was registered as $16.07 \%$ whereas the smallest was recorded as $-89.72 \%$. The quantitative difference between the large and small comes to 105.79 . It shows wide dispersion of return from the expected value. Therefore the variability in returns is very high in the case of Indian Hotels during the period. The same is revealed by the statistic standard deviation with a value of 3.09 and a variance of 9.57. Both the standard deviation and variance were significant. The distribution of the company's earnings was not symmetrical. Skewness with value of -8.8 signals high level of negative grouping and hunchness to the left side of the mean. The distribution was also having an enormous level of peakedness of leptokurtic nature to the tune of 259.6. The sensex and the scrip move together to the tune of 0.262. The coefficient of covariance 0.262 is significant. Correlation coefficient which measures the interdependence between the scrip and the BSE30 the sensex was arrived at 0.047. The systematic risk of the company was recorded at 0.082 . The beta value of the market portfolio was 1 . The scrip's beta of 0.082 was lower than the market beta of 1 . Therefore the relative volatility of the scrip vis-à-vis the market is not significant. $\mathrm{R}^{2}$ value confirms this. $\mathrm{R}^{2}$ is worked out at 0.0022 . It implies that only $0.22 \%$ of the total variance of 9.6 was explained by the market leaving $99.78 \%$ unexplained.

\subsubsection{Daily Returns}

Fig. 43 depicts the behavior of the daily return of the scrip of Indian Hotels for the period under study. The returns of 2642 days were spread thinly over the zero line with minor fluctuation on either side. The lowest value of return occurred is seen on $1947^{\text {th }}$ day.' The return was spread about the expected value within a range of $0-5 \% \pm$. Even if the daily returns were spread within a range of $0-5 \%$ it showed significant variability. The standard deviation was given as 3.9. The standard deviation above 3 is significant. The negative skewness to the extent of -8.8 and the kurtosis of 259.6 were clear evidences of asymmetry in returns.

\subsubsection{Holding Period Yield}

TABLE 2 shows the holding period yield of the scrip Indian hotels. In 1999 the HPY of the firm was $11 \%$. In 2009 it was $124 \%$. The HPY had been increased during the period by 12.3 times. The lowest return recorded during this period was -84 in the year 2006. The highest return recorded was $140 \%$ in 2003 . In 5 years the stock was recorded negative HPY. The overall HPY for the entire period was $14 \%$. The variability from the expected HPY of the actual obtained was significant. There was wide variability in yields. There was variability between the HPY of 1999 and the expected to the extent of (14--11) i.e., 25\%. In 2009 also the difference was (124-14) ie., $110 \%$. In this way wide variability in yield was found showing high volatility.

Fig. 44 shows the erratic behavior of the stock of Indian Hotels. The holding period return never was stable for the scrip. The return was highly volatile. In the graph, the HPY line starts from the Y axis from a point below zero. Then it goes to a peak point in the year 2003. Then it suddenly fell down and bottomed out before touching zero in 2004. HPY again rises to another peak and falls severely. In this way the graph shows a number of peaks and troughs in the movement of the HPY line. The highest return was obtained by the scrip in 2004 and the lowest in 2006. These are apparent from the graph. Because of the variability between the actual HPY and expected there was high degree of volatility in the yield. The volatility in yield could be traced from the graph. The erratic behavior of the yield curve was due to this variability.

\subsubsection{Annual Returns}

TABLE 3 shows the behavior of annual return made by the stock Indian hotels during the period 19992009. In 1999 the annual return was $0.02 \%$. In 2009 it was $0.39 \%$. The annual return during this period had been increased by 19.5 times. The lowest annual return was -0.49 in 2008 . The highest was $0.39 \%$ in 2009 . Four years the company made negative returns. Seven years it made positive annual returns. The overall return for the entire period was $0.04 \%$. The annual returns as shown in the table had high fluctuations. The annual returns of 1999 were $0.02 \%$ against the expected rate of $0.04 \%$. In the year 2009 it was $0.39 \%$ against the expected value of $0.04 \%$ i.e., a difference of $0.35 \%$. The variability was very high. In 2000 the actual was $-0.09 \%$ against the expected $0.04 \%$ i.e., $0.13 \%$ difference. In this way the variability was there for all years' annual returns.

Fig. 45 shows the behavior of the annual return of Indian hotels. The line which shows the annual returns starts from immediately after the zero point in the Y-axis. There were wide fluctuations in the movement of the line. Three peaks and four troughs were formed. The fourth trough is the lowest annual return point. The underlying trend of the line is to stay high. The peaks and troughs found in the graph were due to the variability 
in the annual returns. The actual were different from the expected. This was what the volatility. This leads to uncertainty and chaos. Such return could not be predicted with accuracy. This will entail lot of difficulties to the investors. Fig. 45 reveals high degree of volatility in the annual returns of the stock.

\subsection{Indian Reyons-Aditya Birla Nuvo}

\subsubsection{Summary statistics}

TABLE 1 provides a summary statistics of the performance of Aditya Birla Nuvo (Indian Reyon) for the period 1999-2009. The scrip earned an average return of $0.13 \%$ during the period. It is more than the market average of $0.11 \%$. The holding period yield worked out for the company is $36.82 \%$ which is the expected rate of return of the company. The company's performance was lower than the expected. The firm's HPY $36.82 \%$ was much better than the market average of $0.11 \%$. The largest daily return of the firm was registered as $20.48 \%$ whereas the smallest was recorded as $-56.6 \%$. The quantitative difference between the large and small comes to 75.2. It shows wide dispersion of return from the mean value. Therefore the variability in returns was very great in the case of Indian Reyons during the period. The same was confirmed by the statistics standard deviation with a value of 3.22 and a variance of 10.4. Both the standard deviation and variance were significant. The distribution of the company's earnings was not symmetrical. A skewness with value of -1.5 signals high level of negative grouping and hunchness to the left side of the mean value. The distribution was also having an enorrmous level of peakedness of leptokurtic nature to the tune of 37.2. The sensex and the scrip move together to the tune of 3.14. The coefficient of covariance 3.14 was significant. Correlation coefficient which measures the interdependence between the scrip and the BSE30 the sensex was arrived at 0.005. Correlation was not significant. The systematic risk of the company was recorded at 0.009 . The beta value of the market portfolio is 1. The scrip's beta of 0.009 was lower than the market beta of 1 . Therefore the relative volatility of the scrip visà-vis the market was insignificant. $\mathrm{R}^{2}$ value confirmed this. $\mathrm{R}^{2}$ was worked out at 0.00003 . It implies that only $0.003 \%$ of the total variance of 10.4 was explained by the market leaving $99.997 \%$ unexplained.

\subsubsection{Daily Returns}

Fig. 46 shows the behavior of daily returns of Indian Reyons. The daily returns were spread on the zero line thickly either side throghout the length. The largest value is plotted in between $1^{\text {st }}$ and $287^{\text {th }}$ observation. The deviations from the mean returns were found within the range of $0-5 \%$ positive or negative. The deviations were significant. The $\sigma$ above 3 is significant. Here for the company the $\sigma$ is 3.23. Therefore deviations were significant. Daily returns had a negative skewness to the extent of -1.5 . The return distribution was also of a high level leptokurtic.

\subsubsection{Holding Period Yield}

TABLE 2 shows the behavior of the holding period yield of Indian Reyons. The HPY in 1999 was $2 \%$. In 2009 it was $51 \%$. The HPY during this period had been increased by 25.5 times. The lowest HPY was recorded as -72 in 2008. The highest was recorded as $190 \%$ in 2003. In three years the HPY was negative. In eight years the HPY was positive. The average HPY for the entire period was $36.82 \%$. See the difference between the actual and expected in 1999. The actual was $2 \%$ against the expected $36.82 \%$. The actual was short of $34.82 \%$. In 2003 the actual was 190\% against the expected 36.82\%. The difference was whopping $153.18 \%$. High variability can be found with the HPY. In 2009 the actual was $51 \%$ against the expected $36.82 \%$. The difference was $14.48 \%$. In this way variability of return was there in the holding period yield of the scrip. This shows high degree of volatility in the yield of the stock.

Fig. 47 shows the behavior of the HPY of Indian Reyons. The HPY line shows a lot of fluctuations. There were one peak and two troughs in the movement of the HPY line. The lowest return occurred in 2008 can be located from the graph. The highest HPY can also be readable from the figure. The ending HPY was visible in the picture. The variability of yield of the stock was already found from table. Its graphical representation of the same shows high degree of fluctuations of the actual HPY line. It was going ups and downs above and below of the expected value. Accordingly peaks and troughs were formed. They all show the extreme form of volatility in yields. The yields obtained were not stable and consistent with the expected value. As there exist wide difference between the actual and expected, volatility was said to prevail for the stock. Volatility of high degree was found with the HPY of the stock.

\subsubsection{Annual Returns}

TABLE 3 shows the behavior of annual returns of Indian Reyons. In 1999 the annual return was $0.24 \%$. In 2009 it was $0.23 \%$. The annual returns of the company for the period were reduced by $4 \%$. The lowest return struck for the period was $-0.43 \%$ in 2008 . The highest annual return the company achieved was $0.46 \%$ in 2003. Three years the company could make only negative returns. Indian Reyons made positive annual returns in 8 years. The overall trend was to make positive return. The average for the entire period was $0.13 \%$. As 
shown by the table there was high degree of variability of returns. The difference between the expected value and actual was significant. Take the case of the year 2009. The actual for the year was $0.23 \%$ against the expected return of $0.13 \%$. The actual varies to the extent of $0.10 \%$. In 1999 the actual annual return was $0.24 \%$ against the expected value of $0.13 \%$. The difference was $0.11 \%$. In this way there was wide variability in annual returns of the company. From the figure 48 it could be discerned that the annual return line starts at $0.24 \%$ return point from the Y-axis. It falls down during 2000 to $-0.10 \%$. In 2003 it rises from there and went to $0.07 \%$. It again rose to $0.14 \%$ in 20002.In 2003 it reached the topmost return point of $0.46 \%$ for the period in 2004. In 2005 it fell down to $0.24 \%$. In 2008 the line deeply fell to the lowest return point of $-0.43 \%$ for the period and bottomed out to rise to settle at $0.23 \%$ in 2009 . The return increased and decreased frequently and the scrip faced frequent upheavals and violent fluctuations throughout the 11 year period. In spite of it, the overall trend of the annual return was to keep rising. In majority of years the company earned return below zero-line. Only in few years it earned better. But in 1999 the return formed a peak which caused the overall rate of $0.048 \%$. Due to the variability in returns the graph shows wide volatility in returns of the company. Accordingly, the annual returns line goes ups and downs crossing the average line.

\subsection{ITC Ltd}

\subsubsection{Summary statistics}

TABLE 1 provides a summary statistics of the performance of ITC Ltd for the period 1999-2009. The scrip earned an average return of $0.05 \%$ during the period. It is less than the market average of $0.11 \%$. The holding period yield worked out for the company was $4.27 \%$ which is the expected rate of return of the company. The largest daily return of the firm was registered as $11.08 \%$ whereas the smallest was recorded as $92.74 \%$. The quantitative difference between the large and small comes to 103.82. It shows wide dispersion of return from the expected value. Therefore the variability in returns was very great in the case of ITC Ltd during the period. The same was confirmed by the statistics standard deviation with a value of 2.93 and a variance of 8.58. Both the standard deviation and variance were significant. The distribution of the company's earnings was not symmetrical. A skewness with value of -11.3 signals high level of negative grouping and hunchness left to the mean. The distribution was also having an enormous level of peakedness of leptokurtic nature to the tune of 363.19. The sensex and the scrip move together to the tune of a covariance of -0.016 . The coefficient of covariance -0.016 was insignificant. Correlation coefficient which measures the interdependence between the scrip and the BSE30 the sensex was -0.003. It established the fact that the scrip and the market co-moved inversely. The systematic risk of the company was recorded at -0.005 .The beta value of the market portfolio is 1. The scrip's beta of -0.005 is considerably lower than the market beta of 1 . Therefore the relative volatility of the scrip vis-à-vis the market was not significant. $\mathrm{R}^{2}$ value confirmed this. $\mathrm{R}^{2}$ is worked out at 0.000009 . It implies that only $0.0009 \%$ of the total variance of 8.58 was explained by the market leaving $99.99 \%$ unexplained.

\subsubsection{Daily Returns}

Fig. 49 shows the behavior of the daily return of ITC Ltd for the study period. It can be seen from the figure that the returns were thickly packed along the zero line. The returns were spread to either side of the zero line with a margin of $0-5 \% \pm$. The lowest return is shown in the graph by a narrow line as hanging from the zero line towards the bottom line at $1669^{\text {th }}$ observation. The largest value can also be readable from the graph. The $\sigma$ and variance were not significant. But the return was negatively skewed to the extent of -11.3. The extreme value represented by the kurtosis 363.2 was high leptokurtic. They all showed that the return was highly asymmetrical.

\subsubsection{Holding Period Yield}

TABLE 2 shows the character of the holding period yield of ITC Ltd. In 1999 the HPY was $-12 \%$. In 2009 it was $46 \%$. The yield during this period was increased by 4.8 times. The lowest yield sustained by ITC was $-89 \%$ in 2005 . The highest yield was struck at $49 \%$ in 2003 . Over 5 years the scrip succumbed to negative returns. The other 6 years positive yield were gained. The yield was not steady and stable. Fluctuations were found most frequently in alternating years. Despite it, the overall trend was to go on increase in the HPY. The average holding period yield was $4.27 \%$. In 1999 the actual HPY obtained was $-12 \%$ against the expected 4.27. The variability was to the extent of $16.47 \%$. In 2009 the actual HPY was $46 \%$ against the expected value of 4.27 i.e. a difference of $41.73 \%$. There was volatility in the HPY of the stock.

As shown by Fig. 50 the HPY line goes through all the rough and tough ways to reach the year 2009 from 1999. The scrip confronted three falls, of them one was major and 3 peaks. The largest yield was marked in 2003 above $40 \%$ return level. The lowest level of yield was struck in 2005 below $-80 \%$ yield point. The trend of the line was to go upwards. The actual HPY line shown by the graph had high volatility. It represents high variability between the actual and expected values. While the expected HPY was $4.27 \%$ in 2005 the actual HPY 
was $-89 \%$; a variability of $93.27 \%$. The trough in the year 2005 was owing to this variability in HPY. It shows the fact that there was wide variability between the expected and actual values of HPY.

\subsubsection{Annual Returns}

The annual return based on the daily returns for the period from 1999 to 2009 was furnished in TABLE 3. As per it, in 1999 the annual return was $0.02 \%$. In 2009 it was $0.18 \%$. In the meantime the return had been increased by 9 times. The lowest annual return was noted at $-0.20 \%$ in 2005 . The highest annual return was recorded at $0.18 \%$ in 2009. Over 3 years the scrip ITC confronted negative annual returns. The remaining 8 years the firm made positive returns. In 2000 no annual return was recorded. On average the company managed to secure an annual return of $0.05 \%$. The expected value of annual return was $0.05 \%$. The stock had not earned this expected value or a return near to this in any year. All the actual returns were far away from the expected value. In 1999 the actual returns earned were $0.02 \%$ against the expected $0.05 \%$.The actual varies from the expected to the extent of $0.03 \%$. In 2009 the actual earned was $0.18 \%$ against the expected $0.05 \%$. The variation from the mean was $0.13 \%$. In 2005 the actual was $-0.2 \%$ against the expected $0.05 \%$, a variation of $-0.25 \%$. In this way the annual returns show high level of variability.

As explained above the highly fluctuating line of annual return can be seen from Fig. 51. The annual return starts from just immediately above the zero \% point on $\mathrm{Y}$-axis. There from it can be seen on the table that the return makes twists and turns year after year resulting in violent ups and downs on a straight line before it settles at a comfortable positive return in 2009. In the meantime the scrip faces 3 major downswings and 4 upswings. The second downswing led to lowest annual return for the period under study in the year 2005. The upswings all were resulted in heights which were all more or less identical. The still higher annual return where the line settled was the one in 2009. It can be said that the upswing has slight edge over the downswing. As per the graph, the volatility of the annual returns was very high due to overwhelming variability in returns. The expected and actual returns were not consistent over period. Due to this fact there were too much chaos and uncertainty prevailing over.

\subsection{ONGC Ltd}

\subsubsection{Summary Statistics}

TABLE 1 provides a summary statistics of the performance of ONGC Ltd for the period 1999-2009. The scrip earned an average return of $-0.17 \%$ during the period. It was less than the market average of $0.11 \%$. The holding period yield of the company for the decade was $30.41 \%$. The company's HPY was higher than the average return. The firm's HPY was also higher than the market average $0.11 \%$. The largest daily return of the firm was registered as $17.99 \%$ whereas the smallest was recorded as $-18.72 \%$. The quantitative difference between the large and small comes to 36.71. It shows that the dispersion was moderate. Therefore the variability in returns was lower during the period. The same is confirmed by the statistics standard deviation with a value of 2.7 and a variance of 7.03. Both the standard deviation and variance were lower. The distribution of the company's earnings was not symmetrical. A skewness with value of -0.022 signals low level negative grouping and hunchness left to the mean. The distribution was also having an enormous level of peakedness of leptokurtic nature to the tune of 4.223 . The sensex and the scrip moved together in the opposite direction to the tune of a covariance of -0.135 . The coefficient of covariance -0.016 was not much significant. Correlation coefficient which measures the interdependence between the scrip and the BSE30 the sensex was arrived at -0.028 . This negative correlation was not significant. The systematic risk of the company was recorded at -0.019 . The beta value of the market portfolio is 1 . The scrip's beta of -0.019 was considerably lower than the market beta of 1 . Therefore the relative volatility of the scrip vis-à-vis the market was not significant. $R^{2}$ value confirmed this. $R^{2}$ was worked out at 0.000784 . It implies that only $0.0784 \%$ of the total variance of 8.58 was explained by the market leaving $99.922 \%$ unexplained.

\subsubsection{Daily Returns}

Fig. 52 shows the behavior of daily returns of ONGC LTD. The daily returns were spread on the zero

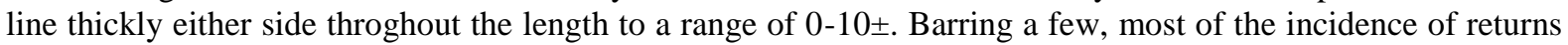
were found around the mean value of $-0.17 \%$. Some extreme values represented by the kurtosis 4.223 could be viewed from the figure. The tail behavior of the extreme values denotes volatility trends of the distribution. Keeping aside the extreme trends the daily returns of the company was distributed tightly. This can be noted from the figure. A slight humping to the left of the mean could be seen due to the negative skewness

\subsubsection{Holding Period Yield}

TABLE 2 shows the character of the holding period yield of ONGC Ltd. In 1999 the HPY was $2.1 \%$. In 2009 it was $72.1 \%$. The yield during this period was increased by 34.33 times. The average yield during the period was $30.41 \%$. The lowest yield sustained by ONGC was $-46.6 \%$ in 2008 . The highest yield was struck at 
$156.4 \%$ in 2002. Over 4 years the scrip succumbed to negative returns. The other 7 years positive yield were gained. The yield was not steady and stable. Fluctuations were found most frequently in alternating years. Despite it, the overall trend was to go on increase in the HPY. In 1999 the actual HPY obtained was 2.1\% against the expected 30.41. The variability was to the extent of $28.31 \%$. In 2009 the actual HPY was $72.1 \%$ against the expected value of 30.41 i.e. a difference of $41.69 \%$. There was volatility in the HPY of the stock (See figure53).

\subsubsection{Annual Returns}

The annual return based on the daily returns for the period from 1999 to 2009 was furnished in TABLE 3. As per it in 1999 the annual return was $-0.32 \%$. In 2009 it was $-0.04 \%$. The lowest annual return was noted at $-0.32 \%$ in 1999 . The highest annual return was recorded at $0.07 \%$ in 2001 . Over 10 years the scrip ONGC confronted negative annual returns. Only one year the firm made positive returns. On average the company had an annual return of $-0.17 \%$. The expected value of annual return was $-0.17 \%$. The stock had not earned this expected value or a return near to this in any year. All the actual returns were far away from the expected value. In 1999 the actual returns earned were $-0.32 \%$ against the expected $-0.17 \%$. The actual varies from the expected to the extent of $-0.15 \%$. In 2009 the actual earned was $0.18 \%$ against the expected $0.17 \%$. In 2005 the actual was $-0.04 \%$ against the expected $-0.17 \%$. The variation was of $-0.13 \%$. In this way the annual returns showed high level of variability.

As explained above the highly fluctuating line of annual return can be seen from Fig. 54. The annual return starts from just immediately above the $-0.3 \%$ point on Y-axis. There from it can be seen on the table that the return makes twists and turns year after year resulting in violent ups and downs on a straight line before it settles at a loss of $-0.17 \%$ in 2009. In the meantime the scrip faces 4 major downswings and 7 upswings. Except in 2001 the upswings never went beyond the zero point. The company had earned a positive return of $0.07 \%$ only once that was in 2001. Annual return was the lowest in 2008 and the highest in 2001.

\subsection{Tata Steel Ltd}

\subsubsection{Summary Statistics}

As per TABLE 1 the average return earned by the Tata Steel Ltd. during the period 1999-2009 was $0.21 \%$ in contrast to the return to the market index of $0.11 \%$. The Holding Period Yield of the company which is the expected return was $39.64 \%$. The variability in return for the period revealed by the standard deviation 3.01 was not much. The overall volatility in return for the period 1999-2009 was within limit. The variance 9.08 was also not abnormal. The variance reports that the distribution of return is close and tight. The skewness of 0.066 tells the fact that the distribution is positively grouped to the right and not symmetrical. The 1.7 kurtosis of platykurtic nature reveals the flatness of the distribution. TABLE 1 states that there is a co-variance between the company and the BSE index to the extent of 0.192 . The stock return tends to vary with the market but at a slow pace. It could also be seen from the table that there was a low positive correlation between the scrip and the BSE index to the tune of 0.035 . The correlation is not significant. The coefficient of determination R2 is worked out at 0.0012 which tells that only $00.12 \%$ of the variance 9.08 was explained by the market. The major part $99.88 \%$ was unexplained by the market. The systematic risk of the scrip vis-à-vis the market index is 0.06 denoted by $\beta$. It signifies that the response of the stock towards the market movement was less enthusiastic.

\subsubsection{Daily returns}

Fig. 55 portrays the behavior of the daily returns of the Tata Steel Ltd. during 1999-2009. 2642 market days were observed during the period. As shown by the figure wide fluctuations about the mean value of -0.21 were found. The returns vary from the mean with a range of $0-10 \pm$. Most of the values were thickly pasted on either side of the mean very close to it. Extreme values were found infrequently. The largest and smallest values could be identified from the figure. The returns had slightly skewed to the right to the extent of 0.066 . Though the skewness was not much serious still indicates some amount of asymmetry. The distribution of returns was flat as the kurtosis was 1.7 that is platykurtic less than normal.

\subsubsection{Holding Period Yield}

TABLE 2 narrates the Holding Period Yield of Tata Steel Ltd. In the year 1999 the HPY was 15\%. In 2009 it was $170 \%$. The HPY during the period had increased by 11.33 times. The HPY of the company was steadily increasing. During the period the company had negative HPY in 5 years and positive returns only in 6 years. HPY was the maximum in the year 2003 with $194 \%$ and minimum in the year 2008 with $-77 \%$. Every year the HPY was subject to drastic change. The HPY changes from $15 \%$ in 1999 to $-15 \%$ in 2000 . The change effected here was $200 \%$. In 2001 the HPY went further down to $-34 \%$, a change of $126 \%$. In 2002 the HPY had been rising to $77 \%$ at a rate $226 \%$. In this way major changes were effected every year denoting the prevalence 
of high level volatility in the yearly holding period yields of the company. Figure.56 depicts the behavior of the HPY graphically. Along the OY the HPY line began at $15 \%$ point in 1999 and went down to $-15 \%$ point in 2000. Then it went further down to $-34 \%$ in 2001 . Then it recovered and shot up to $77 \%$ in 2002 . The HPY rose up still further to the maximum of $194 \%$ in 2003 . There from it made a somersault and fell down to $-14 \%$ in 2004. Then it slipped further down to $-2 \%$ in 2005. In the trajectory, there were 3 peaks and 3 troughs denoting major changes in the yields. The HPY line was highly erratic and zigzag telling the persistence of high level volatility.

\subsubsection{Annual Returns}

TABLE 3 provides the average annual returns earned by Tata Steel Ltd during the period 1999-2009. As per the table in 1999 the annual returns were $-0.31 \%$. In 2009 it was 0.29 . The returns witnessed a rise of 1.95 times from 1999 to 2009. But in between 1999 and 2009 the company experienced negative returns in 9 years. Only in 2 years i.e., in 2007 and 2009 the company had positive returns. The pattern of the flow of the returns was not smooth. On the contrary there were violent variations in returns year after year. Volatility in annual returns was conspicuous. Fig. 57 graphically depicts the above described facts. The annual return (AR) line begins at a point below $-0.2 \%$ along OY axis in 1999. It reaches a point above 0.2 in 2009. In the mean time over 11 years it was going ups and downs with violent twists and turns. In the passage of the line, most of the tenure, it was going through negative space except twice. The figure depicts high degree of volatility in the annual returns of the company.

\subsection{Wipro Ltd}

\subsubsection{Summary Statistics}

TABLE 1 shows the summary statistics of Wipro ltd. As per the table, the average return earned by the stock during the period was $-0.09 \%$. It is considerably lower than the BSE INDEX rate of return of $0.11 \%$. The Holding Period Yield (HPY) for the same period was 3.64\%. HPY of the stock was higher than its average return (HPY>Average return). The largest return earned was 30.63\% and the lowest -18.06 . The standard deviation of 3.57 indicates the existence of high level volatility in the daily returns over a 11 year period from 1999 to 2009. The variance 12.72 was big. The distribution of the returns over the period was not tighter. The movement of the scrip was opposite to the BSEINDEX since the co-variation of it with market was -0.128 . The distribution of return over the period was not symmetrical for the presence of a positive skewness of 0.568 and a peakedness of 6.78 (leptokurtic). The positive correlation of 0.004 of the stock with the market is not significant. The coefficient of determination $\mathrm{R}^{2}$ with value of 0.000016 was confirming the insignificance of the correlation. According to the $\mathrm{R}^{2}$ value only $0.0016 \%$ of the stock's variance 12.72 was explained by the market. $99.99 \%$ of the variance was unexplained. The systematic risk of the stock $\beta$ with a value of -0.004 implies a negative relation with the market. When compared to the market $\beta$ of 1 , the stock's $\beta$ is insignificant.

\subsubsection{Daily returns}

Fig. 58 depicts the behavior of daily returns of the Wipro for the period 1999-2009.The daily return was thickly packed on either side of the mean value of $-0.09 \%$. Wide fluctuations around the mean value could be seen from the figure. The largest and smallest values of returns could also be detected from the graph. It could be observed that the most of the values did not lie within $3 \sigma$ as the $\sigma$ for the period was 3.57. Moreover, the returns were negatively skewed to the left making the distribution asymmetrical. The peakedness of leptokurtic nature at 6.78 implied further abnormality of the distribution. The variance 12.72 and $\sigma 3.57$ were not within limit.

\subsection{3 .Holding Period Yield}

TABLE 2 gives an account of the holding period yield of Wipro for the period 1999-2009. In 1999 the HPY was 43\%. In 2009 it was 174\%. The overall growth of HPY for the entire period was 4times since 1999. On an average HPY of the stock for the entire period was worked out at 3.64\%. Though the HPY was on the rise there were yearly persistent upheavals. The stock was sustaining negative yield in 6 years and gaining positive yields only in 5 years. The HPY was going through ups and downs with violent twists and turns before it reaches the peak value in 2009. In 1999 the HPY was 43\%. In the next year 2000 it fell to -18\%. In the next year 2001 it went further down to $-33 \%$. Then in 2002 it recovered and posted to $2 \%$. Then it rose to $5 \%$ in 2003 . Then again it made somersault to $-57 \%$ in 2004. In this way the trajectory of the stock's HPY was full of ups and downs entailing overwhelming uncertainty. The changes in the HPY were drastic and substantial. Fig. 59 shows the HPY line of Wipro for the period. The movement of the line from 1999 to 2009 was not smooth. Lots of volatility with full of peaks and troughs could be identified in the flight. 4 major peaks and 3 troughs were found. It shows that there was high degree of volatility in the holding period yield of the stock. 


\subsubsection{Annual Returns}

TABLE 3 provides details of annual returns the stock Wipro for the period 1999-2009. In 1999 the AR was -0.05 . In 2009 it was 0.36 . Over 11 years period the annual return had grown by 8.2times. The stock was sustaining negative returns in 8 years. It was making positive returns only for 3 years. Annual returns on an average was worked out at $-0.09 \%$ for the entire period. The volatility in annual returns of Wipro for the entire period could be understood from the figure 60. In 1999 the annual return line begins from a point just below the zero along the OY line and went down in 2000. Then in 2001 it shot up to above 0.2 . Then fell down abruptly to a point below -0.2 . In 2003 it went further down to $-0.33 \%$. In a zigzag pattern through the negative space it reaches to $0.36 \%$ in 2009 .

\section{Empirical results}

Twenty stocks belonging to different industries over the period 1999-2009 on an average had earned only $0.06 \%$ which was lower than the market rate of $0.11 \%$. But the $\sigma$ and variance that represent the variability in return of the stocks were 3.3 and 12.01 respectively were higher than market's 1.79 and 3.2. Even though the individual stocks confronted greater risk than the market, the returns that stocks earned were lower than the market. The market itself had only a very low return of $0.11 \%$ during the decade. It could be noted that the behavior of the returns of the 20 stocks during the period was that it moves just opposite to the BSE index. The average covariance of the 20 stocks in relation to the market was -0.015 . The correlation between the stocks and the market index was a negligible 0.003 . The overall systematic risk represented by $\beta$ (beta) was also a negligible -0.002 . The market share of the total risk represented by the variance of the stocks 12.01 was only $0.66 \%$. The remaining $99.34 \%$ of the variance was due to the stocks' own factors. The stock returns were not at all symmetric during the decade. On an average the 20 stocks return were skewed to the tune of -2.56 to the left of the mean. 12 out of 20 stocks were skewed negatively. 8 stocks were positively skewed. The stocks had high peakedness of leptokurtic nature represented by average kurtosis with the coefficient of 80.78 depicting the presence of extreme values. 18 stocks had kurtosis above 3 and only 2 had the value of kurtosis below 2. The returns-daily, annual and HPY - all were highly volatile during the period. While the daily returns were fluctuating about the mean values with an average standard deviation of 3.3, the annual returns and Holding Period Yields made wide dispersion from the mean. The market return and the individual return of the stocks were very low during this period.

\section{Conclusion}

The individual stocks were found riskier than the market (BSE INDEX 30). But the return earned was lower than the market. There was high level of volatility in the price and returns of the stocks. Stock returns were all skewed, majority of them-12 out of 20- were negatively. Stocks returns had high kurtosis, most of them leptokurtic in nature. The stock prices and return arising were all pathetically low. There was no considerable bond between the stocks and the market. The individual stocks were not yielding up to their risk exposure. The stocks co-move with the market in a limited way. The return and volatility were found due to own and idiosyncratic reasons of the stocks.

\section{References}

[1] Vanitha Tripathi, Company Fundamentals and Equity Returns in India, International Research Journal of Finance and Economics, ISSN 1450-2887 Issue 29 (2009), (C) EuroJournals Publishing, Inc. 2009.

[2] Francis X. Diebold and Kamil Yilmaz, Macroeconomic volatility and stock market volatility, Worldwide, working paper 14269, National Bureau of Economic Research, 1050 Massachussetts Avenue, Cambridge, August 2008.

[3] G.William Schwert, Stock market volatility: Ten years after the crash, National Bureau of Economic Research, December 1997.

[4] John Y Campell and Ludger Hent Schel, No News is Goodnews,: An asymmetric model of changing volatility in stock returns, National Bureau of Economic Research, 1050 Massachussetts Avenue, Cambridge, June 1991.

[5] Jamees M. Poterba and Lawrence H. Summers, Mean Reversion in Stock Prices: Evidence and Implications, NBER Working Paper No. 2343, Issued in July 1989.

[6] Jeremy J.Siegel, The Bhaviour of Stock Returns around NBER Turning Points: An Overview, Philadelphia, Pa 19104, October 1990.

[7] G.William Schwert, Stock Volatility During the Recent Financial Crisis, Working Paper 16976, National Bureau of Economic Research, 1050 Massachusetts Avenue, Cambridge, MA 02138, April 2011.

[8] John Y Campell and Ludger Hent Schel, No News is Goodnews,: An asymmetric model of changing volatility in stock returns, National Bureau of Economic Research, 1050 Massachussetts Avenue, Cambridge, June 1991

[9] Gregory R. Duffee, The long-run behavior of firms' stock returns: Evidence and interpretations, Haas School of Business, University of California - Berkeley, First version: June 2002, This Draft: August 28, 2002.

[10] Robert S. Pindyck, Risk Aversion and Determinants of Stock Market Behavior, Working Paper No. 1921, NBER Working Paper Series, National Bureau of Economic Research, 1050 Massachussetts Avenue, Cambridge, MA 02138, May 1986.

[11] Philip A. Braun, Daniel B. Nelson, and Alain M. Sunier, Good News, Bad News, Volatility, and Betas, The Journal of Finance, Volume 50, Issue 5, (Dec.,1995), 1575-1603.

[12] Pankunni.V, Stock Price Movement in India (Ph.D Thesis), University of Kerala, 2013. 
Study of Behavior of Equity Returns in India

Table 1

Summary Statistics of 20 stocks for 1999-2009 VS BSE INDEX

\begin{tabular}{|c|c|c|c|c|c|c|c|c|c|c|c|c|c|}
\hline Name of Stock & $\begin{array}{l}\text { Mean } \\
\%\end{array}$ & $\sigma$ & $\sigma^{2}$ & $\operatorname{Cov}$ & $\mathbf{r}$ & $\beta$ & skew & kurt & $\mathbf{R}^{2}$ & $\begin{array}{l}\text { HPY } \\
\%\end{array}$ & $\mathbf{L}$ & $\mathbf{S}$ & Range \\
\hline $\mathrm{ACC}$ & 0.09 & 3.32 & 11.04 & 0.15 & 0.025 & 0.05 & -7.6 & 212 & 0.000625 & 13.45 & 15.6 & -91.84 & 107.4 \\
\hline Apollo Tyres & 0.10 & 3.81 & 14.54 & 0.06 & 0.009 & 0.02 & -4.1 & 112.9 & 0.000081 & 24.64 & 25.9 & -89.4 & 115.3 \\
\hline Arvind Mills & 0.07 & 3.9 & 14.9 & -2.28 & -0.33 & -0.71 & 0.77 & 7.35 & 0.1089 & 14.45 & 37.5 & -24.12 & 61.62 \\
\hline Ashok Leyland & 0.11 & 3.79 & 22 & -0.034 & -0.005 & -0.01 & -4.5 & 115.2 & 0.000025 & 48.27 & 18.2 & -89.2 & 107.4 \\
\hline Asian paints & 0.09 & 2.09 & 4.35 & 0.02 & 0.006 & 0.01 & -2.9 & 57.9 & 0.000036 & 23.27 & 11.6 & 36.19 & 47.79 \\
\hline Axis Bank & 0.21 & 3.42 & 11.7 & 0.607 & 0.099 & 0.19 & 0.86 & 5.07 & 0.009801 & 60.09 & 24.9 & -16.37 & 41.27 \\
\hline Ballarpur Industries & 0.08 & 3.61 & 13 & 0.148 & 0.023 & 0.05 & -3.49 & 90.41 & 0.000529 & 16.64 & 21.7 & -79.61 & 101.3 \\
\hline Castrol & 0.02 & 2.34 & 5.46 & 0.025 & 0.006 & 0.01 & -2.5 & 71.1 & 0.000036 & 4.82 & 17.6 & -48.39 & 65.99 \\
\hline Colgate Palmolive & 0.07 & 2.06 & 4.26 & 0.041 & 0.011 & 0.01 & 0.88 & 6.47 & 0.000121 & 12.91 & 20.3 & -9.8 & 30.1 \\
\hline Crompton Greaves & 0.17 & 3.97 & 15.78 & 0.363 & 0.051 & 0.11 & -2.55 & 59.27 & 0.002601 & 61.91 & 20.5 & -78.97 & 99.47 \\
\hline Garware Polyester & 0.17 & 4.83 & 23.36 & 0.311 & 0.036 & 0.10 & 0.87 & 4.08 & 0.001296 & 62.73 & 30.8 & -22.5 & 53.3 \\
\hline Gujarat Narmada & 0.12 & 3.24 & 10.52 & 0.093 & 0.016 & 0.03 & 0.41 & 2.97 & 0.000256 & 37.82 & 18.1 & -15.66 & 33.76 \\
\hline Harrison Malayalam & 0.16 & 4.71 & 22.18 & 0.093 & 0.011 & 0.03 & 0.69 & 3.95 & 0.000121 & 51.91 & 32.9 & -23.73 & 56.63 \\
\hline Hindalco & 0.05 & 3.32 & 11.05 & -0.113 & -0.019 & -0.04 & -7.04 & 194.18 & 0.000361 & 21.27 & 18.4 & $\begin{array}{l}-89.78 \\
\end{array}$ & 108.2 \\
\hline Indian Hotels & 0.04 & 3.09 & 9.57 & 0.262 & 0.047 & 0.08 & -8.8 & 259.6 & 0.002209 & 14 & 16.1 & -89.72 & 105.8 \\
\hline Indian Reyons & 0.13 & 3.23 & 10.42 & 0.029 & 0.005 & 0.01 & -1.5 & 37.2 & 0.000025 & 36.82 & 20.5 & -56.6 & 77.1 \\
\hline ITC & 0.05 & 2.93 & 8.59 & -0.016 & -0.003 & -0.01 & -11.3 & 363.2 & 0.000009 & 4.27 & 11.1 & -92.74 & 103.84 \\
\hline ONGC & -0.17 & 2.65 & 7.03 & -0.135 & 0.028 & -0.02 & -0.022 & 4.223 & 0.000784 & 30.41 & 17.9 & -18.72 & 36.62 \\
\hline Tata Steel Ltd & -0.21 & 3.01 & 9.08 & 0.192 & 0.035 & 0.06 & 0.066 & 1.7 & 0.0012 & 39.64 & 13.0 & -13.77 & 26.77 \\
\hline WIPRO & -0.09 & 3.57 & 12.72 & -0.128 & 0.004 & $\begin{array}{l}- \\
0.004\end{array}$ & 0.568 & 6.778 & 0.000016 & 3.64 & 30.6 & -18.06 & 48.66 \\
\hline Average & 0.063 & 3.3 & 12.01 & -0.015 & 0.003 & $\begin{array}{c}\overline{-} \\
0.002\end{array}$ & -2.559 & 80.78 & 0.006 & 29.15 & 21.1 & -46.64 & 71.42 \\
\hline BSE30 & 0.11 & 1.79 & 3.2 & 3.2 & 1.000 & 1.000 & 0.048 & 5.9 & 1.00000 & 24.18 & 17.35 & -11.1 & 28.45 \\
\hline
\end{tabular}

Table 2

Holding Period of Yield in \% of 20 Stocks from 1999 to 2009

\begin{tabular}{|l|l|l|l|l|l|l|l|l|l|l|l|l|}
\hline \multirow{2}{*}{ Name of Stock } & \multicolumn{9}{|c|}{ Returns } & \multicolumn{1}{l|}{} & \\
\cline { 2 - 15 } & 1999 & 2000 & 2001 & 2002 & 2003 & 2004 & 2005 & 2006 & 2007 & 2008 & 2009 & Average \\
\hline ACC & -75 & -41 & -5 & 12 & 49 & 31 & 56 & 105 & -6 & -54 & 76 & 13.45 \\
\hline Apollo Tyres & 145 & -48 & -10 & 75 & 92 & -14 & 16 & 26 & -85 & -66 & 140 & 24.64 \\
\hline Arvind Mills & -37 & -45 & -32 & 141 & 3 & 94 & -29 & -47 & 73 & -80 & 118 & 14.45 \\
\hline Ashok Leyland & 155 & -64 & 56 & 44 & 199 & -92 & 29 & 43 & 12 & -71 & 220 & 48.27 \\
\hline Asian paints & 30 & -29 & 0 & 22 & 4 & -5 & 80 & 24 & 49 & -21 & 102 & 23.27 \\
\hline Axis Bank & 47 & 75 & -42 & 71 & 210 & 35 & 52 & 63 & 107 & -48 & 91 & 60.09 \\
\hline $\begin{array}{l}\text { Ballarpur } \\
\text { Industries }\end{array}$ & 109 & 0 & -36 & 7 & 91 & 13 & 14 & -5 & 59 & -89 & 20 & 16.64 \\
\hline Castrol & -60 & -17 & -32 & 12 & 13 & -9 & 16 & -10 & 62 & -4 & 82 & 4.82 \\
\hline Colgate Palmolive & 9 & -27 & -2 & -19 & 18 & 6 & 51 & 42 & 4 & -1 & 61 & 12.91 \\
\hline Crompton Greaves & -4 & -47 & -27 & 119 & 256 & 77 & 165 & -72 & 82 & -65 & 197 & 61.91 \\
\hline Garware Polyester & -7 & -29 & -43 & 554 & 70 & -12 & 0 & -17 & 108 & -80 & 146 & 62.73 \\
\hline Gujarat Narmada & 165 & -49 & -24 & 51 & 121 & -7 & 61 & -19 & 107 & -75 & 85 & 37.82 \\
\hline $\begin{array}{l}\text { Harrison } \\
\text { Malayalam }\end{array}$ & -27 & -46 & -3 & -54 & 104 & 360 & 56 & -17 & 38 & -71 & 231 & 51.91 \\
\hline Hindalco & 56 & -15 & -14 & -7 & 141 & 2 & -90 & 19 & 21 & -76 & 197 & 21.27 \\
\hline Indian Hotels & -11 & -29 & -37 & 20 & 140 & 21 & 82 & -84 & 2 & -74 & 124 & 14 \\
\hline Indian Reyons & 2 & -33 & -21 & 33 & 190 & 44 & 70 & 84 & 57 & -72 & 51 & 36.82 \\
\hline
\end{tabular}


Study of Behavior of Equity Returns in India

\begin{tabular}{|l|l|l|l|l|l|l|l|l|l|l|l|l|}
\hline ITC & -12 & 25 & -24 & -3 & 49 & 32 & -89 & 25 & 19 & -21 & 46 & 4.27 \\
\hline ONGC & 2.1 & -43.5 & 10.5 & 156.4 & 128.1 & -0.2 & 41.5 & -27 & 41.1 & -46.6 & 72.1 & 30.41 \\
\hline Tata Steel Ltd & 15 & -15 & -34 & 77 & 194 & -14 & -2 & 27 & 95 & -77 & 170 & 39.64 \\
\hline WIPRO & 43 & -18 & -33 & 2 & 5 & -57 & -38 & 31 & -14 & -55 & 174 & 3.64 \\
\hline BSE INDEX 30 & 64 & -26 & -18 & 4 & 72 & 12 & 41 & 47 & 46 & -52 & 76 & 24.18 \\
\hline
\end{tabular}

Source: Official website of Bombay Stock Exchange

Table 3

Average Annual Return in \% of 20 Stocks from 1999 to 2009

\begin{tabular}{|c|c|c|c|c|c|c|c|c|c|c|c|c|}
\hline \multirow[t]{2}{*}{ Name of Stock } & \multicolumn{9}{|c|}{ YEAR } & \multirow[b]{2}{*}{2008} & \multirow[b]{2}{*}{2009} & \multirow[b]{2}{*}{ Average } \\
\hline & 1999 & 2000 & 2001 & 2002 & 2003 & 2004 & 2005 & 2006 & 2007 & & & \\
\hline ACC & 0.18 & -0.13 & 0.03 & 0.06 & 0.21 & 0.13 & 0.19 & 0.32 & 0.01 & -0.25 & 0.27 & 0.09 \\
\hline Apollo Tyres & 0.50 & \begin{tabular}{|l|}
-0.18 \\
\end{tabular} & 0.01 & 0.29 & 0.32 & $\begin{array}{l}-0.02 \\
\end{array}$ & 0.08 & 0.12 & \begin{tabular}{|c|}
-0.14 \\
\end{tabular} & -0.36 & 0.43 & 0.10 \\
\hline Arvind Mills & -0.11 & -0.18 & -0.03 & 0.44 & 0.49 & 0.33 & -0.10 & -0.20 & 0.27 & -0.52 & 0.41 & 0.07 \\
\hline Ashok Leyland & 0.50 & -0.33 & 0.26 & 0.19 & 0.47 & -0.40 & 0.13 & 0.19 & 0.08 & -0.43 & 0.54 & 0.11 \\
\hline Asian paints & 0.15 & -0.08 & 0 & 0.09 & 0.05 & -0.01 & 0.25 & 0.11 & 0.19 & -0.07 & 0.32 & 0.09 \\
\hline Axis Bank & 0.26 & 0.29 & -0.17 & 0.24 & 0.51 & 0.19 & 0.20 & 0.23 & 0.33 & -0.15 & 0.34 & 0.21 \\
\hline Ballarpur Industries & 0.42 & 0.11 & -0.13 & 0.06 & 0.28 & 0.09 & 0.09 & 0.03 & 0.22 & -0.53 & 0.14 & 0.07 \\
\hline Castrol & -0.24 & -0.04 & -0.12 & 0.05 & 0.07 & -0.02 & 0.08 & -0.03 & 0.21 & 0.02 & 0.26 & 0.02 \\
\hline Colgate Palmolive & 0.10 & -0.09 & 0.01 & -0.08 & 0.10 & 0.04 & 0.18 & 0.18 & 0.04 & 0.02 & 0.21 & 0.07 \\
\hline Crompton Greaves & 0.12 & -0.15 & -0.08 & 0.40 & 0.56 & 0.27 & 0.42 & -0.13 & 0.27 & -0.32 & 0.51 & 0.17 \\
\hline Garware Polyester & 0.20 & 0.05 & -0.02 & 0.89 & 0.34 & 0.04 & 0.04 & 0.02 & 0.36 & -0.57 & 0.47 & 0.17 \\
\hline Gujarat Narmada & 0.50 & -0.17 & -0.08 & 0.21 & 0.37 & 0.02 & 0.28 & -0.04 & 0.34 & $\begin{array}{l}-0.47 \\
\end{array}$ & 0.29 & 0.11 \\
\hline Harrison Malayalam & -0.06 & -0.17 & -0.12 & 0.45 & 0.68 & 0.17 & -0.01 & -0.01 & 0.23 & -0.34 & 0.58 & 0.13 \\
\hline Hindalco & 0.25 & -0.01 & -0.03 & -0.02 & 0.36 & 0.04 & -0.34 & 0.12 & 0.11 & -0.46 & 0.53 & 0.05 \\
\hline Indian Hotels & 0.02 & -0.09 & -0.15 & 0.09 & 0.37 & 0.10 & 0.25 & -0.14 & 0.06 & -0.49 & 0.39 & 0.04 \\
\hline Indian Reyons & 0.24 & -0.10 & -0.07 & 0.14 & 0.46 & 0.19 & 0.24 & 0.28 & 0.22 & -0.43 & 0.23 & 0.13 \\
\hline ITC & 0.02 & 0.15 & -0.08 & 0 & 0.17 & 0.13 & -0.20 & 0.12 & 0.10 & -0.06 & 0.18 & 0.05 \\
\hline ONGC & -0.32 & -0.18 & 0.07 & -0.28 & -0.13 & -0.16 & -0.02 & -0.22 & -0.22 & -0.32 & -0.04 & -0.17 \\
\hline Tata Steel Ltd & -0.31 & -0.37 & -0.26 & -0.19 & -0.08 & -0.37 & -0.35 & -0.14 & 0.06 & -0.56 & 0.29 & -0.21 \\
\hline WIPRO & -0.05 & -0.13 & 0.32 & -0.20 & -0.33 & -0.21 & -0.11 & -0.08 & -0.30 & -0.25 & 0.36 & -0.09 \\
\hline BSE INDEX 30 & 0.25 & -0.07 & -0.01 & 0.09 & 0.29 & 0.10 & 0.17 & 0.18 & 0.17 & -0.24 & 0.27 & 0.11 \\
\hline
\end{tabular}

Source: Official website of Bombay Stock Exchange

\section{Daily Return of ACC}

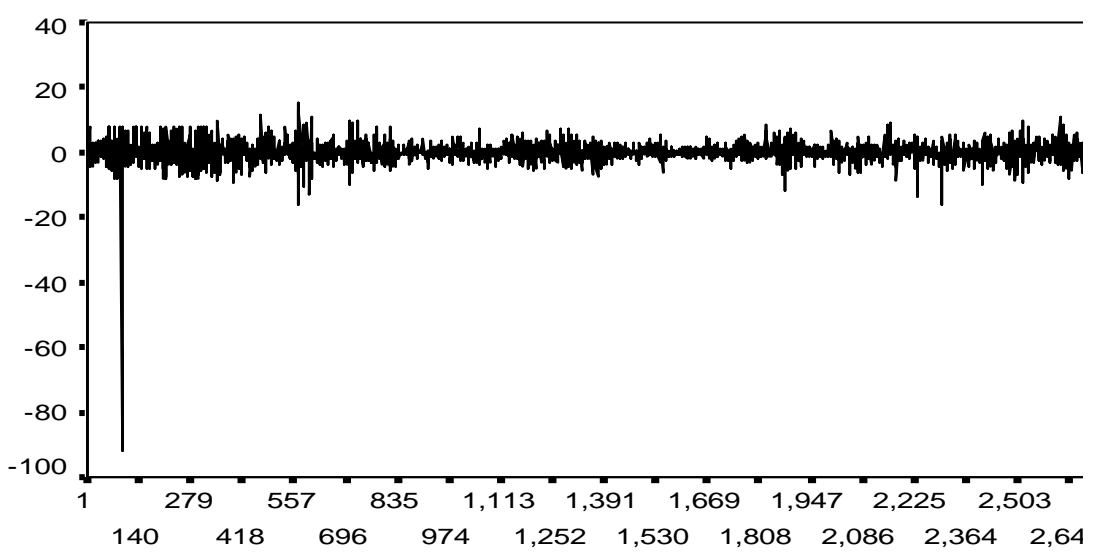

Case Number

No. of observation

Figure 1 Daily returns of ACC 


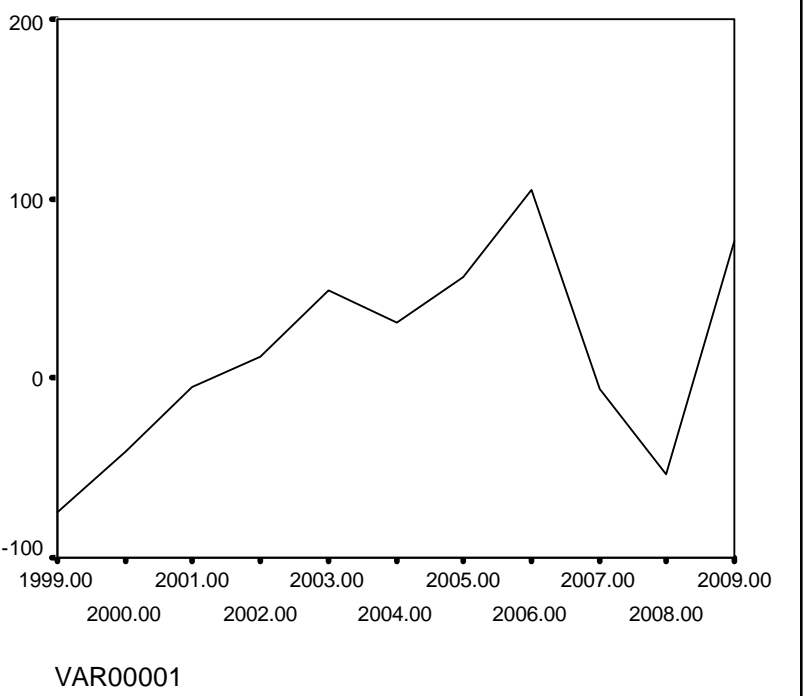

Figure 2 Holding period of ACC IN \%

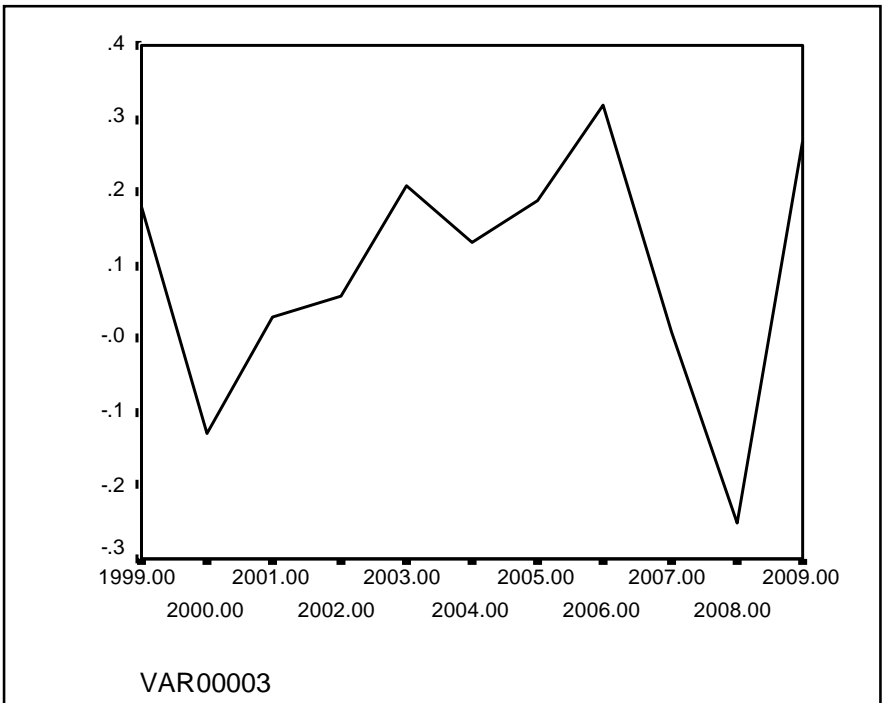

Figure 3 Average Annual Return of ACC in \% for 1999-2009

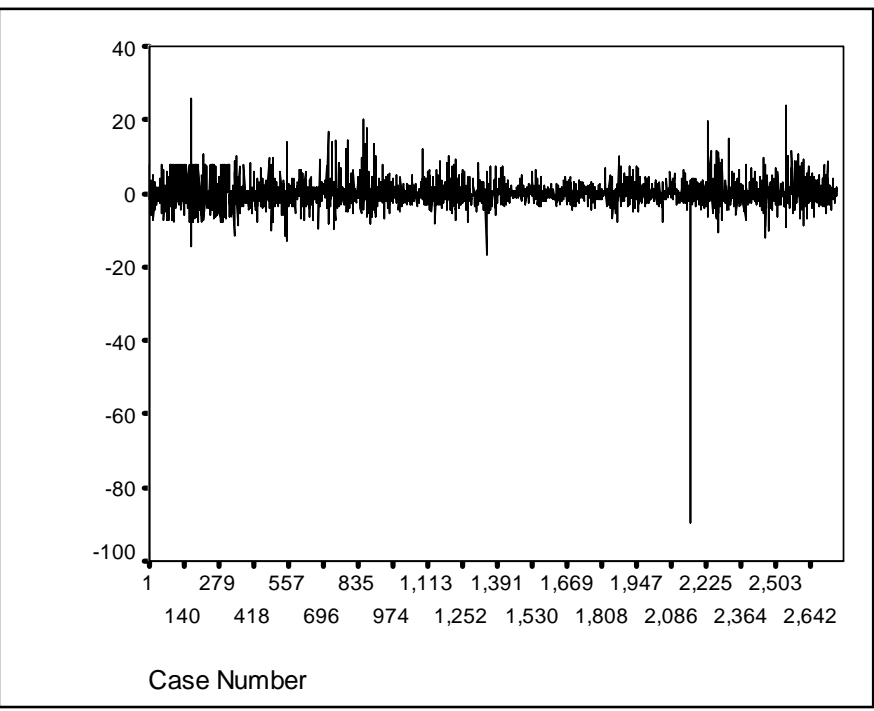

Figure 4 Daily Returns of Appollo Tyres 


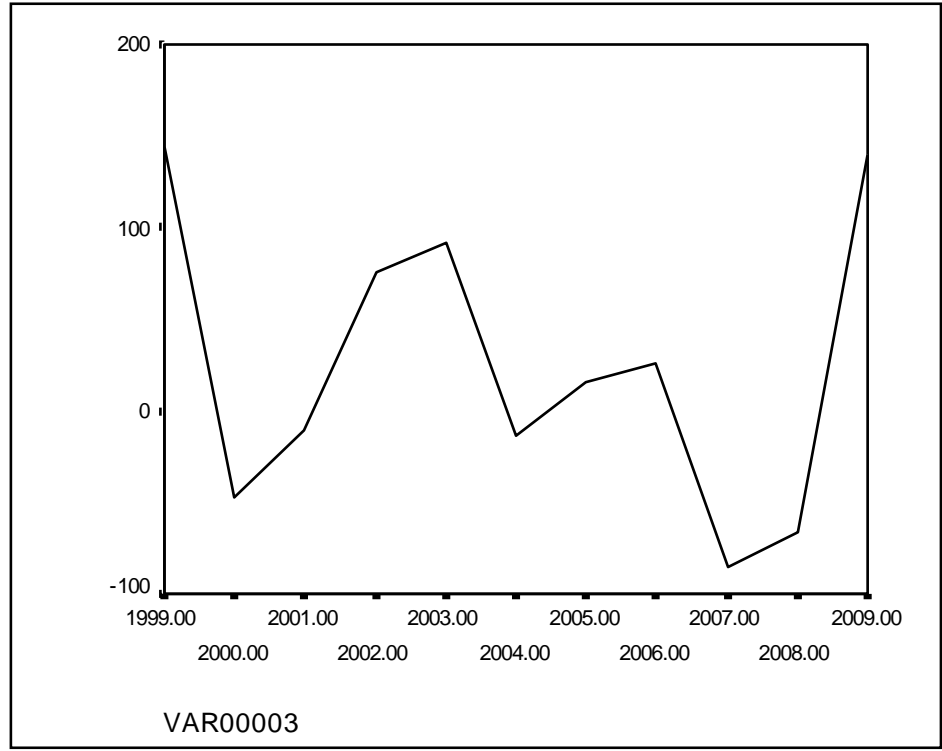

Figure 5: Holding Period Yields of Appollo Tyres

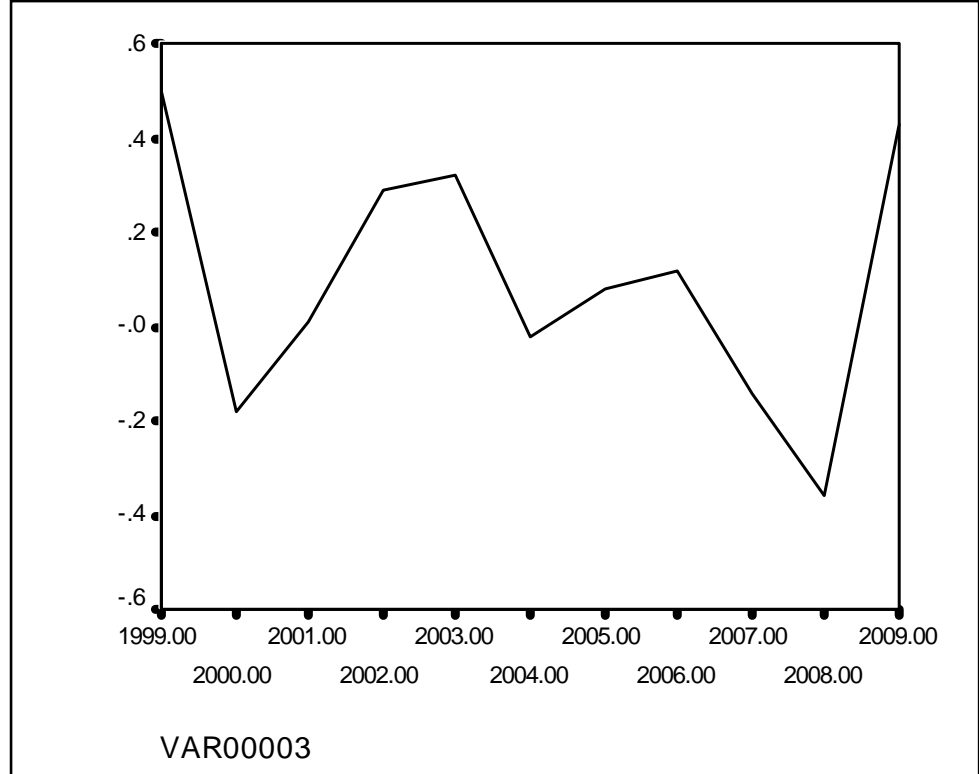

Figure 6: Annual Returns of Appollo Tyres

Aravind mills

Daily Returns

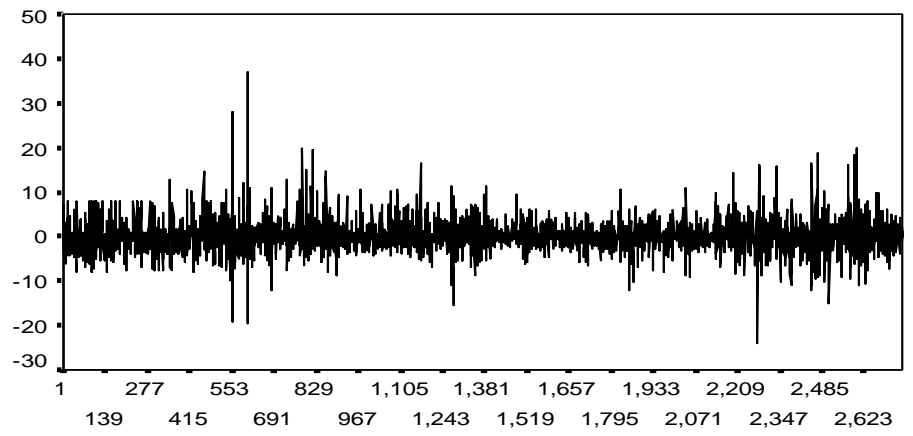

Case Number

Figure 7: Daily Returns of Arvind Mills 


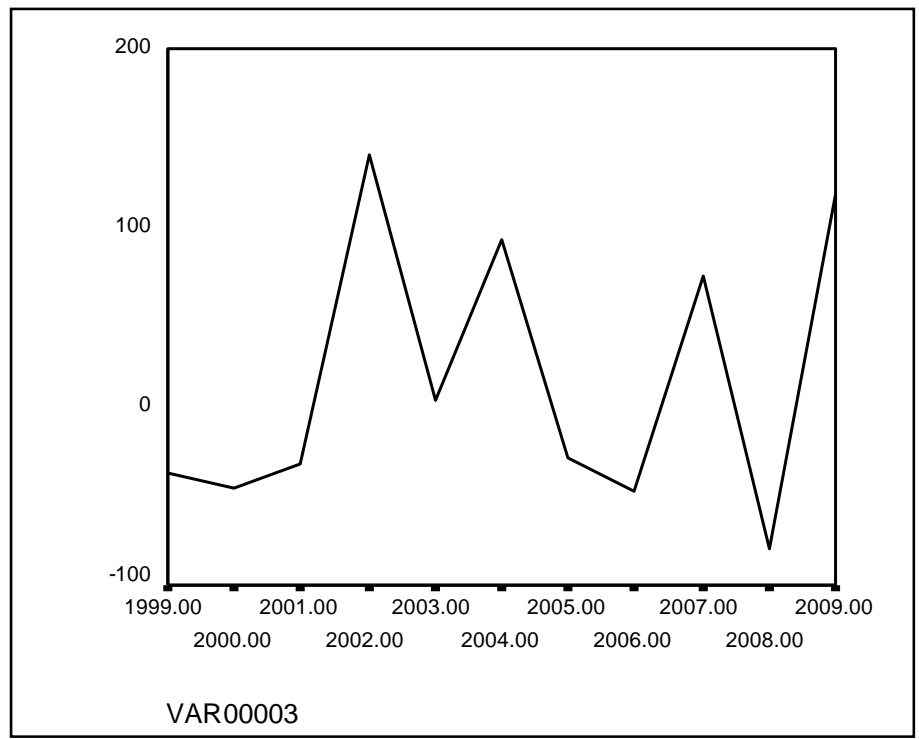

Figure 8: Holding Period Yield of Arvind Mills

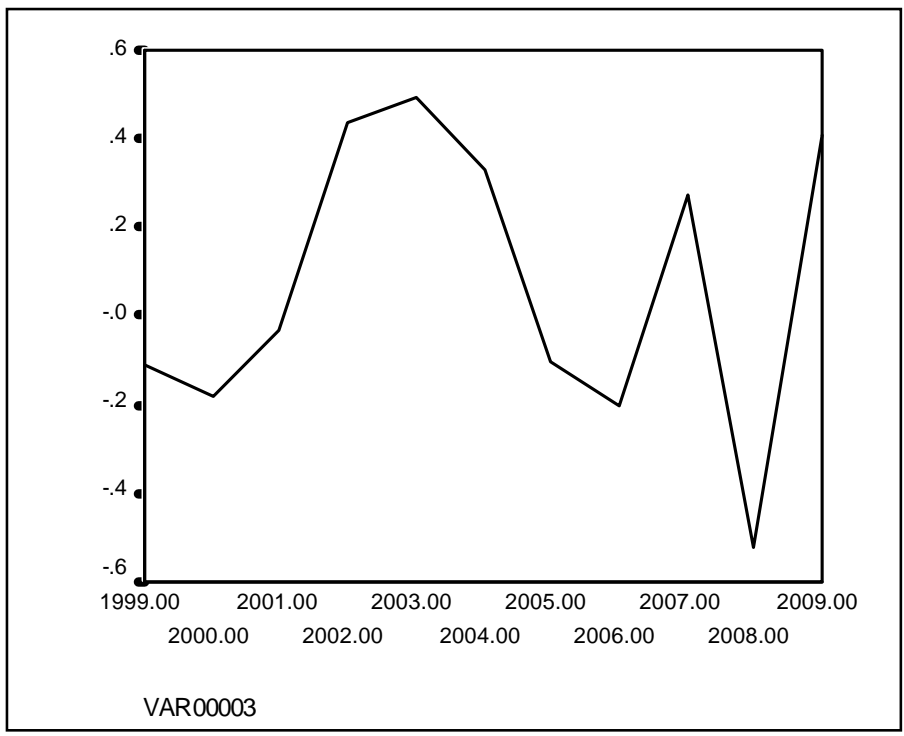

Figure 9: Annual Returns of Arvind Mills

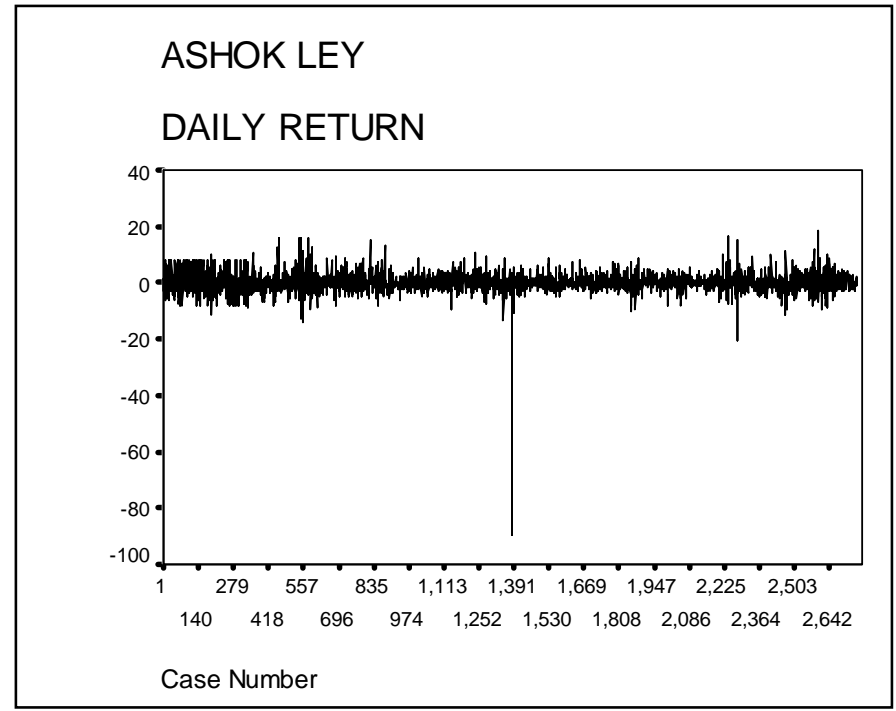

Figure 10: Daily Returns of Ashok Leyland 


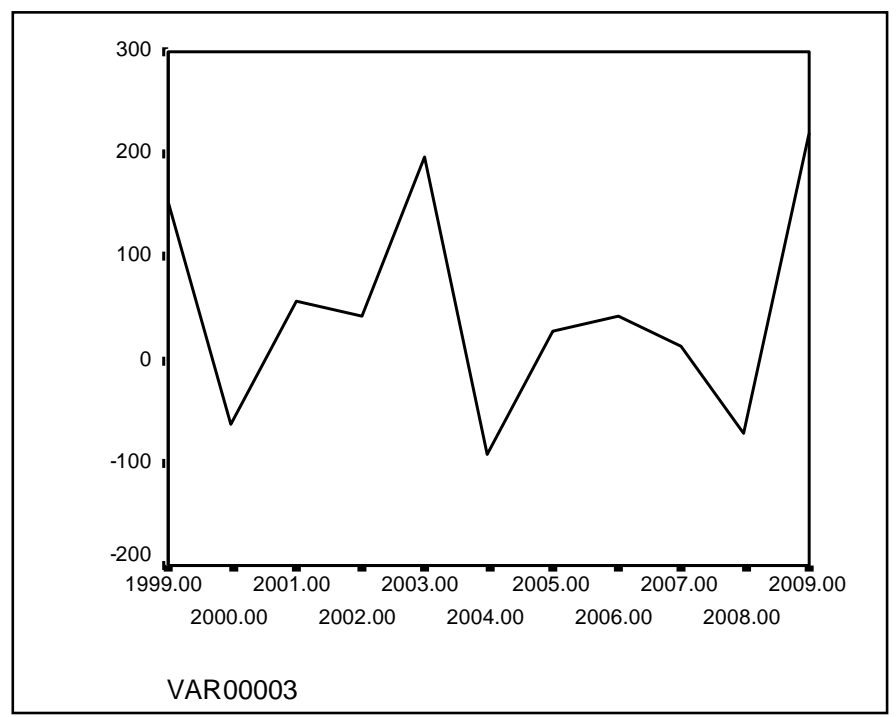

Figure 11: Holding Period Yield of Ashok Leyland

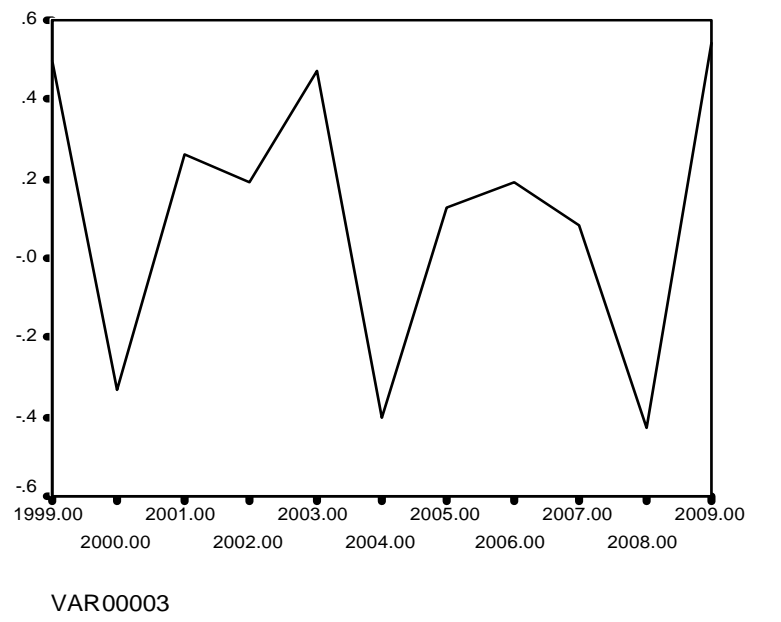

Figure 12: Annual Returns of Ashok Leyland

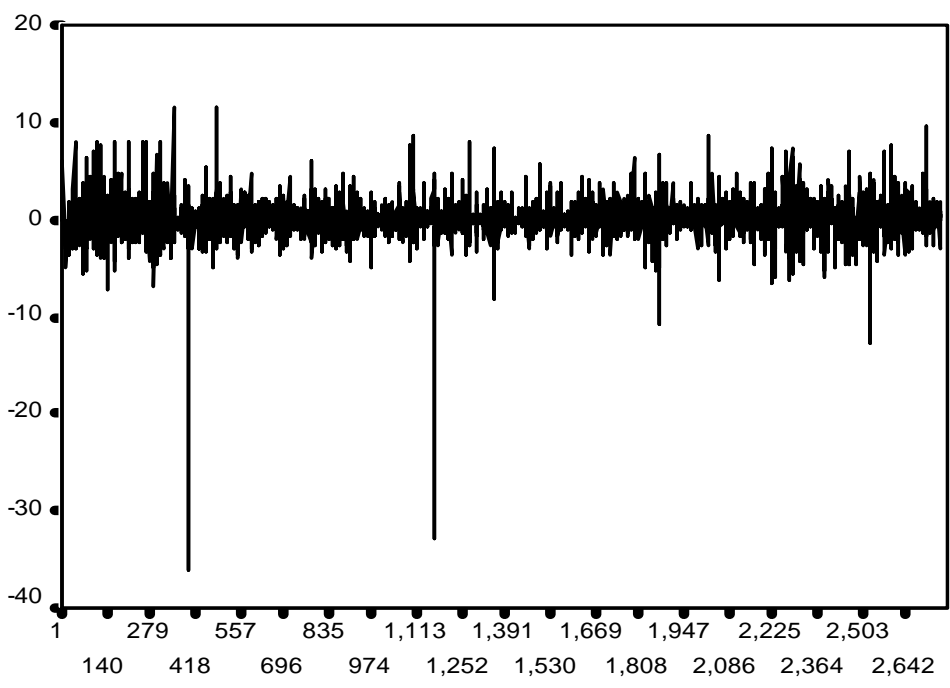

Case Number

Figure 13: Daily Returns of Asian Paints 


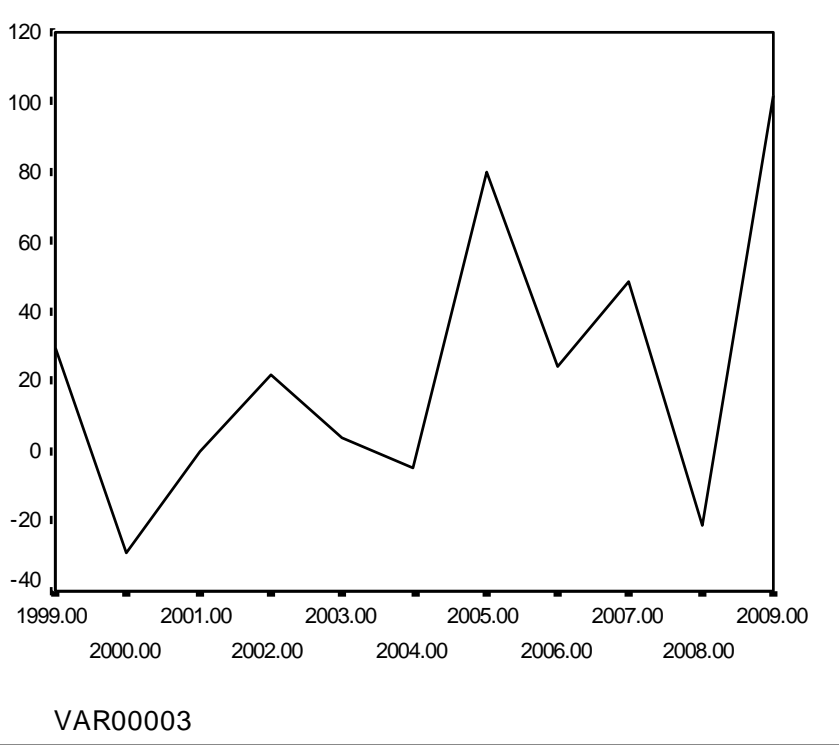

Figure 14: Holding Period Yield of Asian Paints

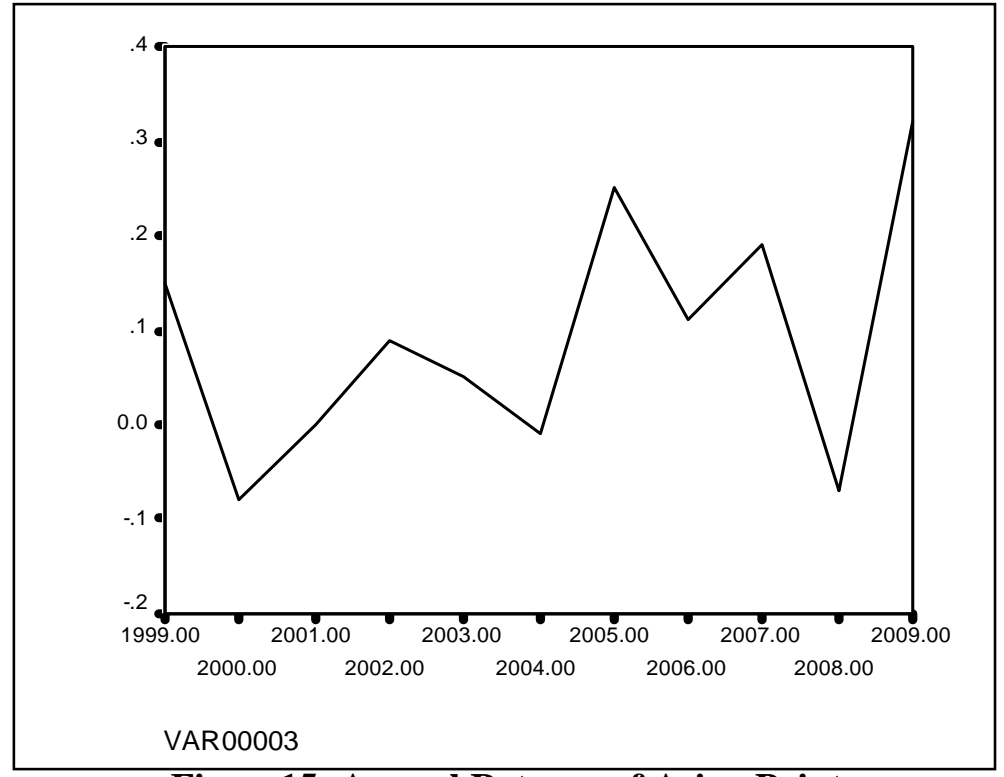

Figure15: Annual Returns of Asian Paints

AXIS BANK

DAILY RETURNS

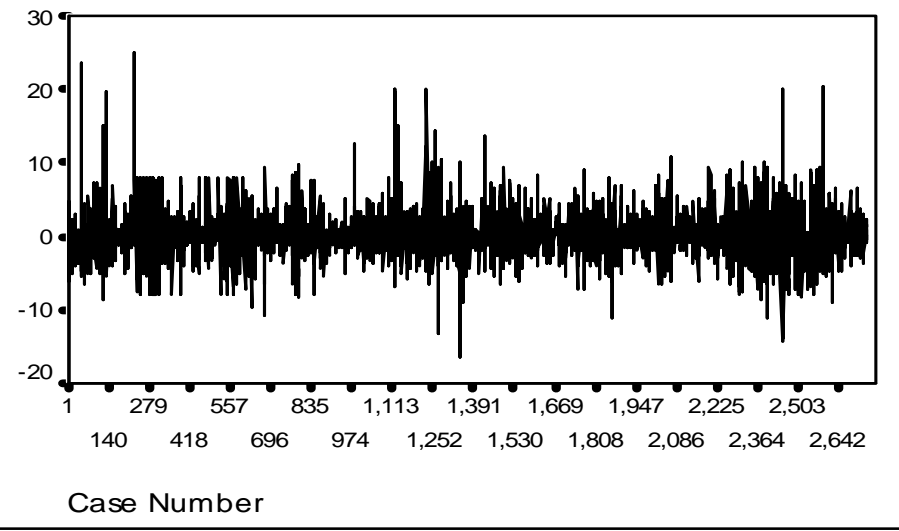

Figure16: Daily Returns of Axis Bank 


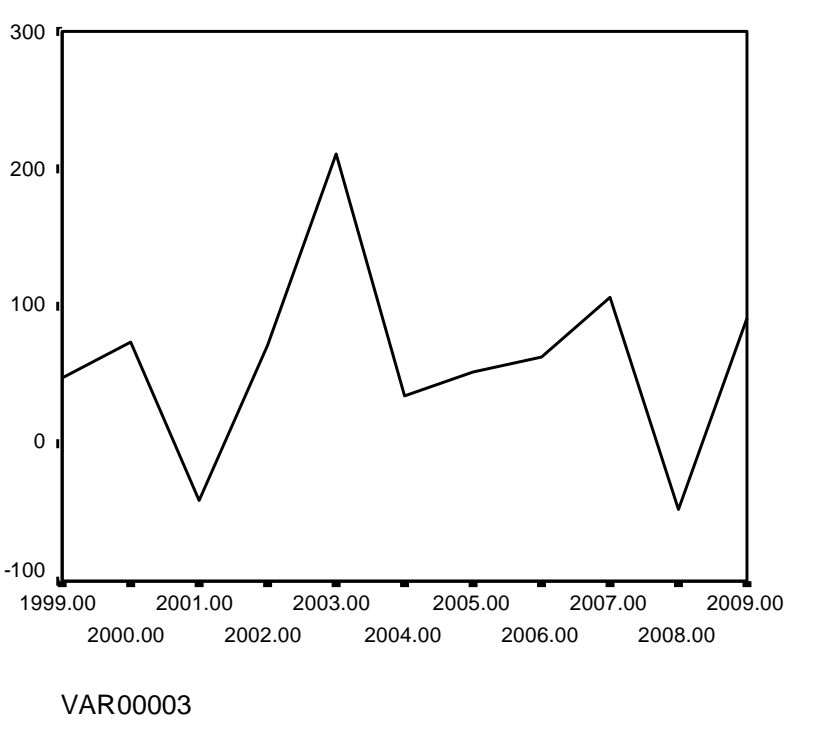

Figure17: Holding Period Yield of Axis Bank

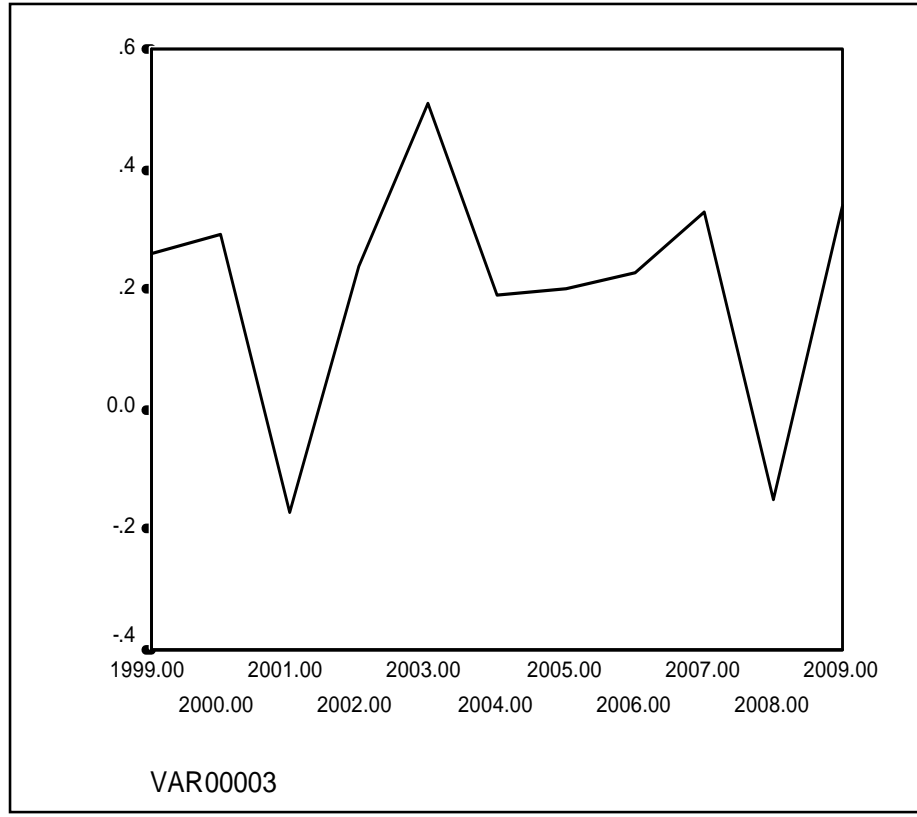

Figure 18: Annual Return of Axis Bank

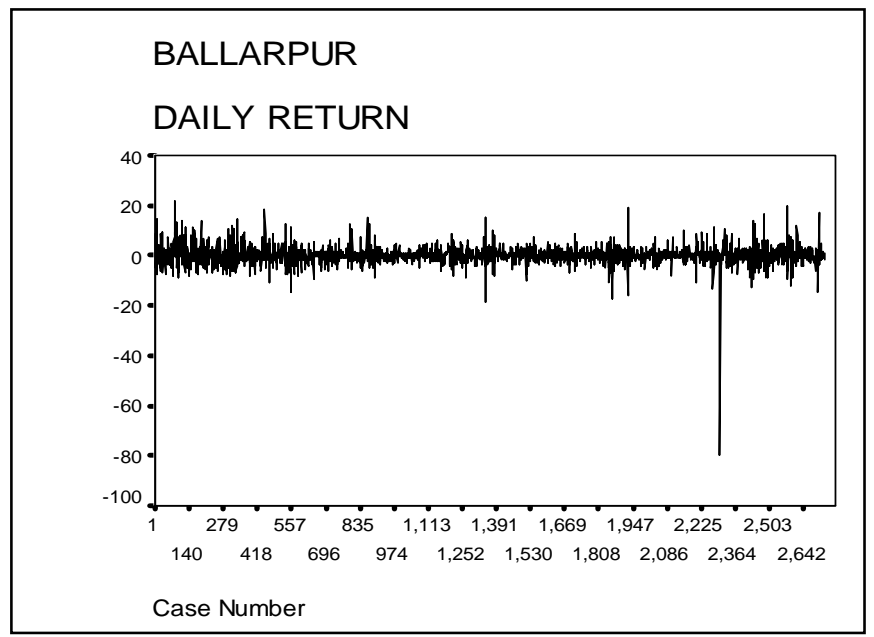

Figure 19: Daily Returns of Ballarpur Industries 


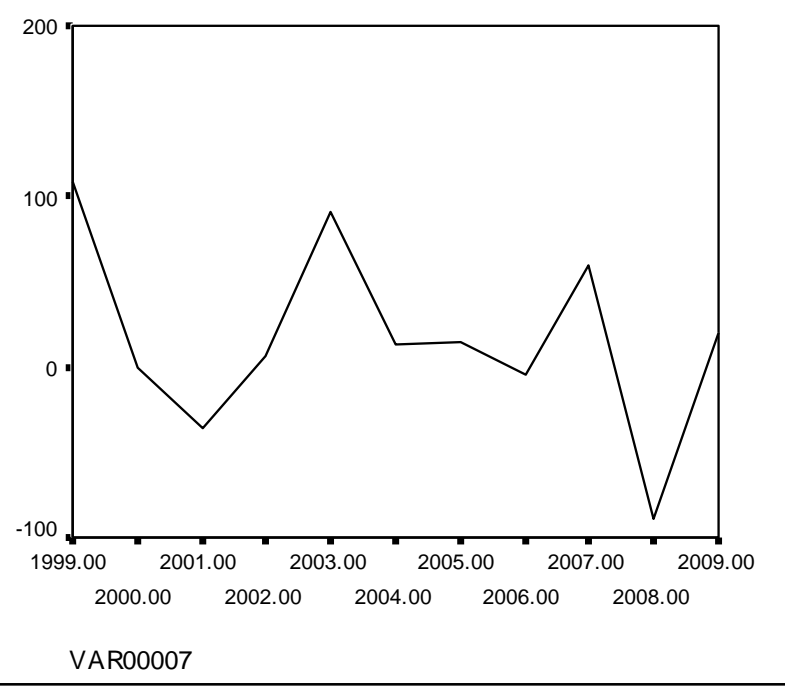

Figure 20: Holding Period Yield of Ballarpur Industries

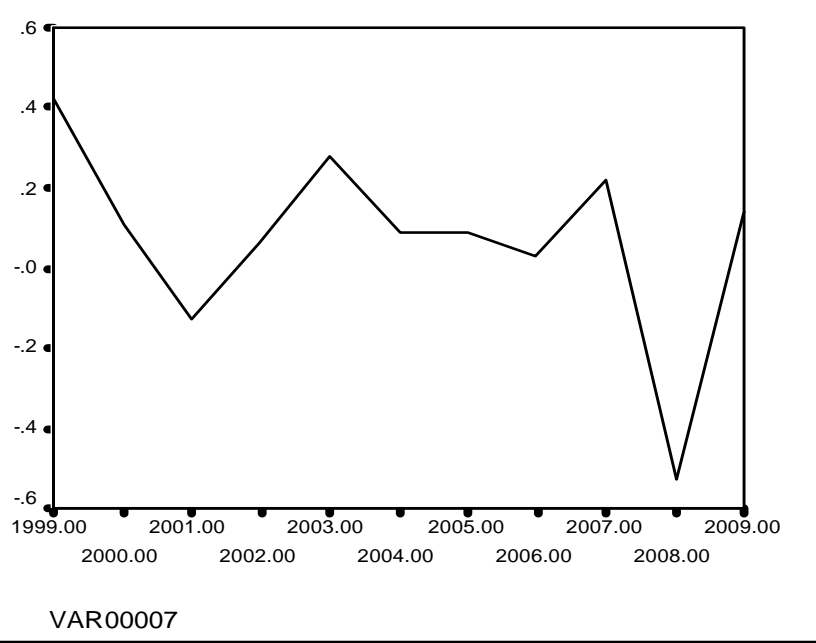

Figure 21: Average Annual Returns of Ballarpur Industries

\section{CASTROL \\ DAILY RETURNS}

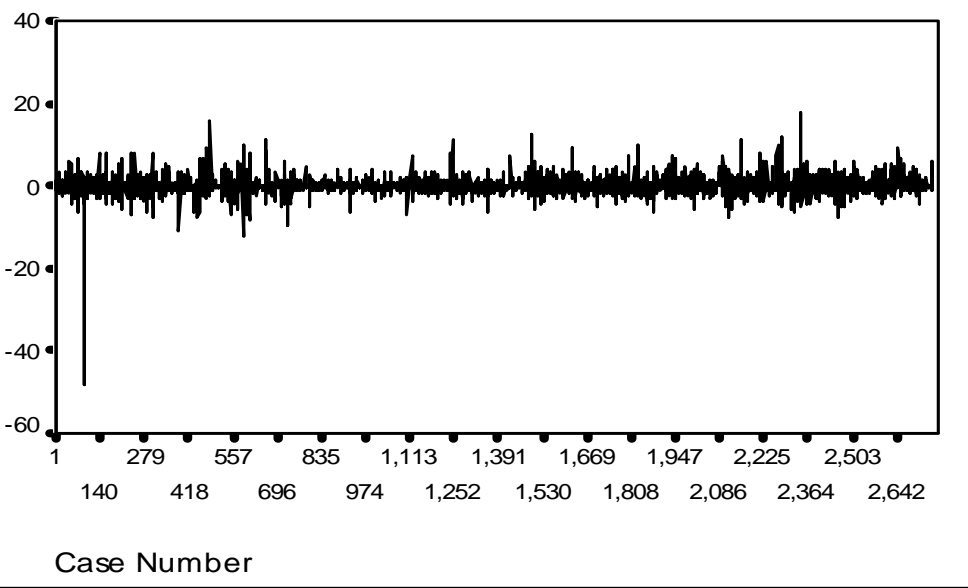

Figure 22: Daily Returns of Castrol 


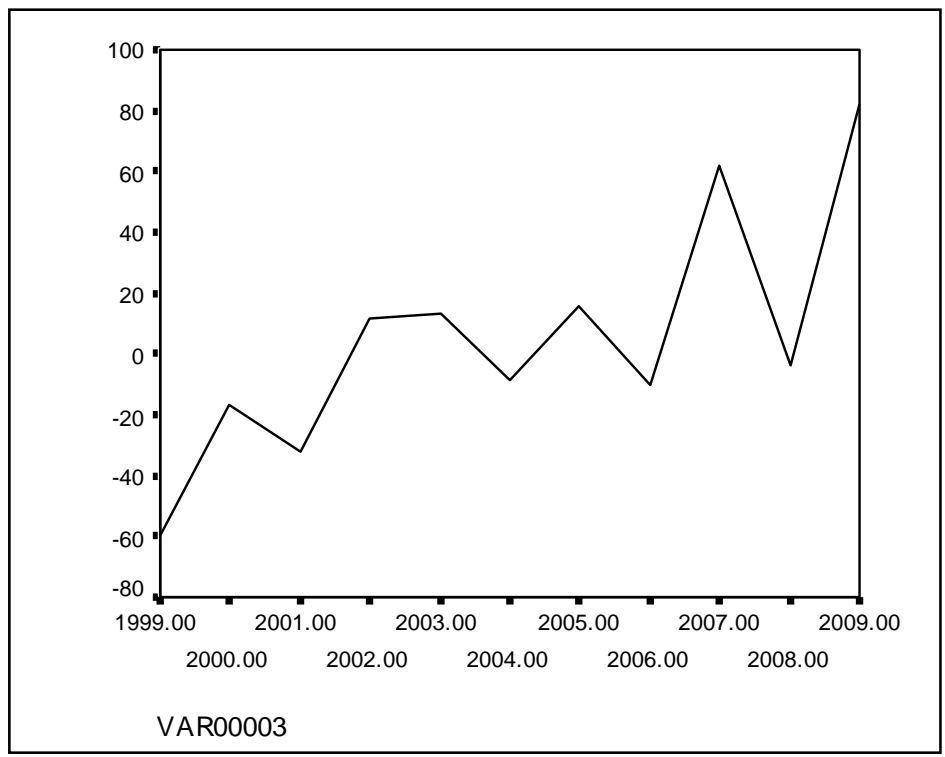

Fig.23: Holding Period Yield of Castrol

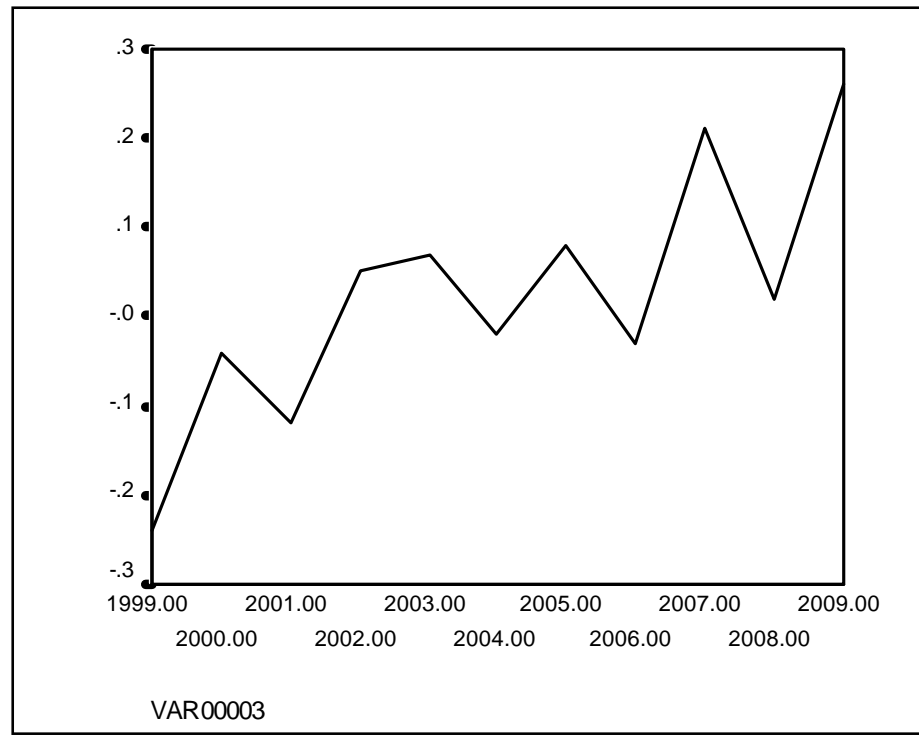

Fig.24: Annual Returns of Castrol

COLGATE PALMOLIVE

DAILY RETURNS

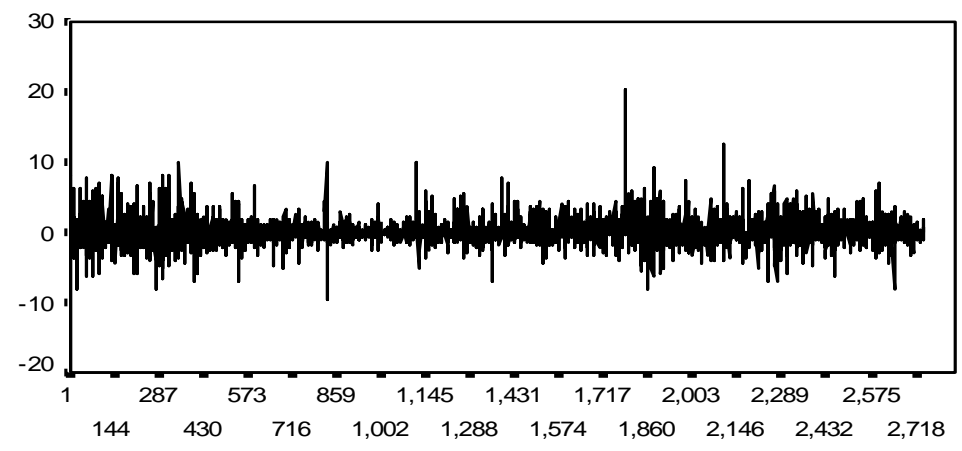

Case Number

NO.OF OBSERVATION

Figure 25: Daily returns of Colgate Palmolive 


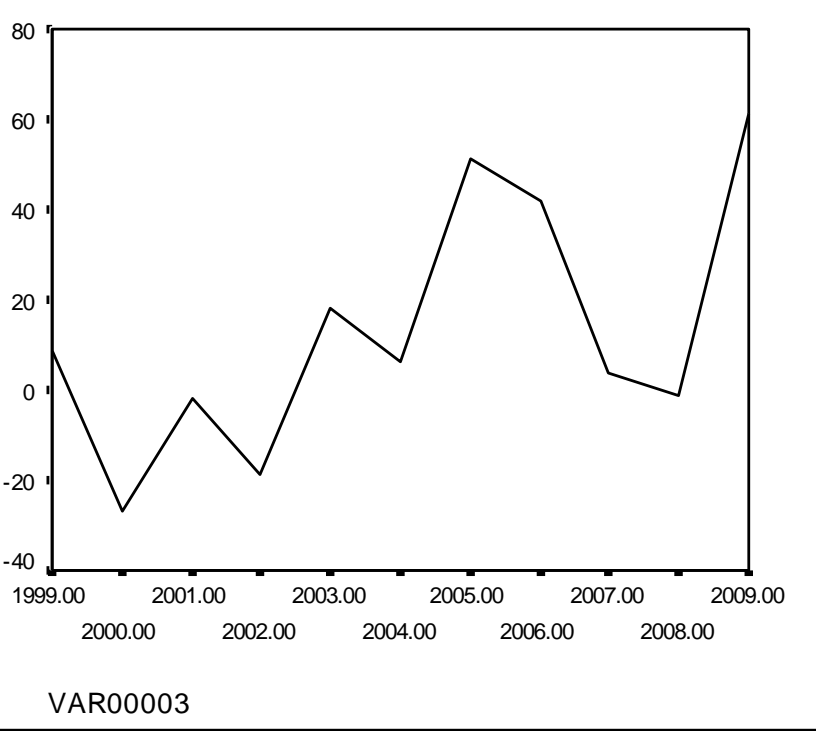

Figure 26: Holding Period of Colgate Palmolive

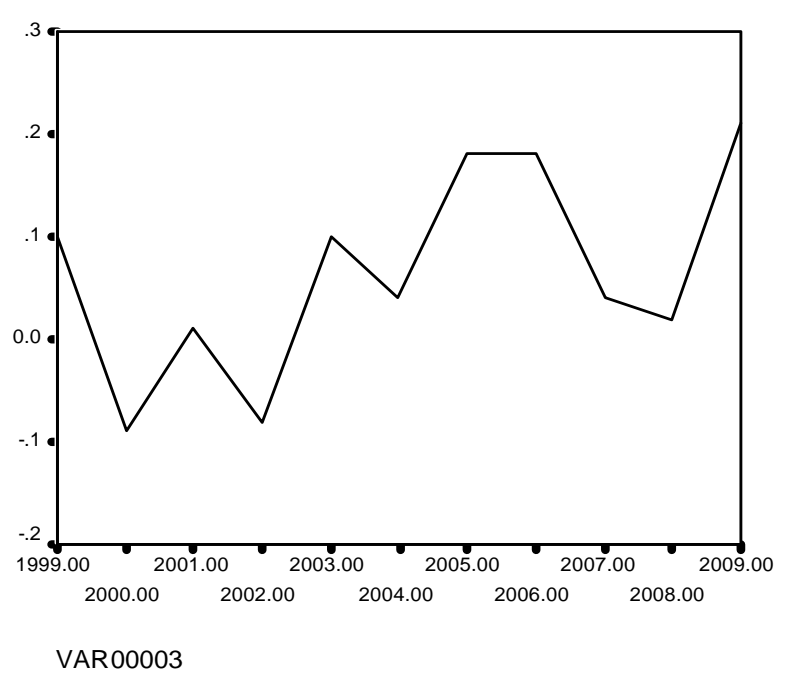

Figure 27: Annual returns of Colgate Palmolive

\section{CROMPTON}

DAILY RETURN

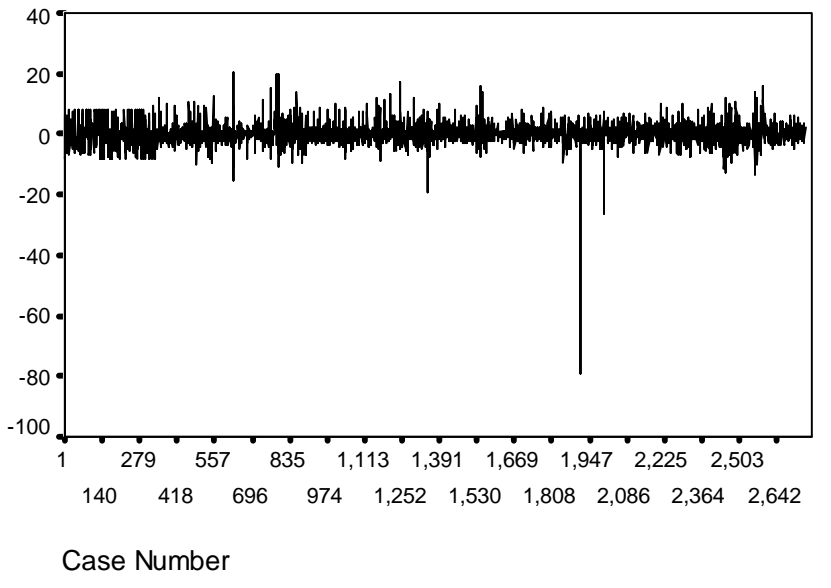

Figure 28: Daily returns of Crompton Greaves 


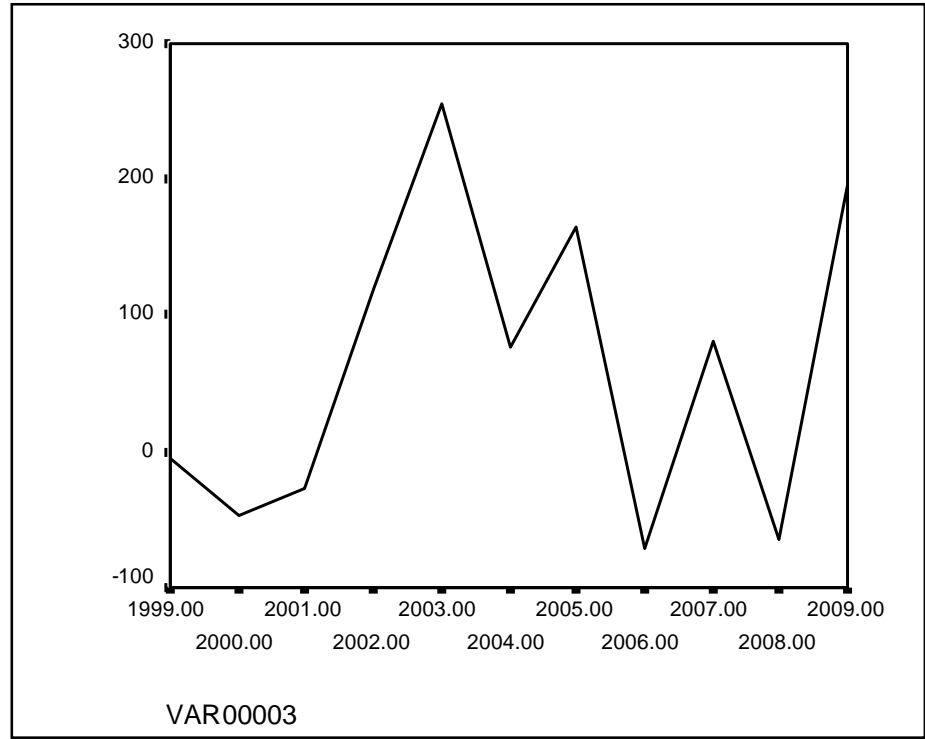

Figure 29: Holding Period of Crompton Greaves

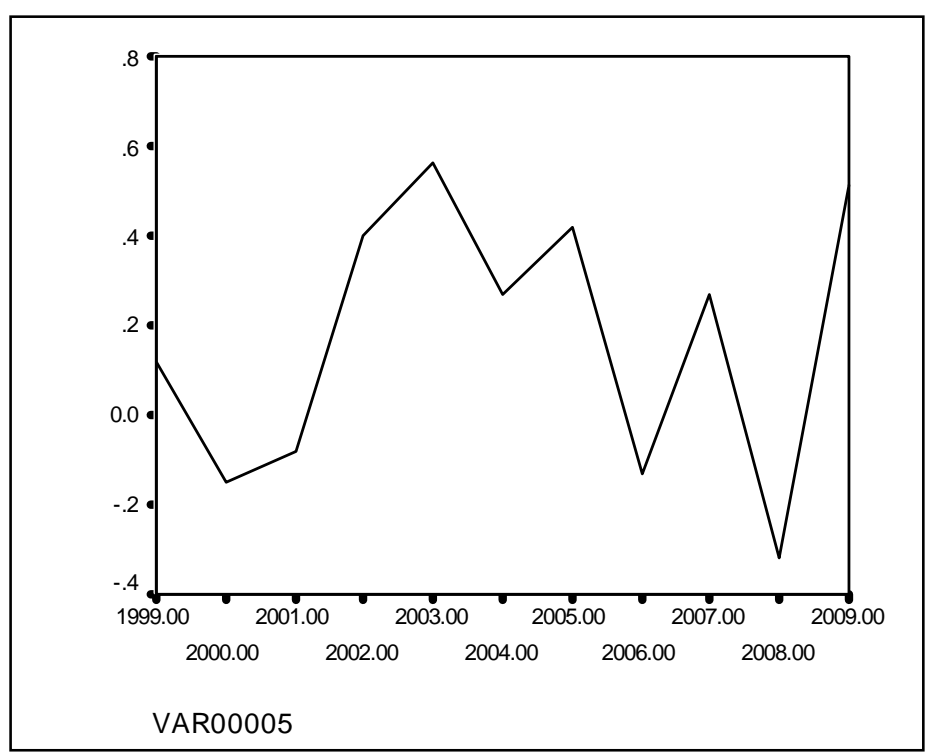

Figure 30: Annual returns of Crompton Greaves

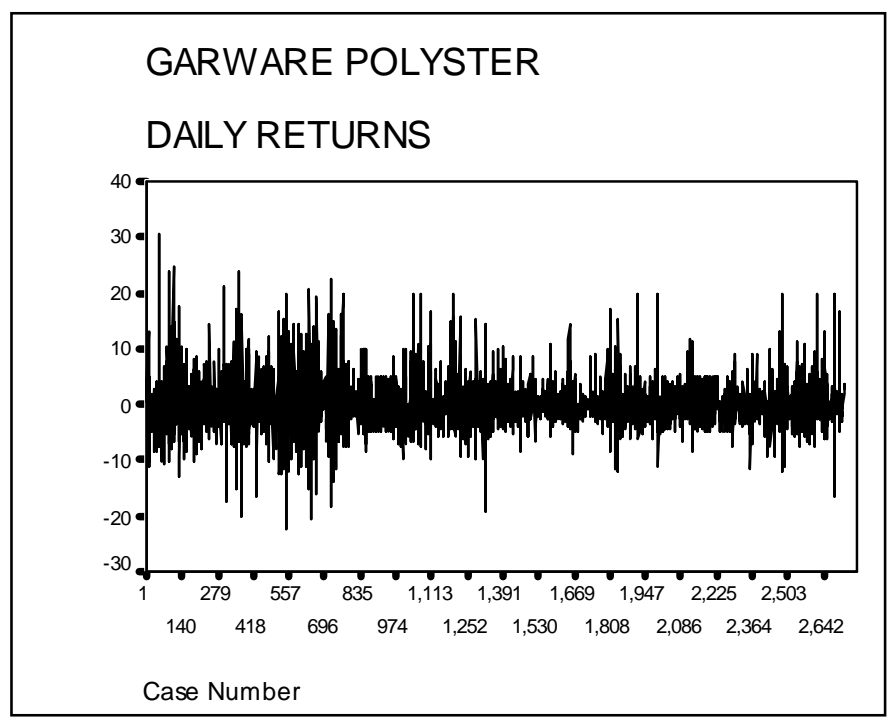

Figure 31: Daily returns of Garware Polyester 


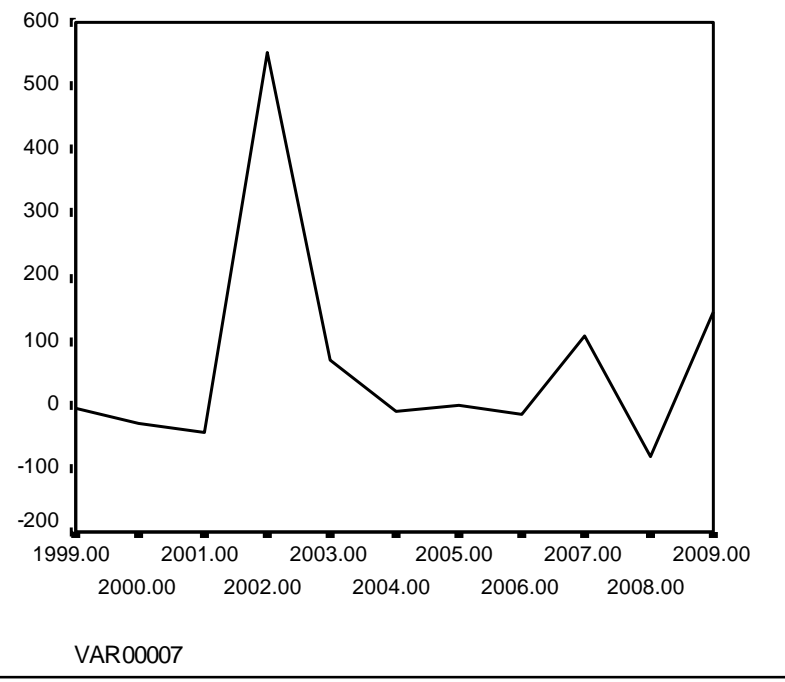

Figure 32: Holding Period of Yield of Garware Polyester

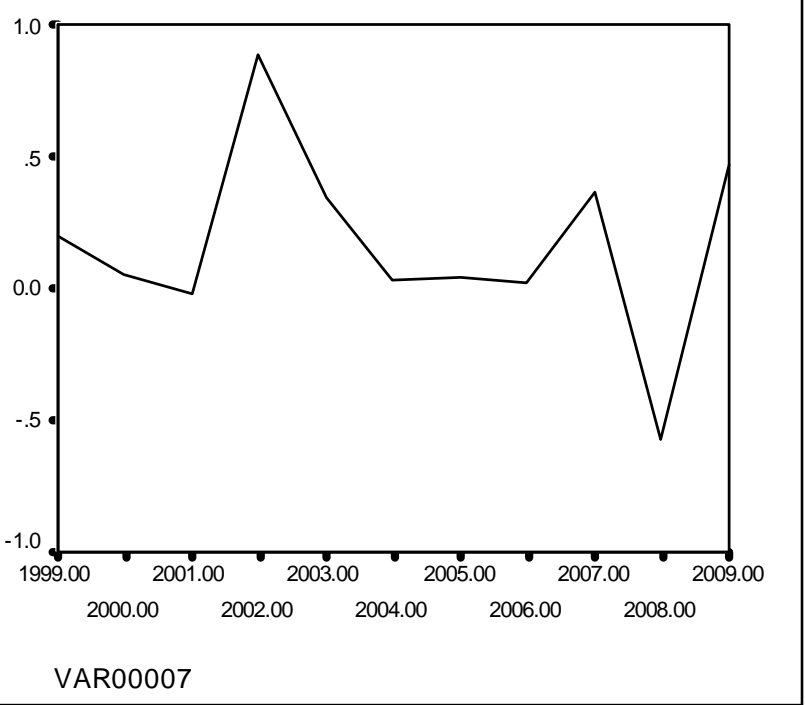

Figure 33: Annual Returns of Garware Polyester

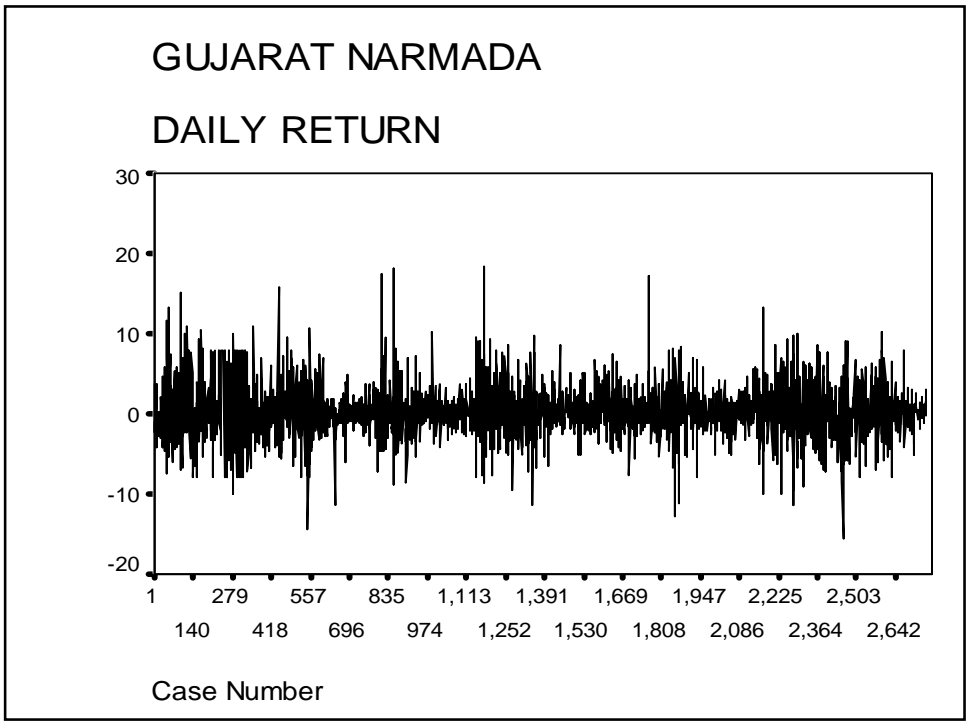

Figure 34: Behavior of Daily returns of Gujarat Narmada 1999-2009 


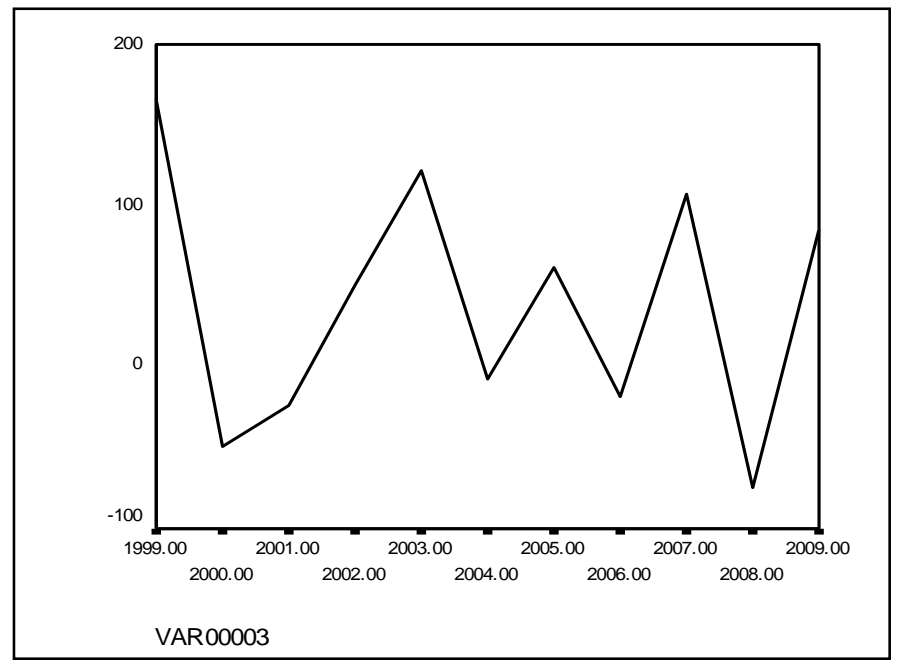

Figure 35: Behavior of HPY of Gujarat Narmada

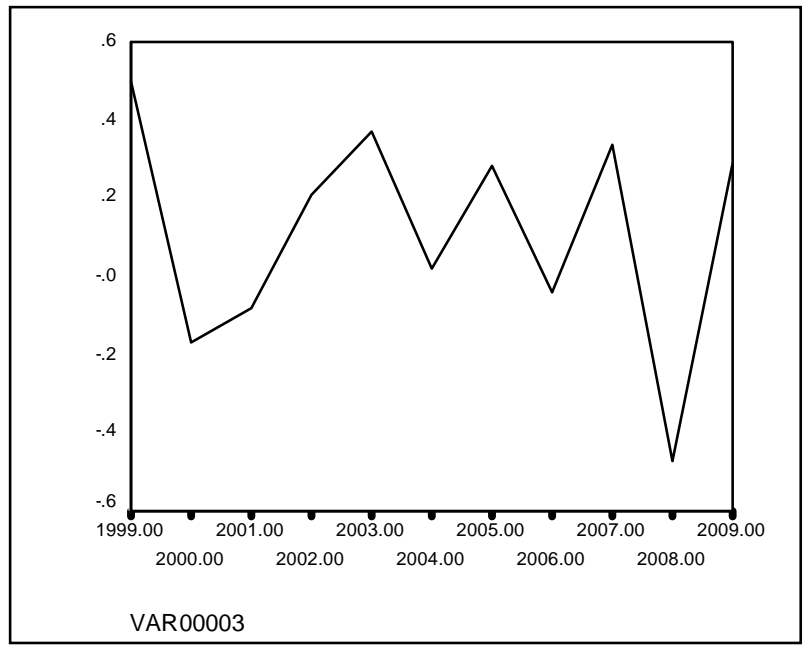

Figure 36: Behavior of Annual Returns of Gujarat Narmada

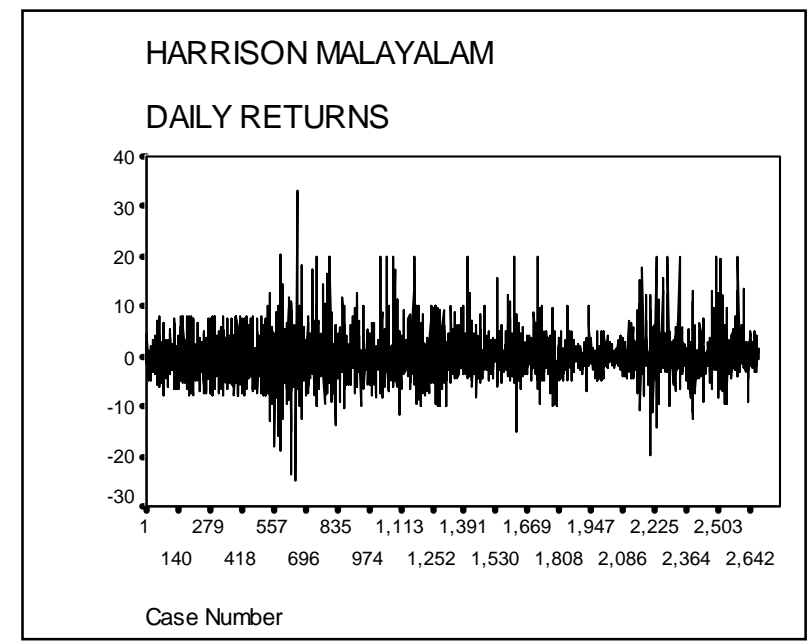

Figure 37: Behavior of Daily returns of Harrison Malayalam 


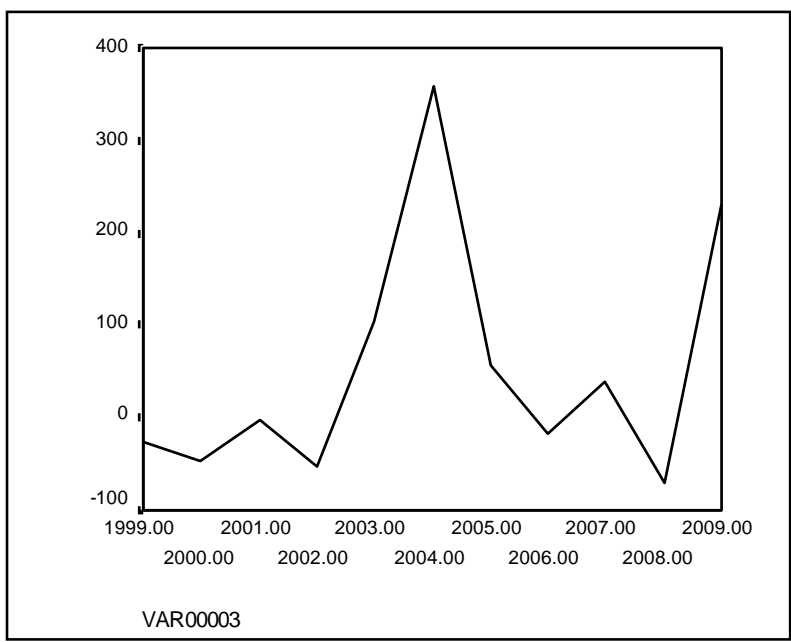

Figure 38: Behavior of HPY of Harrison Malayalam

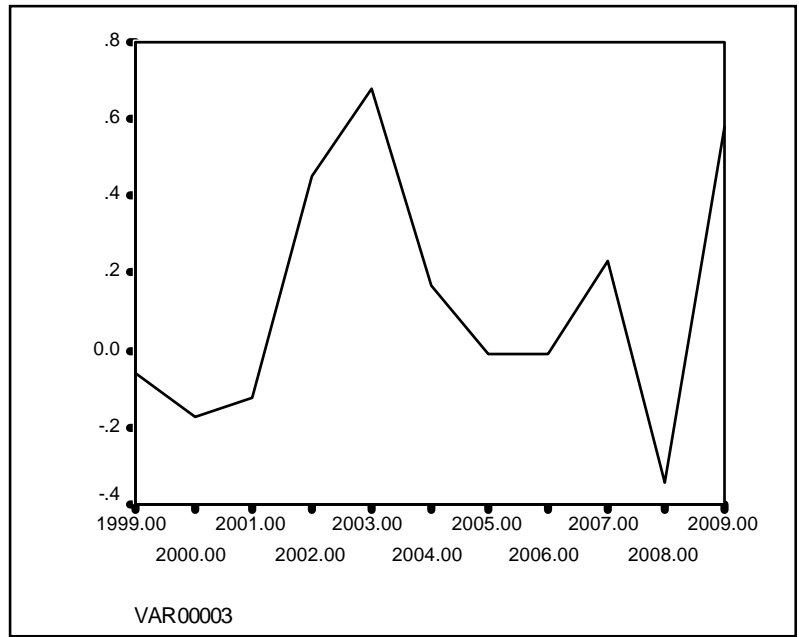

Figure 39: Behavior of annual returns of Harrison Malayalam

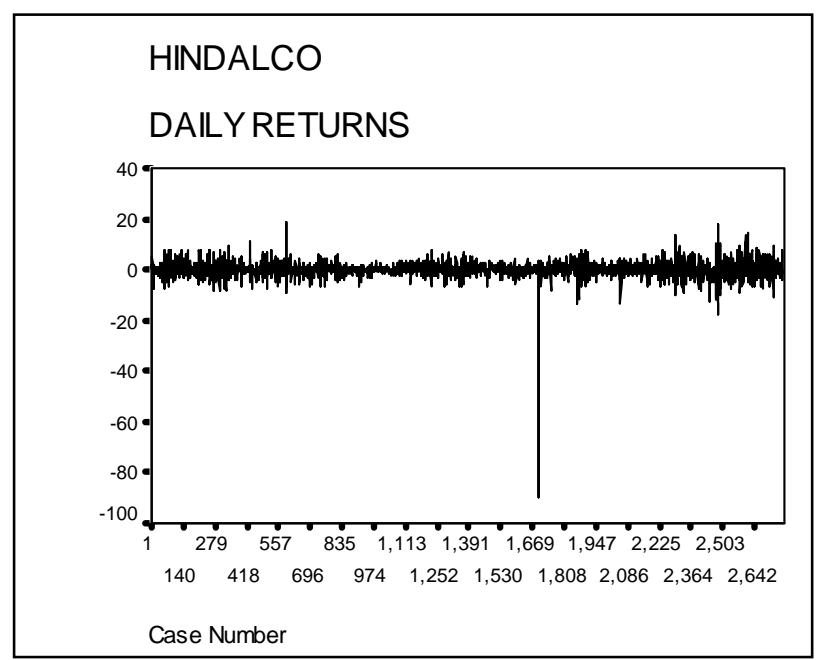

Figure 40: Daily returns of Hindalco 


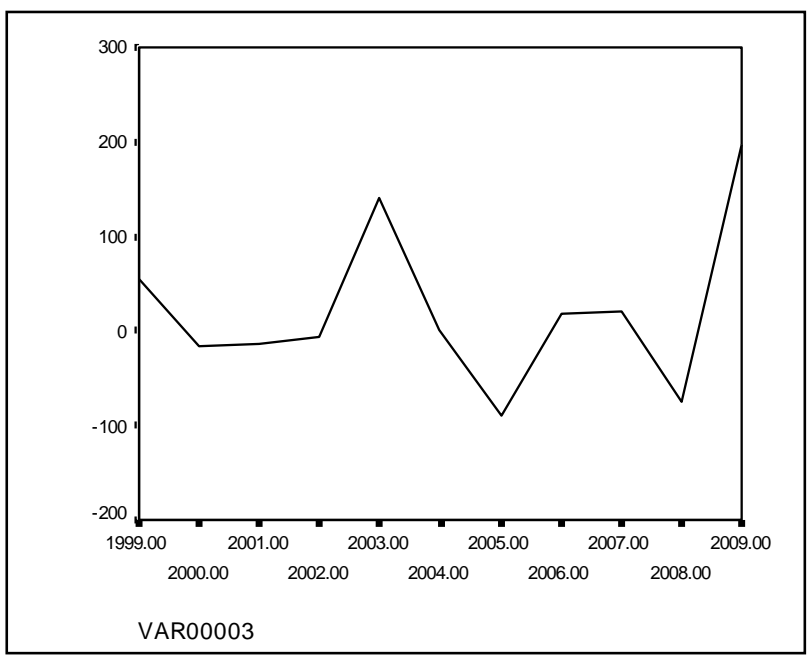

Figure 41: Holding Period Yield of Hindalco

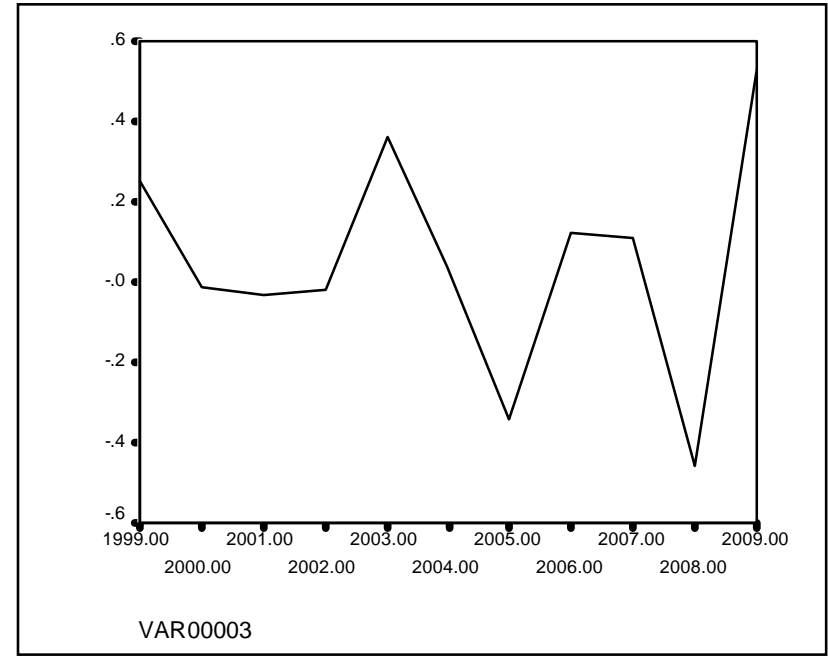

Figure 42: Annual returns of Hindalco

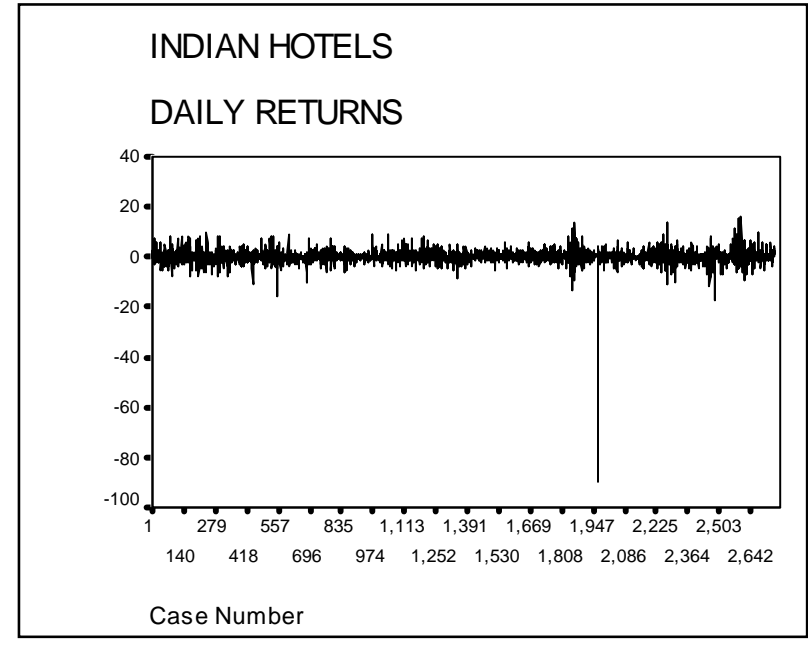

Figure 43: Daily returns of Indian Hotels 


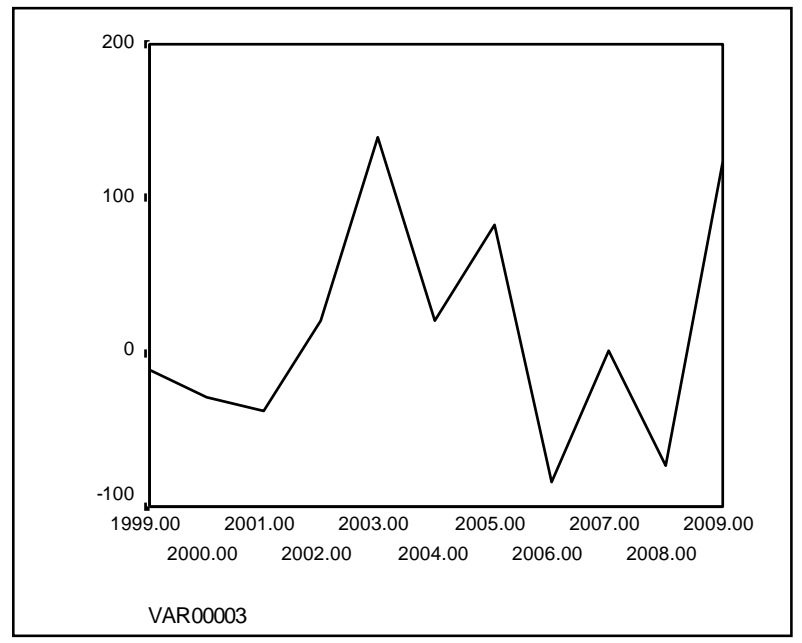

Figure 44: HPY of Indian Hotels

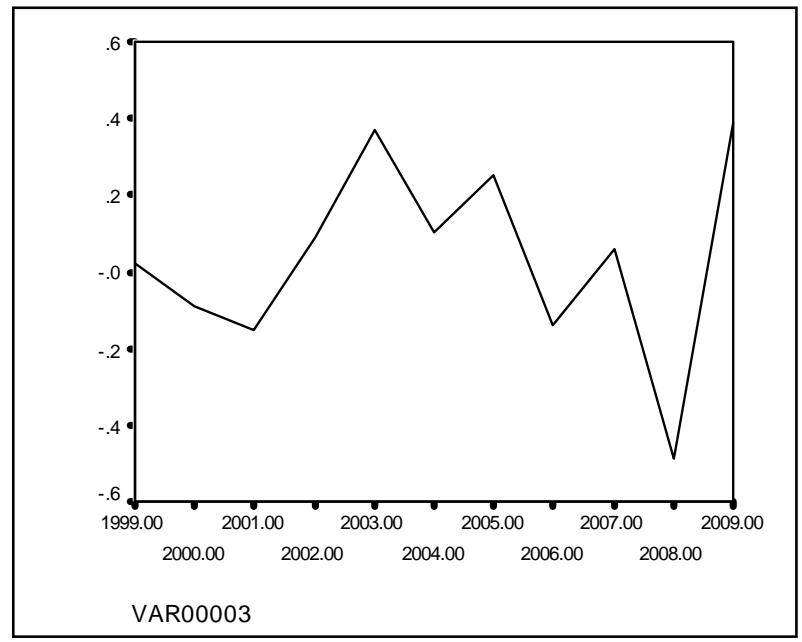

Figure 45: Annual returns of Indian Hotels

Indian Reyons

Daily Returns

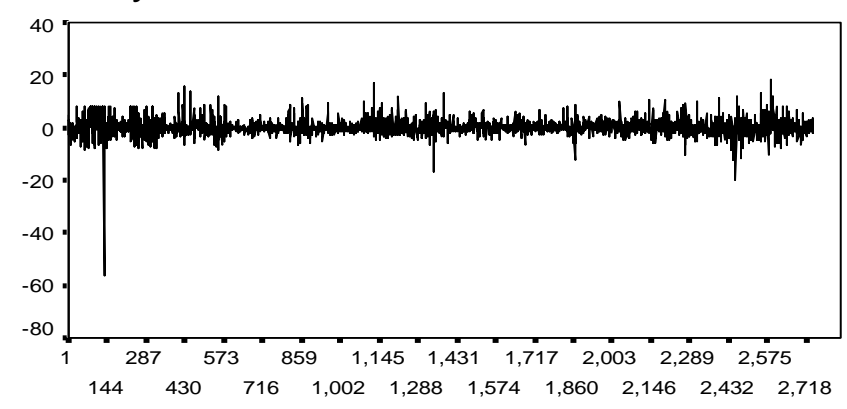

Case Number

No.of observation

Figure 46: Daily returns of Indian Reyons 


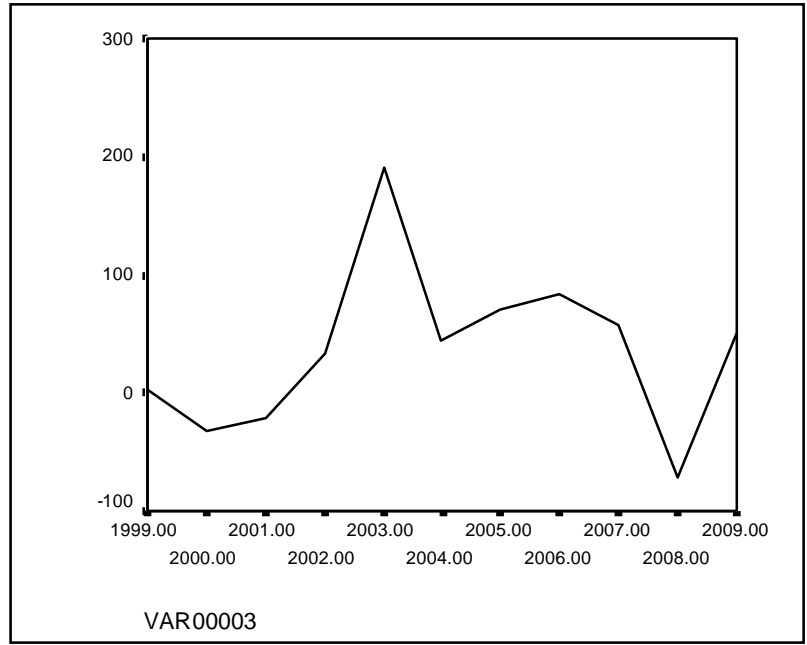

Figure 47: HPY of Indian Reyons

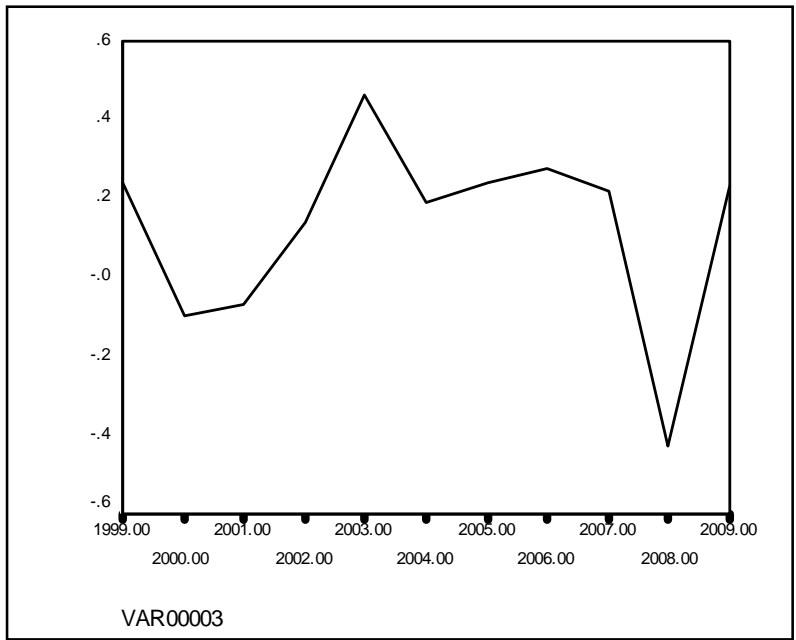

Figure 48: Annual returns of Indian Reyons

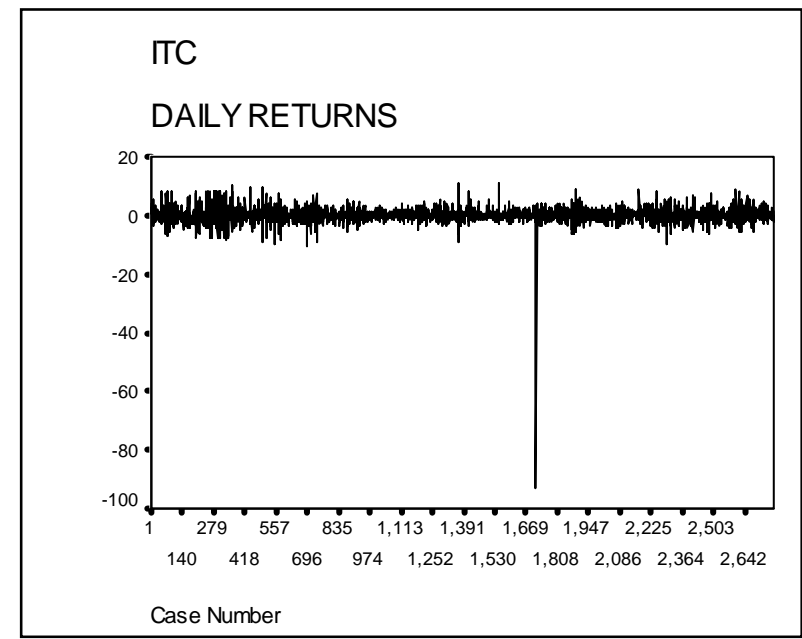

Figure 49: Daily returns of ITC 


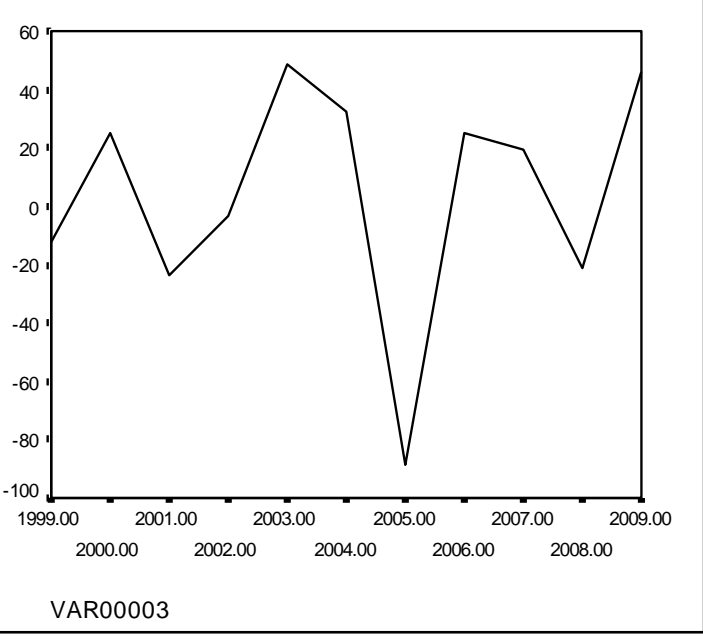

Figure 50: HPY of ITC

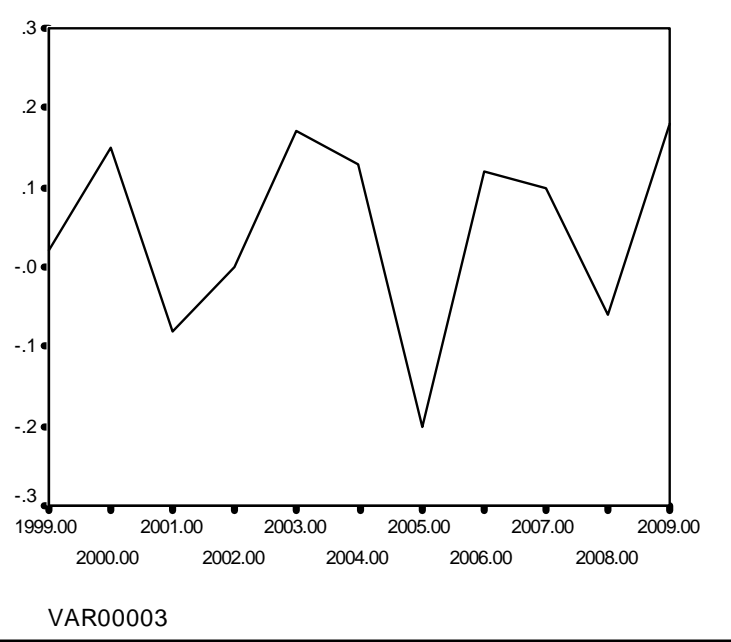

Figure 51: Annual returns of ITC

Daily return in \%

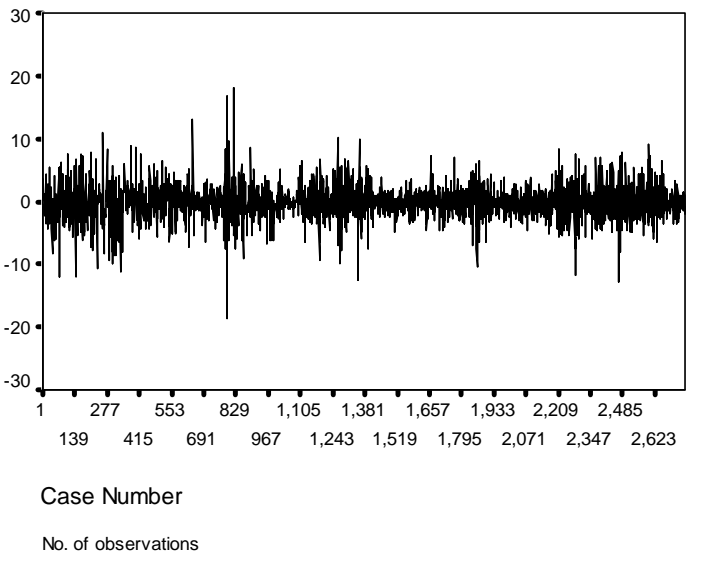

Figure 52: Daily returns of ONGC Itd. 


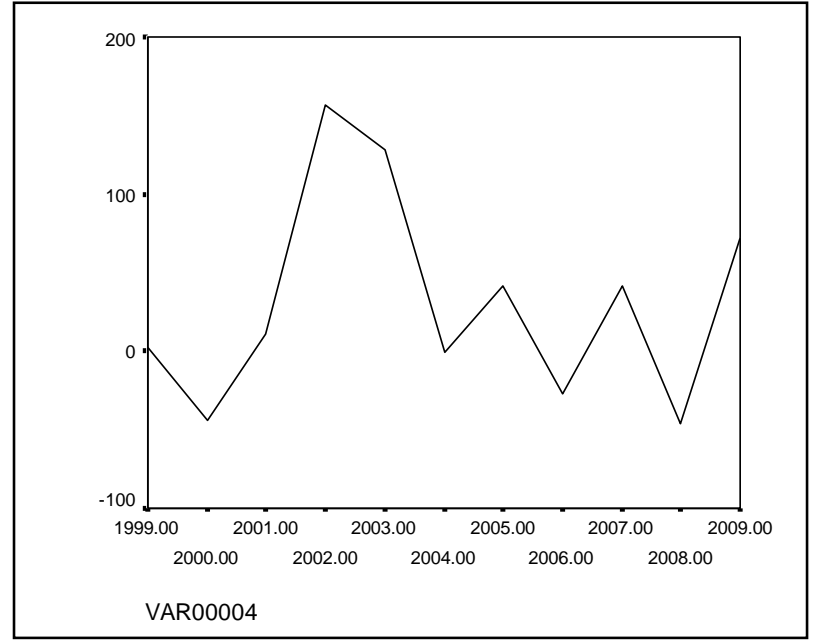

Figure 53: HPY of ONGC LTD.

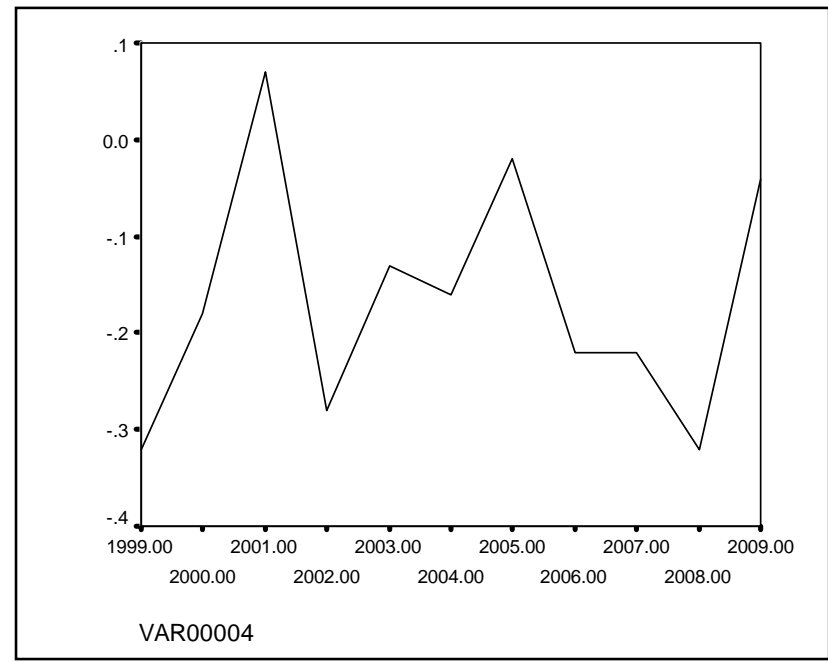

Fig.54: Annual returns of ONGC LTD

TATA STEEL LTD

DAILY RETURN

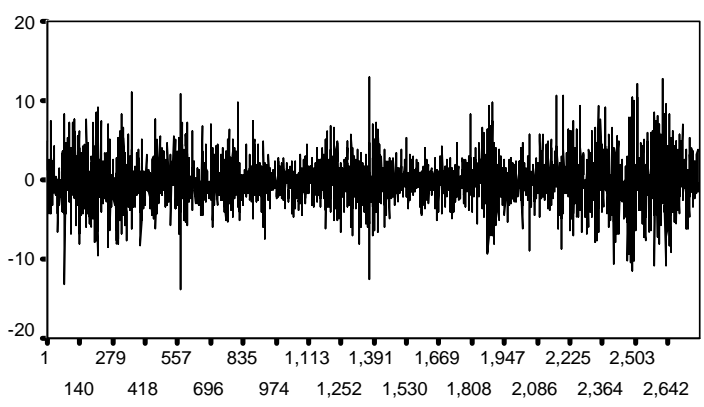

Case Number

NO. OF OBSERVATIONS

Figure 55: Daily returns of Tata Steel Ltd 


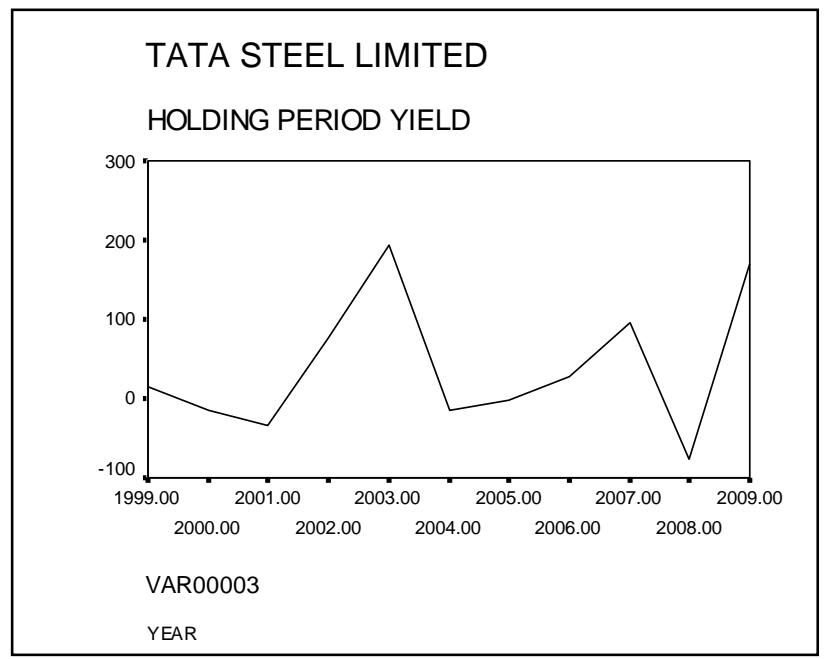

Figure 56: HPY of Tata Steel Ltd

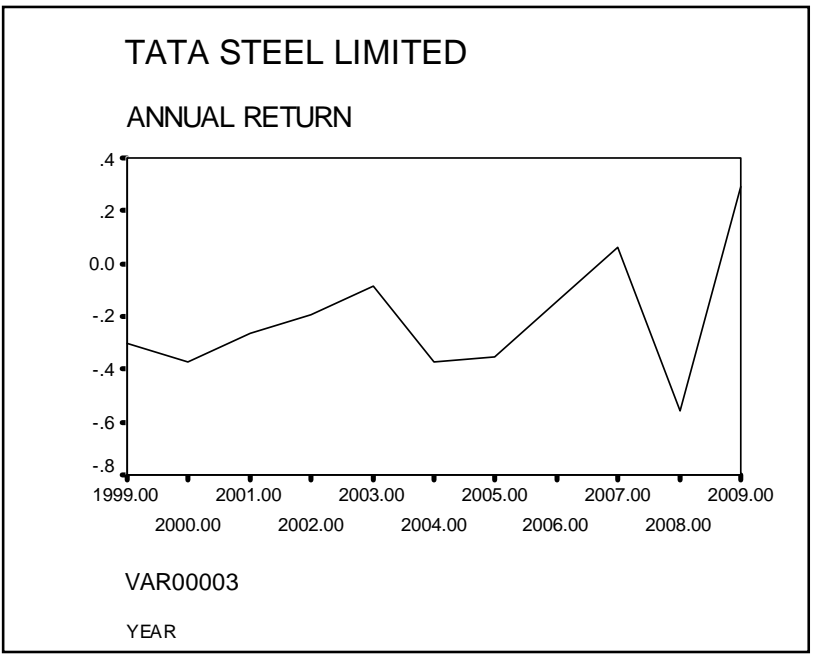

Figure 57: Annual returns of Tata Steel Ltd

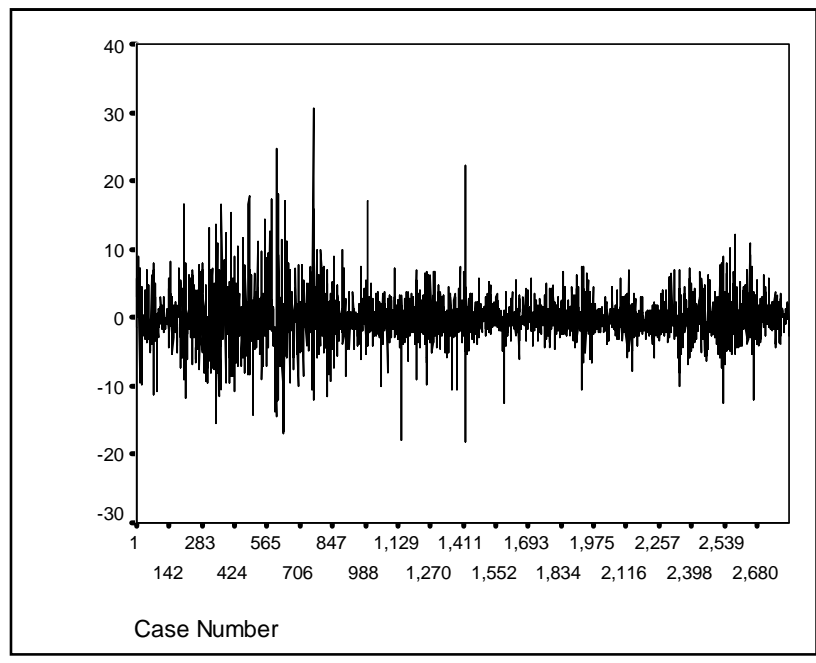

Figure 58: Daily Returns of Wipro Ltd 


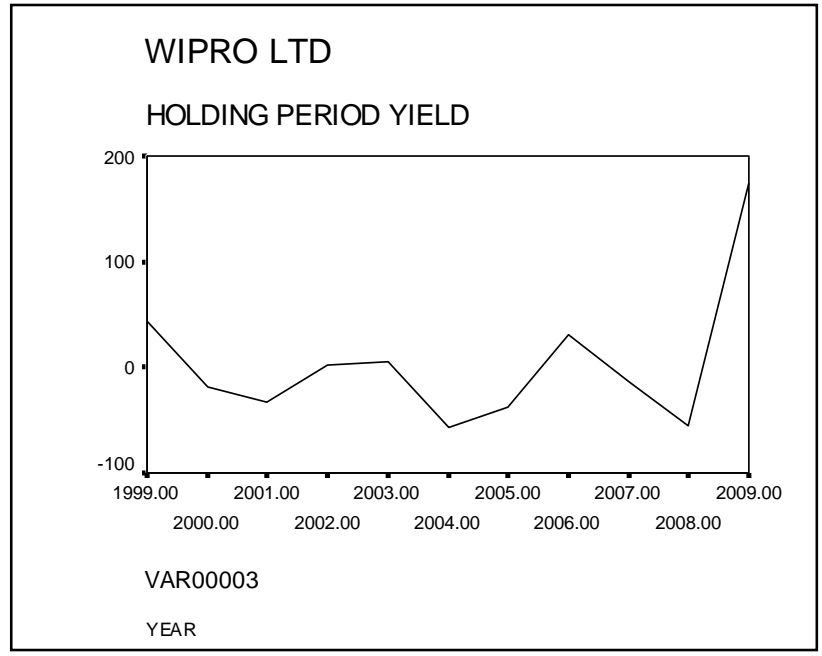

Figure 59: HPY of Wipro Ltd

\section{WIPRO LTD}

ANNUAL RETURN \%

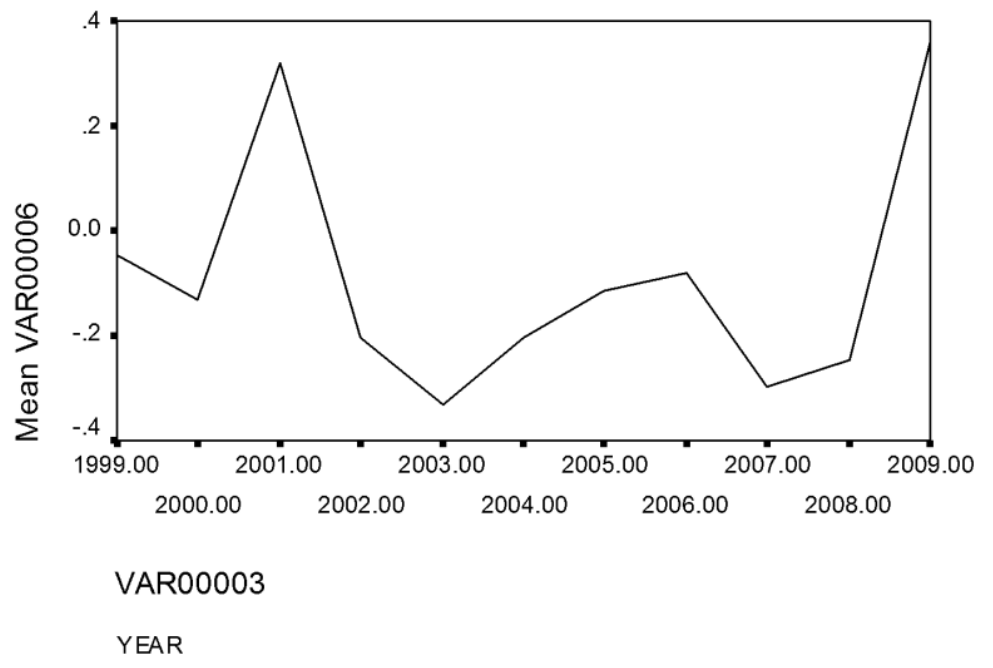

Figure 60: Annual returns of Wipro Ltd. 